\title{
Using in-game biofeedback to induce player serenity
}





\section{Using in-game biofeedback to induce player serenity}

By

Kunyang Ji

A thesis

submitted to the

Victoria University of Wellington

in fulfilment of the

requirements

for the degree of

Master of Design Innovation

Victoria University of Wellington

2017 
Supervisor:

Tom White

\section{Acknowledgments}

Participants:

Xiaoxue Chen,

Charlie Chen,

Regan Petrie,

Alasdair Tarry,

James Bodnar

Eliot Slevin
Technical support:

Zara Fong

\section{General support:}

Family and friends, and the staff at

Victoria University of

Wellington 


\section{Contents}

1

\section{Acknowledgments}

3 Abstract

5 Introduction

4

23 Design Review

23 Journey

25 Proteus

25 Nevermind

27 The gap

2

9 Literature Review

10 Role of emotions in games

12 Game components and Emotional experience

14 Serenity in games

If Biofeedback gaming and Affective feedback

17 Strategic thinking

5

\section{Methodology}

29 Method

29 Physiological response detection

30 Sensor testing

$3 \mid$ Iterative design
3

19 Theoretical Concept

19 Player experience

19 Physiological emotion

20 Affective game design approaches

2l Color theory for positive emotions 
6

\section{Affective Game}

Design Criteria
7

35 Design process

36 Sensor testing (Results)

38 Experiment 1

39 Experiment 2

41 Experiment 3

42 Experiment 4

43 Prototype 1

47 Prototype 2

54 Final prototype
8

63 Results

69 Conclusion

72 Reference

78 Appendix

77 Figure list 


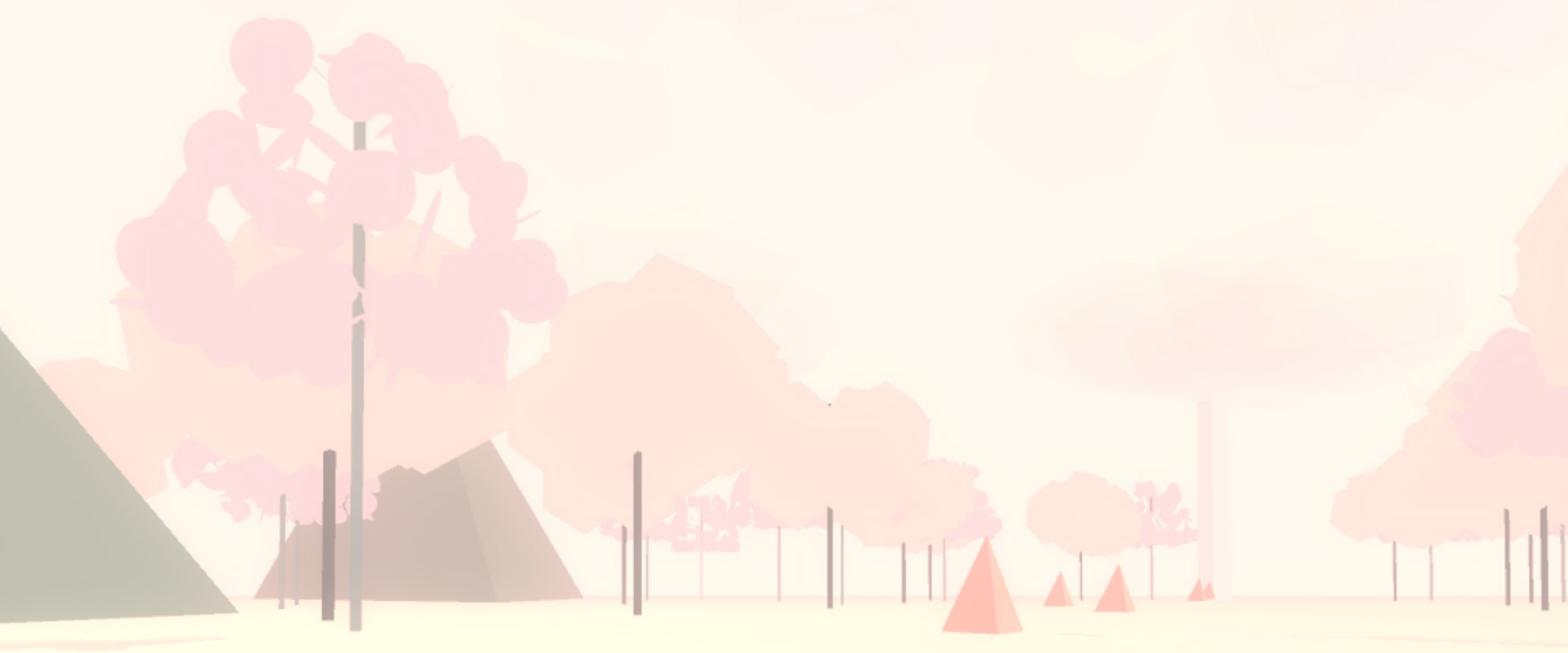


Video games no longer predominantly emphasize mere entertainment or excitement, they now investigate more complex emotions. As a new dimension of player input, biofeedback (University of Maryland Baltimore Washington Medical Center, 2015) can be used to track a player's body signals in real-time. This biofeedback can impact a player's experience during gameplay and making a game affective.

This research aims to design game mechanics to connect game environments with a player's physiological data, and to thereby trigger a serene gameplay experience. The development process was based on 1) game design strategies for inducing serenity, 2) design methods for biofeedback interaction in video games. Combined with these theoretical approaches, this research followed an iterative design process by prototyping, observations, individual interviews, questionnaires, and data analysis.

The player's physiological information was detected through three types of sensor: A heart rate (HR) sensor, a galvanic skin response (GSR) sensor, and a webcam with a software library for facial expressions. The game system adopted certain design elements such as color schemes to communicate the biological information these sensors gathered.
There are two hypotheses in this research. One is that the adjustments of the game environment based on the player's physiological information can impact the relationship between the player and the game. The other one is that changing the game environment's color schemes according to the player's physiological data can strengthen their emotions.

The final output was a brief (2-5 minutes) 3D exploration game attached with sensors to players. The game contained abstract nature-related visual elements and non-competitive mechanics that were applicable for biofeedback-based interaction. The result of final prototype showed that the nature-related elements and the adjustments of the color schemes in the game helped make players feel serene. The biofeedback-based interactions were effective because they helped some players feel more connected to the game. Ultimately, this work is expected to make the player experience more personal rather than generic and improve the game's replayability. 
Introduction 
I see biofeedback as the next level of immersion in games. - Lat Ware (2012), designer of Throw Trucks With Your Mind

\section{Background}

Video games can build a strong emotional bond with players due to their rich forms of interactivity. Players choose to play video games to experience various emotions (Yannakakis \& Paiva, 2014). Most video games available today are not embedded with any dynamic inputs based on a player's physiological reaction (Bischke \& Debnath, 2014). In 2015, a horror game Nevermind (Flying

Mollusk) was released on Steam. This game detected players' HR values and facial expressions. It helps players manage their stress and anxiety by adjusting the degree of the game difficulty to the player's real-time emotions. Biofeedback is a technique that manipulates physiological functions by collecting the information from certain bodily processes such as HR and skin temperature. Games use biofeedback as a human-computer interaction ( $\mathrm{HCl}$ ) approach to communicate with players directly and engage with their personality or preference. They generally focus on a simplistic purpose such as stress regulation (Bouchard, Bernier, Boivin, Morin \& Robillard 2012) or difficulty adjustment (Ambinder, 2011).
Unlike these innovative video games, games using traditional inputs (e.g. keyboard and mouse) have strived to provoke complex emotions including empathy or serenity (Freeman, 2004). Journey (Thatgamecompany, 2013) as an example offers players a sense of peacefulness through the environmental setting and art direction. An increasing number of game developers have devoted themselves to creating more meaningful experiences rather than pure excitement

Game design using biofeedback technology remains underexplored by game designers and researchers. Physiological input in gameplay is mainly limited to games for emotion regulation. This research focuses on how to combine design concepts for complex emotions in games and biofeedback to induce and enhance feelings of serenity. 


\section{Aims and Dbjectives}

This research had the following aims alongside specific objectives:

\section{Aim 1}

Examine design strategies for producing a positive emotional experience in video games

a. Analyse research on how to manipulate positive emotions especially serenity through game components

b. Explore effective design solutions for players to interact with a biofeedback-related game

\section{Aim 2}

Implement biofeedback in a video game environment to induce and enhance the player's serenity

a. Establish a game design criteria based on the findings from aim one

b. Produce a game prototype where biofeedback techniques coincides with the design criteria

c. Test the output with participants

\section{Dutput}

A brief video game will be produced using three types of physiological data: beats per minute (BPM) for HR, GSR, and facial expressions. It will evaluate the effectiveness of the game design criteria by testing the design with participants. The final output will be developed in "Unity ${ }^{\circledR}$ " software (Unity Technologies, 2017), a game engine to design $3 \mathrm{D}$ or $2 \mathrm{D}$ digital games. 


\section{Thesis Dutline}

Chapter 2 presents a literature review on the role of emotions and how to trigger positive emotions in video games. It refers biofeedback system in video games and it analyzes three precedents that emphasizes on emotional gameplay experience and game implementing biofeedback techniques.

Chapter 3 introduces certain theories about the emotion modeling, design approaches for biofeedback games, and positive emotions with colors.

This research relies on these specific theories to develop the design criteria combined with literature review.

Chapter 4 reviews three video games including two traditional games and one biofeedback-based game.

Chapter 5 demonstrates the methods employed in this research.

Chapter $\mathbf{6}$ presentes a design criteria as a guideline for the following game development process.

Chapter $\mathbf{7}$ describes the details in design process including sensor

experiment, game prototypes, and testing. The final output is also presented in this chapter.

Chapter $\mathbf{8}$ discusses the results of the final prototype from the qualitative and quantitative data.

Chapter 9 summarizes the findings discovered from final results. It also discusses the future directions for the research on serene gameplay experience in biofeedback-based video games.

\section{Limits of Research}

Prototype was produced by only one person. This fact enforce certain limits on the project:

1) the duration of the final output did not exceed 10 minutes.

2) the heart rate sensor and GSR sensor might not work properly sometimes during gameplay as they were not for professional medical uses.

3) only a smiling face and a sad face was captured by the webcam and the game system only estimated the BPM values was increased or decreased.

4) other game design factors such as the character design and the audio production were not considered much in this research. 


$$
2
$$


Video games progressed on physical realism over the past few decades. Graphical realism and structural world complexity (e.g. audio-visual evolution, credible narratives, and simulation complexity) can now represent hyper-realistic worlds, engaging players as thoroughly as possible. While visual realism and hardware performance have drastically evolved, the social and affective realism of game characters and game environment remain at relatively straightforward levels (Hudlicka, 2009). The game research community has begun to devote themselves to the promising yet underexplored area of biofeedback gaming. This new form of gameplay uses a player's emotional state to manipulate the game system, shifting the system from static to more dynamic (Aguiar, 2014).

The first biofeedback-based video game concept was developed in NASA flight simulation research (Pope \& Palsson, 2001) and subsequently, biofeedback gaming has been explored by some notable game industry giants. Valve Software (Ambinder, 2011) has conducted several experimenta research projects implementing biological sensors for their existing games to gather players' biophysical information. Nintendo intended to release its Wii Vitality sensor to sense a player's pulse, although this feature was cancelled.

A video game with real-time physiological information does not mean it is affective (Gilleade, Dix, \& Allanson, 2005). Some biofeedback-based games such as Bionic Breakthrough (Atari, n.d.) only use a player's body signals to control the in-game movements, replacing conventional inputs (e.g. keyboard and joystick). Biofeedback games have to respond to players' emotional signals to generate emotional gameplay experiences.
This literature review discusses emotions in gaming and current biofeedback gaming research. I selected the literature based on the following questions:

1. What role does emotion play in video games?

\section{What components of video games can produce an emotiona} experience?

3. What conflicts occur when a game is created for a serene experience?

4. What game design approaches can be used for an affective game using biofeedback?

5. Can biofeedback induce and enhance serenity in a video game environment? 


\section{Role of Emotions in Games}

\section{Motivations of playing games}

Video games are structured activities. They are easy-to-start and many people enjoy them. Video games are usually discussed in relation to other visual technologies including painting and film (Frome, 2007). Playing a video game is a different experience from watching a movie. The former activity is active and allows a player to explore the environment in real-time The latter one is a passive activity from a fixed viewpoint (Shinkle, 2008). Video games can offer a player options to change outcomes compared with other media (Salen \& Zimmerman, 2004).

Playing games voluntarily (Suits, 2014) allows players to shape and craft their experience individually. According to Lazzaro's research (2004), there are four major reasons why people play video games and two of them should be mentioned. One is that the internal experience that focuses on how the external game elements create emotions inside a player. Those emotions generally relate to excitement, relief, and amusement. The other one is immersion, with players focused on experiencing the game instead of winning. People moves from one mental state to another during gameplay. This mechanism awakes players' sense of curiosity and wonder. The reasons above indicate that people play a video game for the experience that the game creates. Most players like to go through the strong emotions awakened by the game even if they are negative, such as fear or sadness (Bopp, Mekler, \& Opwis, 2015)

\section{Guidelines in game design}

A compelling game is not developed by accident (Isbister, 2016). Emotion can not only generate different gameplay experiences but can also drive the design process of most game genres. Swink (2009) introduces several practical game examples - e.g. Super Mario Brothers (Nintendo, 1985) and Bionic Commando (Capcom \& Nintendo, 1987) - embedding a concept of the game feel. This concept refers to five common experience: aesthetic pleasure, pleasure of mastering the game control, extension of the senses, extension of the identity, and the feeling when interacting with virtual ingame objects. Game feel is about how a game impacts a player in a specific way. Game designers can use it as a design principle in turn.

The concept of game feel relates to a "Emotional Alignment (Felder, 2015)" approach that a player's desire should accord with the game's predetermined paths. If the goal of a game is split from a player's desire, the immersion will be broken. This results in a weak bond between the player and the game. One of the examples is the invisible wall in the game. Sometimes players want to explore the edge of an area but find an invisible wall blocking their way, which make them feel frustrated. 
Some video games are designed to provoke certain emotions. That Dragon, Cancer (Numinous Games, 2016) allows a player follow a family struggling with how to take care for their son who has terminal cancer. The designers aim to share their feelings of losing someone they love and cheering up after this. Other games including Proteus (Key \& Kanaga, 2013) and Her Story (Barlow, 2016) express complex emotions like serenity, empathy, and grief. These games act as emotion elicitors to engage players in a broader range of emotions.

\section{Fun relating to a emotional and meaningful experience}

Video games are primarily intended as a form of entertainment. Huizinga (1950) states that fun is an essential component of play. Fun games are described specifically as being challenging, addictive, intuitive, and detailed (Rogers, Woolley, Sherrick, Bowman, \& Oliver, 2017). The fun that players experience when playing a casual game like Candy Crush Saga (King

2012), however, is not the same as that when playing a game like Flower

(Thatgamecompany, 2009). Both of them do not have complicated rules, but they engage people in different dimensions of emotion.
Video games have evolved to be imbued with meaningful and complex experiences. Geslin (2015) argues that a video game should be recognized for the quality of the complex emotions it creates. This research (Oliver, Bowman, Woolley, Rogers, Sherrick, \& Chung, 2015) regards the introspection and self-reflection from playing games as compatible with entertainment. Previous research suggests that fun and meaninglessness in video games are not mutually exclusive. A game with strong emotions and meaningfulness can also be as enjoyable as a fun game. Some players describe Portal (Valve Corporation, 2007 ) as a fun game because of its interesting mechanics, and a meaningful game because it explores the human psyche. 


\section{Game components and Emotional experience}

\section{Emotion classification in games}

According to Lazzaro, there are four types of feelings that games provide: hard fun, easy fun, serious fun, and people fun. These feelings are similar to the motivations Lazzaro describes for players wanting to play games. Emotions can be defined by valence ( i.e. intrinsic positive or negative

feeling) and arousal (bodily activation or deactivation) based on the dimensional model of emotions (Larsen\& Diener, 1992). In-game emotions are constituted of six basic affective states: fear, anger, relaxation, pleasure, joy, and depression (Ravaja, Salminen, Holopainen, Saari, Laarni, \& Javinenn 2004 ).

Jonathan (2007) proposed a classified model of video-based emotions. He classified four types of emotions: game emotion, narrative emotion, artifact emotion and ecological emotion, and based on the two roles of a player: observer-participant and actor-participant. Each type of emotion can generate a particular perception through these two player roles. For example, connection to a game character and the pleasure of roleplaying are narrative emotion, generated from observer and actor respectively. Departing from academic research, Lockhart (2016) who is the director of Important Little Games classifies emotions in an interesting way. He ranks the difficulty in awakening certain emotions in a single-player game. The emotions easiest to induce are fear and disgust while emotions like serenity or remorse are hard to evoke. According to Norman (2002), there are three levels of experience processing: visceral, behavioral, and reflective. To bring emotions to games, visceral and reflective are the main ones to consider. Visceral refers how a game makes a player have an experience, and reflective level is the way a game affects a player's self-image.

\section{Narrative}

Narrative is a general game component that designers consider to elicit complex emotions. Video games have the ability to refine the story based on players' actions and choices. which might lead to different emotional experiences.

Bizzocchi (2007) constructed a narrative framework and examined five components. This includes storyworld, character, emotion, micronarrative, and narrative interface. This research only discusses the first three components as they are fundamental to constructing the virtual game world. Whereas a game with actual characters, especially human characters, needs a detailed story due to the player's desire, an abstract game can

have less narrative (Mateas, 2005). Game environment with different visual design associated with narrative varies players' feelings at the beginning of the game. Two examples are the utopian city in the game Bioshock : Infinite (Irrational Games, 2013) and the old house on a snow mountain from the horror game Until Dawn (Supermassive Games, 2015). Both of them help a player build an initial impression about where the story begin. Video games are interactive fictions and provide a player "fiction emotions" (Tavinor,

2005). "Fiction emotion" is generated from the content and background of the game narrative. Characters including avatars and non-player characters (NPCs) drive the progress of the story and the game. A successful story enables players to care about their avatars. The details in character will be discussed in Character section. 


\section{Mechanics}

Mechanics are the various actions and controls provided to players within game context (Hunicke, LeBlanc, \& Zubek, 2004). For example, the mechanics of a shooting game involve weapons, supplies, and spawn points. Adjusting the game mechanics influences the overall gameplay experience. Long-term goals can be achieved by choosing options within mediumterm tasks which consist of short-term challenges (Falstein, 2005). Making a choice implies that players contribute to the game and this creates an experience for the player in turn. The quality of such experience depends on the choices the player makes in the game.

\section{Aesthetics}

Game aesthetics is an expression when players experience emotions and pleasure in video games (Niedenthal, 2009). Game aesthetics is identified with gameplay experience. This research (Zagal \& Tomuro, 2010) identifies the impact is one of the primary elements of gameplay aesthetics referring to how games make players feel. Kirkpatrick (2011) argues that both explicit and implicit factors in games (e.g. game world and rules) are related to game aesthetics. According to Jonathan Frome's framework of emotion classification in games, players can experience artifact emotion while

playing games. Artifact emotion is a concept to explain players' emotiona responses to the game as an artwork and how this artwork presents its story and content. For example, artifact emotions include admiration for the unique black-white art style in Limbo (Playdead, 2010 ).

The graphic design reinforces players' perceptions, especially when the visual appearance and the symbolism is familiar to the player. Prior study has demonstrated that game designers can use certain colors to lead to different emotional experiences (Geslin, Jégou, \& Beaudoin, 2016). The color theory for positive emotions will be discussed in chapter three. 


\section{Characters}

In-game characters are categorised as either avatar or NPCs. The game protagonist is known as the avatar. The avatar is a player's identification and has, according to Fullerton, "agency" (2014). Avatars' personalities, capacities, and desires directly affect a player on a psychological level. They make a player identify with the game objectives, which is defined as "empathy". This emotional attachment can be highlighted in four layers: visceral, cognitive, social, and fantasy (Isbister, 2016). Visceral feedback includes the powers the character has and how this contributes to the game world. Its qualities might impact the intensity of player satisfaction and immersion. Cognitive involvement refers to the way players manage their actions as the avatar within the game's mechanics. Social connection will be triggered when the player interacts with either NPCs or other players. The last layer speaks to players' real-life desires, hopes, or issues. Players act as those characters to achieve their fantasy.

Game designers use NPCs to populate the game's story world. A player's feeling towards NPCs differs from the relationship built between the player and the NPC (Coulson, Barnett, Ferguson, \& Gould, 2012). A player can collaborate with or be against an NPC. The design of NPCs evolves to be more dynamic, adapting to the game story progression or a player's reaction. This make NPCs more believable and effective.

\section{Serenity in Video Games}

\section{Attributes of serenity}

Serenity has been identified as a spiritual state that reduces stress, relating to inner peace (Boyd-Wilson, McClure, \& Walkey, 2004). Previous study (Roberts, \& Cunningham, 1990) argues that serenity is in the high level of pleasure certainty, and predictability. It is an untroubled and relaxed situation. Research into serenity also tends to analyse the causes of depression, and anxiety.

The majority of video games highlight violence, stimulation, and horror. Serenity can described as a calm or relaxing experience during gameplay. This article (Bogost, 2007) has shown feeling relaxed and calm is related to decreased the aggression during gameplay. 


\section{Contemplative gaming}

There are few attempts to develop meditation games. The walking simulator (Mackey, 2015) is an typical style of video games that uses minimalist

approach (Bone, 2015) combined with traditional interactive game elements. This hybrid approach makes a player focuses on the story or environment. Although this new type of game is controversial among both game

designers and players, walking simulators offer a contemplative experience and make the player slow down (Stuart, 2016). Contemplative games

emphasize the art design of the environment, so that players can appreciate it (Welsh, 2012). Being in a unique environment can be a rewarding experience to a player. Lieve Oma (Veltman, 2016), which won a Nuovo Award of Independent Games Festival (IGF) in 2017, features the player walking in a autumn forest with the avatar's grandma. This game reminds players of their memories and their relationship with their families.

\section{Serene or bored?}

A generic problem of relaxing and serene games is lack of explicit goals. Players feel confused and bored as they do not do something influencing the game or the feedback from the game is implicit. Dear Esther

(TheChineseroom, 2012) is an experimental narrative game where a player only can walk around without any objectives beyond discovering some narrated text. Players have very limited interactivity with the game.

\section{Serene or anxious?}

Some relaxation games actually produce frustration and anxiety rather than serenity and peacefulness. Players reported that they struggled to control the character's movement when playing Cloud (USC Interactive Media

Division, 2005) This was the opposite of the designers' desires. A game need a intuitive and effortless controls otherwise it will frustrates players (Fullerton, 2014 ). Additionally, different camera viewpoints immerse a player differently in the game world. 


\section{Biofeedback Gaming and Affective Feedback}

Biofeedback technique was originally used in the medical domain and spread to other $\mathrm{HCl}$ areas including information technology (IT) and video games (Ortiz-Vigon Uriarte, Garcia-Zapirain, \& Garcia-Chimeno, 2015).

Biofeedback implementation requires attaching certain sensors to the body to collect people's physiological information such as heart rate, GSR, brain activity, muscle flexion, and skin temperature. Video games using biofeedback techniques have the potential to make a gameplay experience more personal, based on a player's physical and emotional responses.

Previous biofeedback-based game research generally adopts an indirect control method. Games for relaxation use a "relax to win" approach (Bersak, 2001 ) within indirectly-controlled physiological input. Players are required to feel relaxed and calm, which reflecting on the decrease of their GSR or BPM, to win the game. The Journey of Wild Divine (Bell, 2003) requires players to keep their breath in a static rhythm for low BPM to finish the level. The mechanics of relax to win sometimes instills the sense of anxiousness as players has to be completely concentrated. Biofeedback-based games predominantly are developed to support a specific therapy including muscular rehabilitation or stress management. Those games focus on practical purposes rather than the gameplay experience itself.
There are two control forms of physiological input in biofeedback games: direct control and indirect control (Nacke, Kalyn, Lough, \& Mandryk, 2011). The direct control includes conscious body reactions (e.g. contraction of a muscle, and gaze). The indirect control refers to those physiological functions (e.g. heart rate, GSR, and brainwave) that players can not directly control, but that are influenced by activities such as deep breathing or meditation.

\section{Affective feedback}

A game simply replacing conventional inputs with biofeedback is regarded as straightforward biofeedback (Gilleade, 2005). These traditional

biofeedback games contain a standard loop where people are trained to control their bio-state based on the information collected by sensors and presented on a device. Bersak argues that a system should present and affect people's physiological state in a more meaningful way. To engage players emotionally, physiologically-controlled games should harness affective feedback. Affective feedback refers certain game components that are designed to affect a player's emotions. The game will adjust to the induced emotions. 
Affective feedback systems increasingly focus on adapting game difficulty level (Liu, Agrawal, Sarkar, \& Chen, 2009 ) and audio-visual effects (Dekker \& Champion, 2007) to a player's affective states. These adaptations improve the in-game experiences and make the experience more characteristic. Some research focuses on analysing the emotional response patterns of a player combined with the game elements. This method compares the difference between the designed emotion and the actual emotion of a player through different game events. Designers can determine which game element should be modified to generate a stronger emotional impact.

One of the examples in affective gaming is the modified version of HalfLife 2. In this version, the game dynamically adapted its audiovisual and gameplay elements to a player's heart rate variability (HRV) and GSR, increasing a horror experience. The changes in audiovisual aspect included game shaders, screen shakiness, and the background music. The game also dynamically adjusted enemy spawning points and weapon damage to enhance the gameplay experience. The results were encouraging as most players enjoyed this biofeedback-driven activity.

\section{Strategic Thinking}

A prime concern of designing video games is to manipulate emotions and make them satisfying to players. Emotional and meaningful video game experiences should be more accessible to audiences. Games should blend various game components to induce emotions. Narrative, mechanics,

aesthetics, and characters have their own advantages to generate various emotions. Game designers should be aware of the balance between traditional game mechanics and certain innovative game design methods. For an emotion-driven video game, players might feel bored or confused if the game objectives are implicit. Uncomfortable control scheme and camera viewpoints will frustrate players. Interactive contemplation is a concept to deepen and expand the meaning and understanding of the game. Biofeedback-based video games need to make players feel relaxed unconsciously rather than forcing them to control their physiological states. 


\section{3 \\ Theoretical Concept}




\section{Player Experience}

Player Involvement Model (Calleja, 2011), identifies player experience through certain dimensions of involvement. These dimensions include 1) the control schemes and camera viewpoint, 2) the exploration in a game environment, 3) the game mechanics and objectives, and 4) the emotions induced during gameplay. Each manipulation of the first three dimensions will impact emotional involvement.

Players induce more positively-valenced emotions and less negativelyvalenced emotions when they explore and immerse themselves in the game environment (Calleja, Herrewijn, \& Poels, 2016). According to Calleja, a player engages more when they are in the first-person view, and thirdperson view can make a player increase the awareness of the game world. Players need to learn the layout of a new game world. The more knowledge they gain from the environment, the more sense of belonging and comfort they will feel. There are two keys to reducing a player's frustration and boredom in the design guideline developed in this research (Fabricatore, 2007). One is that designers should minimize the learning time and number of core mechanics. The other one is renewing a player's interest in specific mechanics by forbidding them temporarily.

\section{Physiological Emotion}

It is essential to define a player's serenity through physiological measures for this research. The game system only can estimate if players feel relaxed based on their real-time bodily signals. Physiological measures such as heart rate, skin conductance, blood pressure, and brain activities can be sensitive and responsive to certain emotions (Cacioppo, Tassinary, \& Berntson, 2007). Facial expressions work reliability to define people's intended emotions

(Ekman \& Friesen, 1975). Expressions including smiles and frowns are usually the most obvious signs of an emotional engagement. A video game using facial expressions to define a player's emotion should be aware of cheating problems. Players might make a fake smile if the game requires them to be happy to win. Most physiological measures (e.g. HR, GSR, and skin temperature) can reflect the arousal level of emotions, however, only a few (e.g. facial expressions and electroencephalography (EEGs)) can determine the valence. To annotate emotions through physiological information relies on the technology of the sensor and the accuracy of the sensor.

From a circumplex emotion model by Barrett and Russell (2005), serenity and other similar emotions (e.g. calm and relaxation) is in the dimension of high valence and low arousal. Previous research suggests that high valence/ low arousal could result in decreasing amount of HR and GSR. 


\section{Affective Game Design Approaches}

Prior research in interaction with an affective game focus on two approaches. One is adjusting fixed game events if a player's emotional state is observed (Cavazza, Pizzi, Charles, Vogt, \& Andre, 2009). The other one is simulating emotional reactions through NPCs' behaviour (Bernhaupt, Boldt, Mirlacher, Wilfinger, \& Tscheligi, 2007). Gilleade proposed an affective gaming system model in three variants: "assist me," "challenge me," and "emote me"(ACE). This model suggests that an affective game should be capable of 1) dealing with a player's frustration, 2) adapting challenge levels to the intensity of player engagement, and 3) leading a player to the emotional states desired by designers. Combined with Gilleade's work, Yannakakis (2011) proposed three basic requirements to succeed in integrating affective feedback within games:

1) the game should adjust according to a player's physiological response pattern

2) the adjustment should be fast

3) the adjustment should accord with the game context,
As discussed in the literature review, game designers adapt audio-visual elements to a player's physiological data. They predominantly focus on adjusting sound effect and environment ambiance. For example, Vanish (Nogueira, Torres, Rodrigues, Oliveira, \& Nacke, 2016) maps some environmental events such as lights failing and distant cries to a player's GSR for a more horrifying experience. Directly-controlled biofeedback games should be easy to control, while indirectly-controlled biofeedback games should emphasise adapting more obvious game components. An effective design approach for affective gaming is to make a player notice the change of their physiological state through game events or game objects. The game system should provide feedback reacting to a player's emotional state accurately and in time. 


\section{Colar Theory for Positive Emations}

Kaya (2004) indicated that one color can affect people in both positive and negative ways. For example, the color red evokes feelings of excitement as well as aggression. Joosten, Lankveld, and Spronck (2010) conducted an experiment examining how to elicit specific emotions in video games using color. This was a home-built game with a questionnaire. It argues that the color yellow is associated with positive emotional response while the color red refers negative emotions.

Previous research showed that people can be influenced drastic changes in color and light. Color consists of four parts: brightness, hue, temperature (warm or cold), and saturation. People release tension when they transition from high saturation, brightness, or warm colors to low saturation brightness, or cold colors.

Colors have rich symbolic meanings. Kaya demonstrates that these meanings depend on the way people associate colors with things. Blue and green provoke a large number of positive emotions such as calmness, relaxation, and hope. The reason was that people related the color blue to ocean and sky and associated the color green to the nature (Hemphill, 1996). In addition, different intermediate hues affect an individual differently. Red-purple and yellow-red elicit a high number of positive responses.

Shannon and Donald (n.d.) proposed a new concept of color in which details including texture, light and chroma can alter the emotions evoked by objects. The same object with different details leads to a different emotional reaction. 


\section{4}

\section{Design Review}


This chapter reviews two traditional video games and one biofeedback video game. It investigates game design approaches to build positive ingame emotional bonds in Journey and Proteus. The reason these two games were chosen is that they are innovative in the way they affect the player's emotional state. Both evoke a serene and relaxing gameplay experience. Nevermind is discussed to explore potential game design methods when implementing biofeedback sensors.

\section{Journey}

\section{Game description}

Journey is an indie game developed by Thatgamecompany. This game is described as "an interactive parable" and "an anonymous online adventure" by its designers to let players experience a person's lifetime journey. This game has two modes: single-player and two-player online mode. This section only discusses the single-player gameplay experience.

The game requires four to five hours to finish. The player controls a redrobed, gender neutral character. This avatar's scarf allows them to float briefly. The avatar wakes alone in a vast desert environment and the goal is to reach the looming mountaintop. There are ruins throughout the game environment. When the player gets close to these, they can "awaken" them These ruins can build a path for the player. The game objective is to travel through each level until the player reaches the mountaintop.

\section{Aesthetics}

One of the motivations for playing video games is their aesthetic value. This article (Niedenthal, 2009) proposed two core meanings of the term "game aesthetics": in-game sensory phenomena, and a particular game experience related to emotion or sociability. Sensory phenomena refers to the way that the game presents itself such as art direction and music. The settings of the game should be in accord with the mechanics. Journey aims to make the player experience awe and peacefulness. The design of the avatar and game environment facilitates this aim.
Journey's avatar is a small and simple figure. Its scale compared with the majestic and sparse landscapes helps make the player feel small and insubstantial. Journey is set in a desert with vestiges of an ancient religion. The atmosphere Journey conveys is vague and metaphoric. Its game models are non-photoreal and not many objects are in the same scene. These allow the player to concentrate on immersing themselves in the game world, experiencing the emotions that the game wants to provoke.

The choice of color has a huge influence on the player's impression of game scenes. The game is visually stunning and the design team maps the color of the environment in each scene to the emotion the scene expresses. The color evolves through the game to show the narrative progress between scenes. The harmony of the color schemes, such as analogous and complementary colors, can provide the player a sense of calm and peacefulness (Joosten, Van Lankveld, \& Spronck, 2010). The player will experience a dramatic change in their emotional state when the color's hue and saturation changes suddenly and unexpectedly.

\section{Mechanics}

One of the mechanics for Journey is that the graphics are the gameplay. The game increases the playability of some simple actions by placing players in a beautiful game environment. For example, the effects of the sunset and the lighting when players are floating down a corridor of flowing sand lead they to an emotional climax. This breathtaking experience makes players consider that it is not merely something to observe, but something that is fun to do.

Another essential mechanic of Journey that makes players feel serene is that the game avoids emotional distractions. It removes competitive and aggressive mechanics such as death conditions, killing enemies, and the scramble for resources. These mechanics might induce frustration or anxiety in a player. The lack of an interface helps a player immerse in the game without barriers. Journey keeps a player concentrated on its intended path by only putting appealing objects in the primary areas. It follows the design principle of emotional alignment. The game succeeds in making the player unwilling to go anywhere outside of the designers' intentions. 


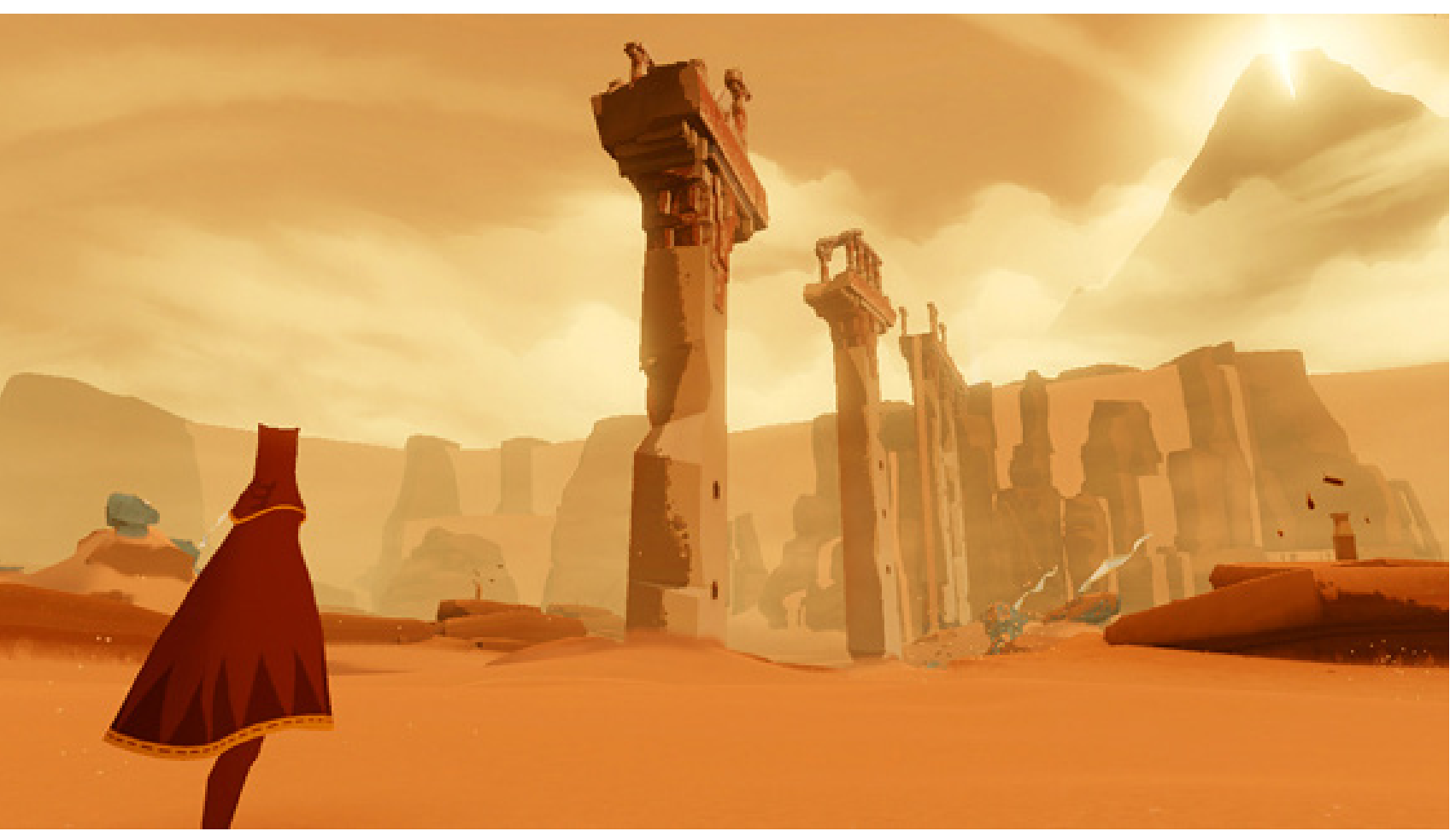

Figure 4.1 A screenshot from Journey.

\section{Emotional arch}

The design team create an emotional arch as a foundation of the game narrative and game aesthetics. They reference the Three Act Structure (Cutting, Brunick, \& DeLong, 2011) when designing the arch. This arch indicates the intensity of the player's emotion during the journey. Players will experience deeply negative emotions before they are at the end of the game. Thus, there will be a huge rise to the final emotional climax that is called catharsis ("Journey,"n.d.). This is because what is important to catharsis of an emotion is the intensity, not the emotion. 


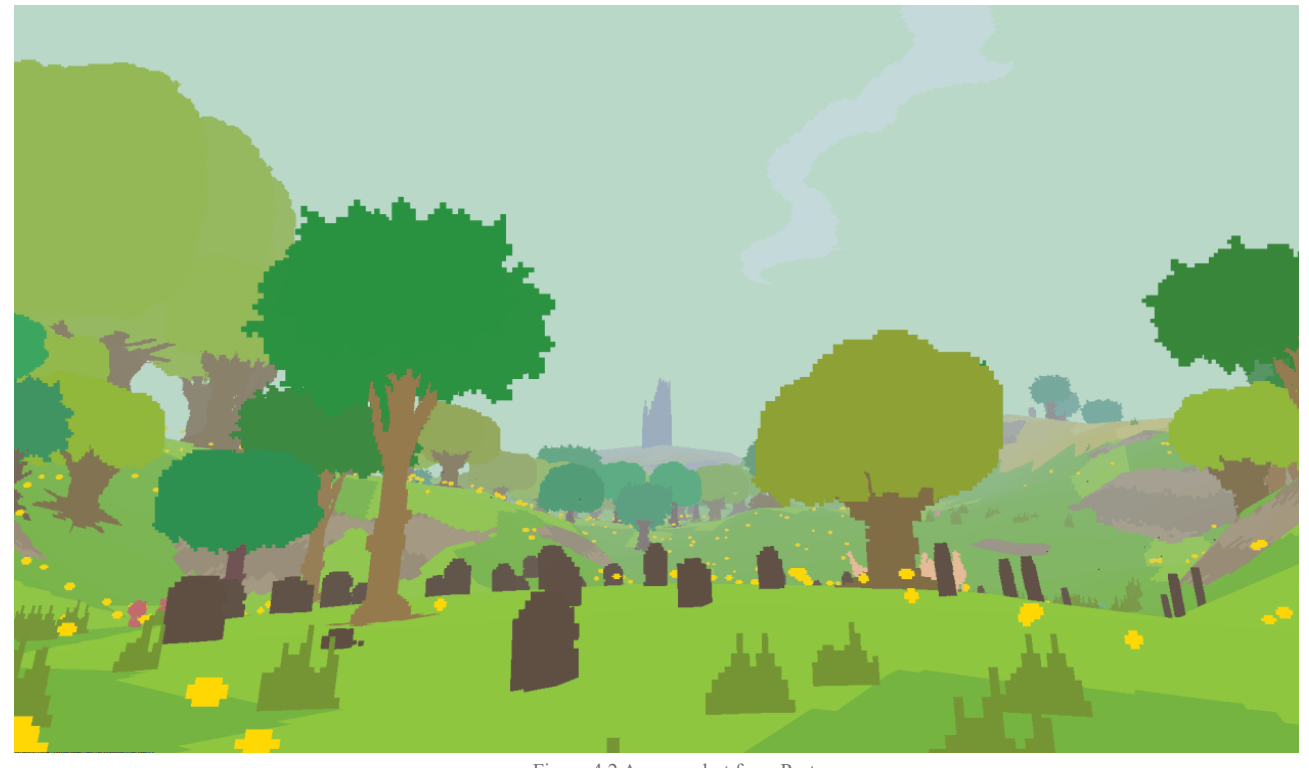

Figure 4.2 A screenshot from Proteus.

\section{Aesthetics}

The graphics of this game are 3D pixel style, and not in a high quality. The game environment consists of nature-related elements such as trees, grass, mountains, and flowers. Animals and creatures are also included in the game world to enhance the vitality of the environment. The scale difference between the avatar and the landscape is not too obvious, which make the game world more intimate to players. Players are experience four seasons in four scenes and there are some particular events in each scene relating to the features of seasons. For example, there will be an aurora if players are in Summer, while they will encounter a snow when they are in Winter. Those events can enrich the game world, which might evoke feelings in the player similar to experiences they might have in real nature, such as relaxation.

The color schemes used in the game are less dedicated than Journey. The designer simply select the color that is similar to what the object should be in real world (e.g. the trees are green, the sky is blue). Players can witness the effects of time on the game environment. The emotions that players haves in daytime might differ from those when they are in nighttime. Proteus may be not be aesthetically satisfying to a player as much as Journey is, however, it creates emotional reactions in players using rich visual changes in the game environment.

\section{Proteus}

\section{Game description}

Proteus is a first-person experimental video game released in 2013. It allows the player to explore an island environment freely without rules or narrative. Flora and fauna in the game world produce a unique sound, and players can make different combinations of sound based on their surroundings. Players have an implicit goal which is to advance the island's seasons from spring to winter. This is a directionless game and the emphasis of the game is on exploration rather than interaction. This game is more like a walking simulator, and reviews of the game tend to be a polarised. Some players state that they had an intoxicating experience, while some were confused or bored since the gameplay is just walking around the island.

\section{Mechanics}

One mechanic that should be mentioned is that players can listen to different combinations of sound from their surroundings. The higher players reach, the lower and less the sound is. Players can experience the gradual changes of sounds if they move from mountaintop to the plains. This mechanic increases the interactivity of the game and impacts players' emotions in a positive way. Players are able to be contemplative and meditative during gameplay as there is no explicit objective forced upon them. 


\section{Nevermind}

\section{Game description}

Nevermind is a first-person and biofeedback-enhanced horror game. Players act as a physician exploring twisted and strange worlds by solving puzzles. The mystery represents the traumatic experience in each patient's inner psyche. The goal in this game is to help those patients recover and find peace.

This game dynamically adapts to the player's feeling of stress or fear. The visuals in the game will be more terrifying when players feel scared, which increases the difficulty of the game. The game is conceived to manage the stress and anxiety level of players.

\section{Sensor implementation}

Nevermind detects the real-time heart rate variability and facial expressions in players. It supports several heart rate monitor devices such as Apple Watch, Mionix Naos QG Mouse, Wild Divine lomPE, and Polar H7 Heart Rate Chest Strap. The game also investigates available sensor options through independent projects such as the Pulse sensor (Murphy \& Gitman, 2011). The game captures players' facial expressions with a webcam via Affectiva's Affdex technology.

The playtesters reported that the sensors were not intrusive and did not impede the gameplay experience (Reynolds, 2013). The designers indicated that it was not necessarily that biofeedback-based sensors for games need to be fully accurate at all times as players would increase their awareness of their emotional states when the game is responding to players' emotions.

Nevermind adapts certain game components including difficulty and aesthetics to players' physiological responses. This section only discusses aesthetics in the game.

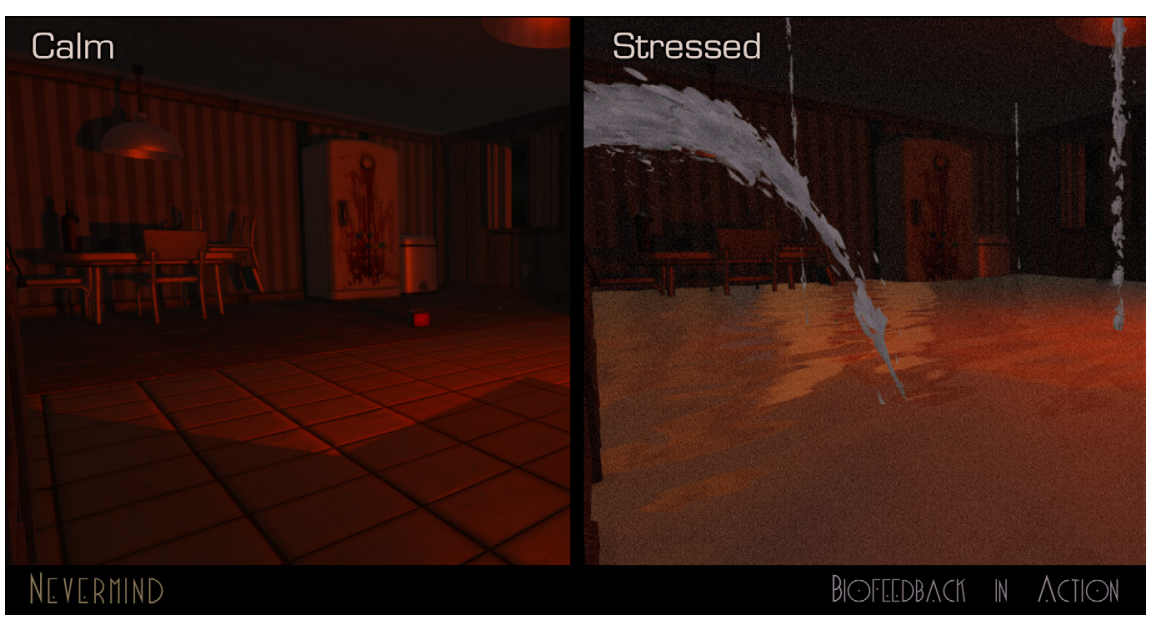

emotional states.

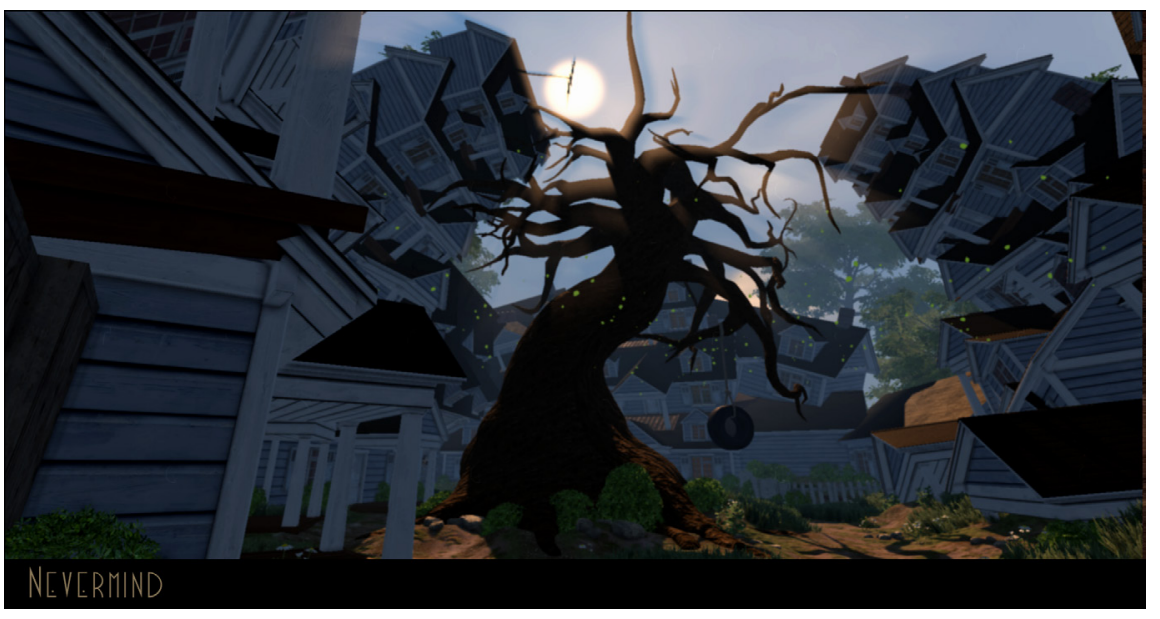

Figure 4.4 A screenshot from Nevermind 
The game is strongly dependent on the aesthetics of the environment to create a horrifying experience. Its biofeedback mechanics follow a design principle: thematic congruence. Thematic congruence states that the art, colors, assets, and lighting settings must accord with the desired messages conveyed by each scene and with players' physiological data. For example, there is a scenario where a player is standing in milk. The milk will rise higher when a player feels stress increasingly. Players will drown and restart the game if they stay in a high level of stress. The milk will subside if players return to being calm. In that case, being in milk causes a player to feel anxious and suffocated. The adjustment of the milk's height based on the player's stress level make the gameplay experience more personalized. Although Nevermind has a similar goal to the relaxationfocused biofeedback-based games above, players do not have to adjust their physiological state to be relaxed because being relaxed only impacts the game difficulty instead of the win condition.

\section{Summary}

Aesthetic design has its effectiveness to create or enhance an emotional experience for these three games. Journey and Proteus change game environments especially in their graphics to make players react emotionally. As to Nevermind, changing the environment accordingly is effective when introducing biofeedback techniques.

\section{The Gap}

Affective video games for relaxation or serenity normally adopt a "relax to win" approach. Players are forced to be relaxed otherwise they lose the game. This might induce frustration and anxiety in a player. Designers should create a more voluntary way for players to feel serene. They also should consider using the design strategies for serenity from traditional video games due to their proven effectiveness.

Previous research usually use BPM and GSR values to estimate a player's emotional state in a game. Facial expressions are not as common as these two values applied in affective games. Facial expressions have potential as effective physiological measures for interaction with an biofeedback-based game because players can directly control them and a game system can easily determine a player's emotional state. 


\section{5}

Methodology 
This research establishes affective game design criteria as guidelines for the game development process. The criteria involve two aspects: Approaches for an affective game interaction, and game design strategies for a serene emotion. They are extracted from the literature review, theoretical concept, and design review.

Biofeedback video games face challenges related to sensor accuracy. This research investigates reliable and accessible physiological responses with suitable sensors, as well as how compatible they are with "Unity ${ }^{\circledR}$ " software. Before the game's development, I conducted a sensor experiment to gather information about biofeedback input sensors in a video game environment. Combined with the results from the sensor testing, I made a game based on these criteria using an iterative design process.

The participants both for sensor testing and playtesting (Fullerton, 2014) were students at Victoria University of Wellington (VUW). Ethics application was approved by VUW. Participants are ages 22 to 27.

The design criteria will be demonstrated in chapter six. The following sections will discuss the sensor experiment including physiological response selection and iterative design process.

\section{Method}

\section{Physiological response detection}

Heart Rate (HR) is commonly used in biofeedback-based games. HR is implicit, however, it is easy to detect. An HR monitor detects a player's heartbeat. This is transformed into BPM values. Most HR monitors are designed as an independent device (e.g. running watches or chest straps) for fitness purposes, therefore, it is difficult to deliver the data to other software. In this research, I used the Pulse sensor, open-source hardware developed by Murphy and Gitman. The sensor includes a band and a clip allowing users to wear it either on the hand or ear. The developers have shared a coding script online that enables a user to obtain BPM values directly. This sensor can work with Arduino, a electronics platform based on hardware and software. "Unity ${ }^{\circledR}$ " software can communicate with Arduino and read the sensor input via certain code. The Pulse sensor is not specifically for medical use and has limited accuracy.

Galvanic skin response (GSR) is a common measurement of electroderma activity arising from the eccrine (sweat) glands. Impressive changes in GSR can be triggered by emotional stimulation. The higher the arousal, the more sweat, resulting in higher GSR. In the prototypes, I used a GSR sensor (Grove, n.d.). This sensor attaches two electrodes with two straps to two fingers on one hand and it also works with Arduino.

Detecting facial expression normally requires a webcam or camera rather than an external sensor attached to players. It mainly relies on the software using sentiment analysis and sonic algorithm to recognize specific responses (68). There are several softwares available on the market. Due to the price and compatibility with Unity3D, I used the software development kit (SDK) and the cloud-based Application Programming Interface (API) from Affdex (Affectiva, 2013). The SDK and API supports with "Unity ${ }^{\circledR}$ " software. This technology can detect seven emotions and twenty expressions. The game prototype only detected inner brow raise, lip corner depressor, and smile. Based on the Facial Action Coding System (FACS) built by Friesen and Ekman (1977), those expression can map to two emotions: joy and sadness. The range of values is from 0 to 100 . 


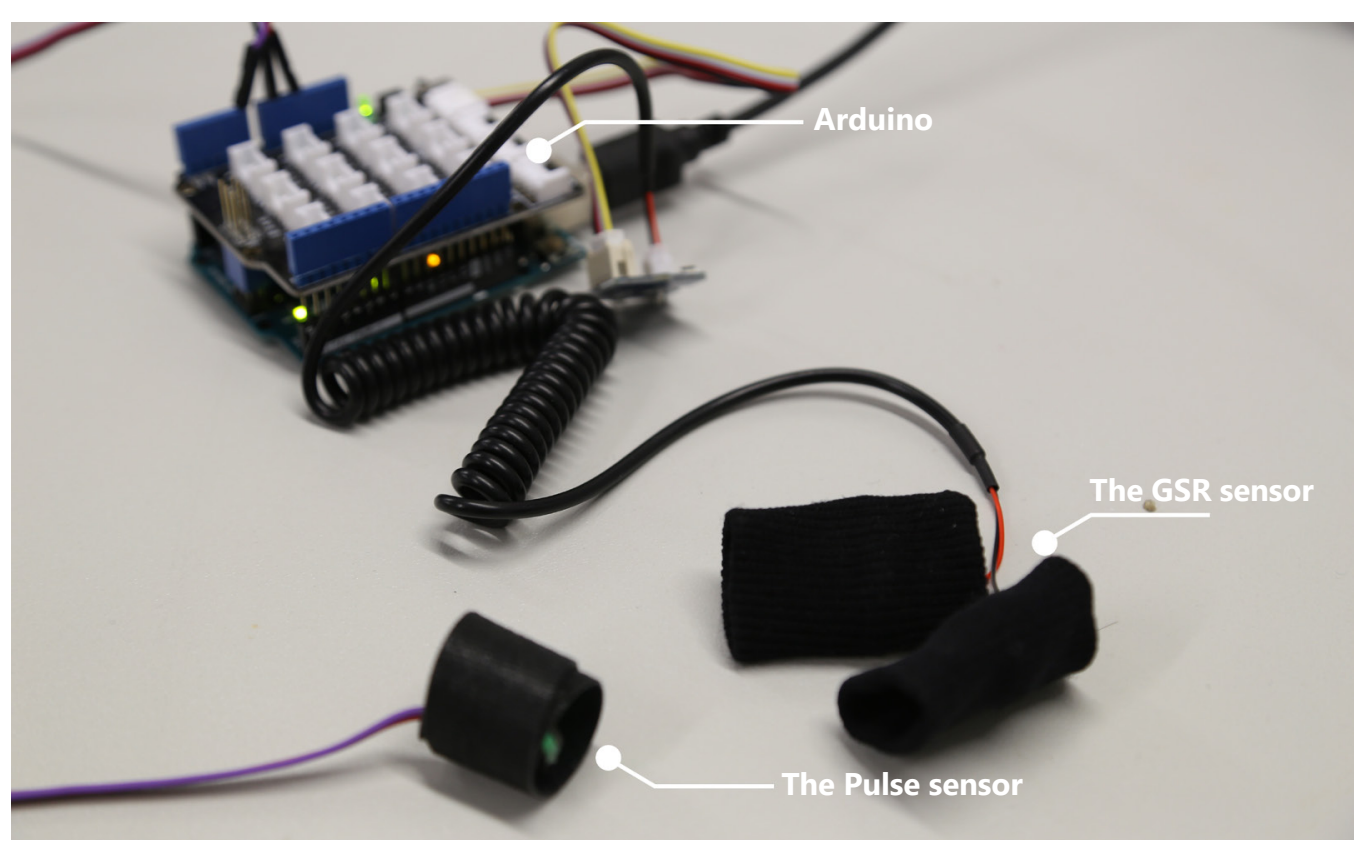

Figure 5.1 Conn ecting the Pulse sensor and GSR sensor to Arduino.

\section{Sensor testing}

This testing is to:

1) provide basic knowledge about using biofeedback sensors in video game development

2) investigate the relationship between emotions and audiovisual elements through data analysis

3) learn how different sensors work and how well they suit my research

This experiment assumes that people will feel more positive when they are experiencing something enjoyable or relaxing and they will feel the opposite emotions when they are watching something negative.

The testing contained four videos with background music. Participants watched these videos on a laptop with the webcam on. Each video was one minute long and the whole duration time of the testing was five to six minutes. According to Carroll (1999), film genres engage emotions and some genres are named by the emotion intended by the director. Based on this theory, this test selected the trailers of four typical films according to the genres they belonged to. This included La Grande Vadrouille (Universal Pictures Home Entertainment Benelux, 2012), Little Forest (StarlingsFilm, 2014), The Shining (Movieclips, 2011), and Voyage Of Time (Movie Trailers, 2016). This test assumed that these four videos can provoke feelings of joy, relaxation, horror, and awe respectively. 
A Pulse sensor was attached to participants' left thumb to detect their BPM. This test built an application based on the shared code mentioned above to transform the signals into a dynamic graph with numbers. The webcam recorded the testing process and captured participants' facial expressions. The SDK was used to detect all types of expressions and emotions, as well as the engagement and the valence value. The engagement measured the activation of facial muscles that address a participant's expressiveness and the range of values is from 0 to 100 . The range of valence value is from -100 to 100 . As to results, this test only focused on the valence and engagement values as the aim of the test was how the videos affect the participants and how intensely. This test created another application to play the videos and present the real-time number collected by the SDK.

There were 13 people participating in this testing, however, only nine people's data was recorded due to a webcam error. Following watching these videos, participants finished questionnaires about how each video made them feel. They were asked to only use one or two words to describe these feelings.

\section{Iterative design}

The iterative design process contains the development of digital prototypes (Fullerton, 2014) with sensors, playtesting, data analysis, and refining. The testing included user observation while playing. Players reported their feelings through "thinking aloud" (Bereiter \& Bird, 1985). After gameplay, players undertook interviews and a questionnaire for qualitative data collection to provide more specific results about player interaction with the game and their emotional experiences.

Digital prototyping was divided into four parts: aesthetics, game mechanics, biofeedback mechanics, and kinesthetics. The mechanics both for game and biofeedback interaction aim to reduce players' frustrations and increase their feelings of serenity. The biofeedback mechanics also focus on building an emotional relationship between the game and the player. The aesthetis design includes concept environment design, color schemes, and interface design. The kinesthetics are about how the controls feel and how accessible the tutorial and instructions are. The game development process had three iterations. Each iteration combined the results of the last iteration with a new focus. A detailed plan of prototyping progress appears in chapter seven

Playtesting was conducted by two stages: self-testing, and testing with other participants. In the earliest game development stage, the research used self-testing methods to experiment with fundamental concepts. Playable prototypes with clearly defined mechanics including final prototype were tested with other audiences. 


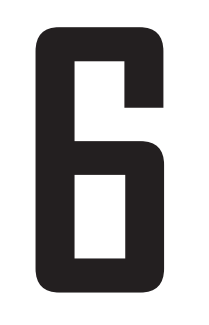

Affective Game Design Criteria 
Based on the literature review, theoretical concept, and design review, this research proposes four design criteria below. The design criteria divide the research question into two parts: serenity and biofeedback interaction.

\section{Walking simulator}

This research identifies the final prototype using the features of walking simulator. The game should consider how to keep players on the designed path.

\section{Nature-related stimuli}

This research identifies that a serene gameplay experience can be triggered by a natural environment. Previous research demonstrates that people viewing footage of natural settings experienced a significant increase in affective-valence ratings. The contents of these footages included several scenes from beaches, forests, lakes, and parks. Thus, the natural environment built in the game prototypes will include elements related to trees, water grass, mountains, and flowers. The design should investigate how to create scenes similar to the real world.

\section{Gentle color schemes}

This research identifies gentle color schemes either for the game environmental design or for the biofeedback interaction design. The schemes use lower-contrast and higher-brightness colors. In this case, the design should explore what is a comfortable color combination for each scene.

\section{Avoid distractions}

By analysing Journey, the research identifies a design principle is to avoid distractions either in mechanism or aesthetics. No death, harm, and competitive mechanics are in the game, reducing a sense of frustration. Secondly, the visual design adopts abstract geometric shapes to present the game world rather than using realistic textures and materials. Thirdly, players should be guided easily by the game tutorial and instruction at the beginning of the game. The game should consider which camera viewpoint to use to engage players more.

\section{Emotional arch}

This research identifies an emotional arch based on the Three Act Structure. Players should experience a negative emotion before they enter the last scene.

\section{Adjustment of Game environment}

The game adapts the game environment to a player's physiological data. The design should determine which aspect of the environment should be adapted. This biofeedback-related interaction approach should enhance the connection between players and the game world, as well as the awareness of the change of their emotional state. 


\section{7 \\ Design Process}


The game development process will be described in the following chapters This research aims to design a single-player exploration game embedding biofeedback techniques. The game is developed in "Unity ${ }^{\circledR}$ " software, with a Pulse sensor and GSR sensor attached to the player, and webcam capturing facial expressions. The GSR value was only used for physiological data collection, not involving any biofeedback interaction in the game. Before the prototyping process, this chapter will summarize the results from the audiovisual testing as a reference to design the biofeedback-related mechanics. The prototyping process is divided into seven stages and the following figure shows the details of each stage:

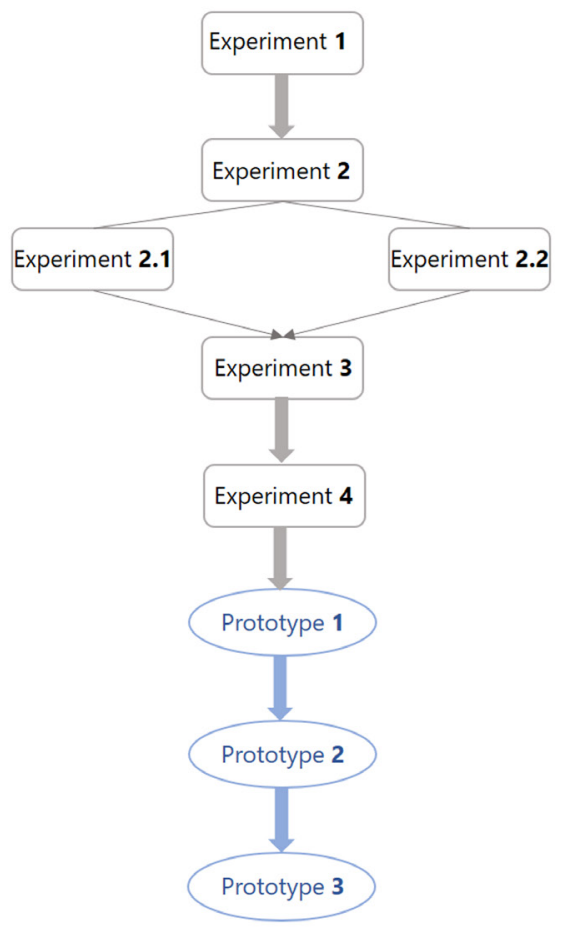

\section{FOCUS}

Control scher

Adapt to BPM

(2D \& 3D environment)

Adapt to facial expression

Game environment adjustment (color, new objects)

Walking simulator

abstract visual design, nature-related

settings, color adjustment during

gameplay)

Exploration

(tutorial, whole environment

change)

Final game
Tested by other participants 


\section{Audiovisual testing (Results)}

\section{Heart rate}

\begin{tabular}{|cccccccccccc|}
\hline & A & B & C & D & E & $F$ & $G$ & H & I & MEDIANS \\
\hline Avg & 69 & 66.25 & 81.25 & 90 & 76 & 95 & 88 & 75.75 & 92.5 & $\mathbf{8 1 . 2 5}$ \\
\hline Joy & -2 & 1.75 & -15.25 & -1 & 0 & -23 & & 0.25 & 4.5 & $-\mathbf{0 . 5}$ \\
\hline Relaxing & 1 & -1.25 & -16.25 & -1 & -1 & & -3 & 0.25 & -2.5 & $-\mathbf{- 1 . 1 2 5}$ \\
\hline Horror & -2 & -0.25 & 35.75 & 3 & -1 & 23 & 3 & -1.75 & 0.5 & $\mathbf{0 . 5}$ \\
\hline Awe & 3 & -0.25 & -4.25 & -1 & 2 & & & 1.25 & -2.5 & $-\mathbf{0 . 2 5}$ \\
\hline
\end{tabular}

Figure7.2 This table compares the difference between the average and actual BPM of the participants for each video. The fields containing blue indicate that the actual BPM is higher than the average.

The result of HR indicates that the average level of heart rate varies between individuals. Some participants have a higher level of HR than the others (e.g. participant $D, F$, and I). The result shows that watching the video tagged as

horror increases the BPM. Participants did not experience significant changes when watching the other three types of videos.

\section{Facial expression}

\begin{tabular}{|lcc|}
\hline & engagement & valence \\
\hline Joy & 30 & 20 \\
\hline relaxing & 7 & 4 \\
\hline Horror & 7 & -3 \\
\hline Awe & 5 & 1 \\
\hline
\end{tabular}

The result of engagement and valence shows that participants were more engaged and felt positive when they were watching joyful videos. Participants felt slightly negative emotions when they were watching a horror video. Videos tagged either relaxing or epic produce more neutral feelings since the valence of participants is nearly to zero. 
Questionnaire

\begin{tabular}{|l|l|}
\hline & Described word \\
\hline Joy & joyful, funny \\
\hline Relaxing & calm, relaxed \\
\hline Horror & scary, fear \\
\hline Awe & awe, peaceful \\
\hline
\end{tabular}

The result of questionnaire shows that the intended emotion of the videos seem to accord with the actual feelings that the participants experienced.
Strategic thinking

Different audio and visual elements can generate certain emotions. Things that are joyful, relaxing and epic have potential to induce more positive emotions.

Emotions can impact the physiological states of people. Positive emotions appear to decrease BPM, and increase valence. Negative emotions such as fear tend to increase the and decrease valence.

The physiological states of people vary.

Both the Pulse sensor and SDK have limits. The Pulse sensor might have a high-rate of error at the start. Participants have to sit right in front of the camera otherwise the facial expressions cannot be captured. 


\section{Experiment 1. Movement and Camera viewpoint}

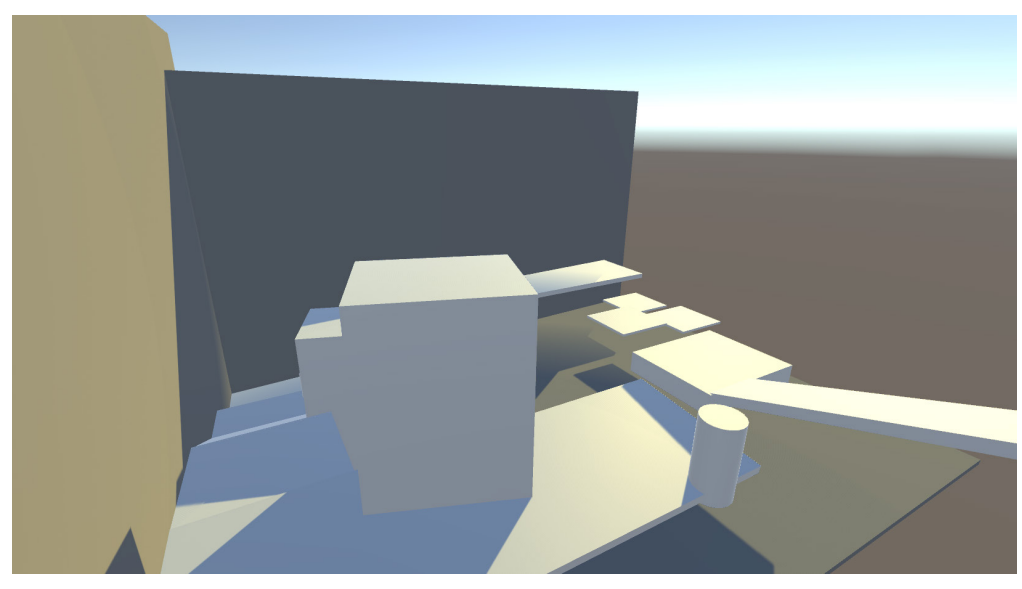

Figure 7.5 Third-person view 1.

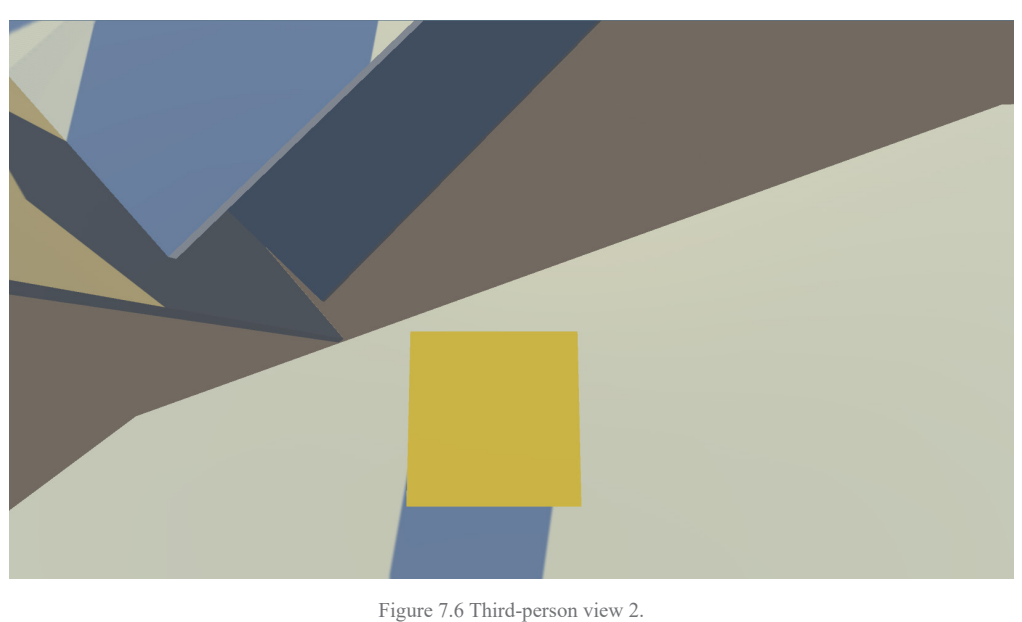

Figure 7.6 Third-person view 2.

The experiment aimed to design an intuitive control scheme and

comfortable camera viewpoint. The designer assumed using W, A, S, D on

keyboard to move and using mouse to control the view was natural to the

players, especially the gamers. This experiment was set in a third-person

view and the designer found the camera should not be either too close or

too low to the avatar. 


\section{Experiment 2. Color adjustment}

\subsection{Basic color change using BPM}

This experiment built a simple color scheme and adapted the color to the BPM. The color was designed to change from Color $\mathrm{A}$ to Color $\mathrm{C}$ once there was an increase of BPM. Each color represented an interval range of BPM. The experiment aimed to investigate how the color would change from one to the other. This result of the experiment shows a comfortable gradual change of the color. It was not obvious enough to distinguish the different BPM level.
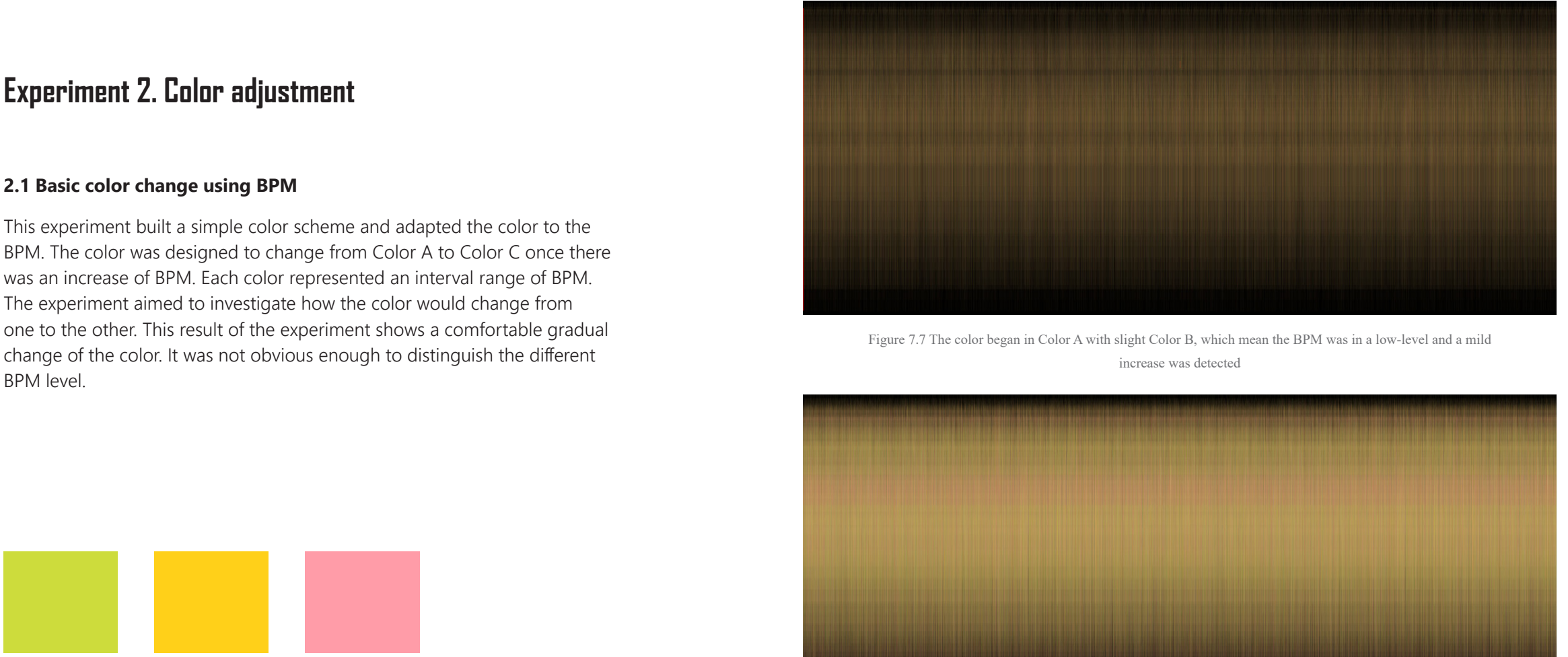

Figure 7.7 The color began in Color A with slight Color B, which mean the BPM was in a low-level and a mild increase was detected

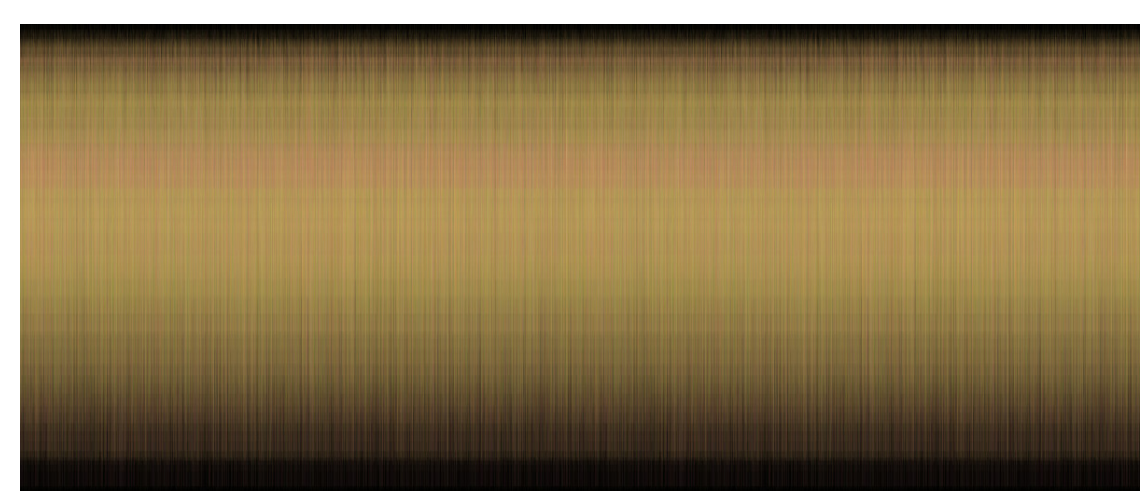

Figure 7.8 The color was in Color B with slight Color C, which mean the BPM was in between 60 to 80 and it tended to increase to above 80

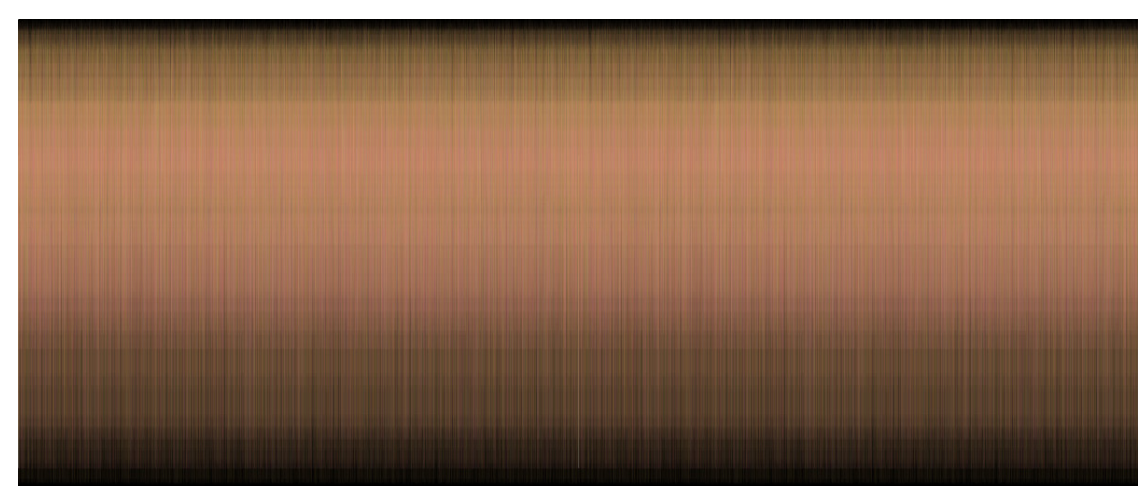

Figure 7.9 The color mostly was in Color C, which mean the BPM was larger than 80. 


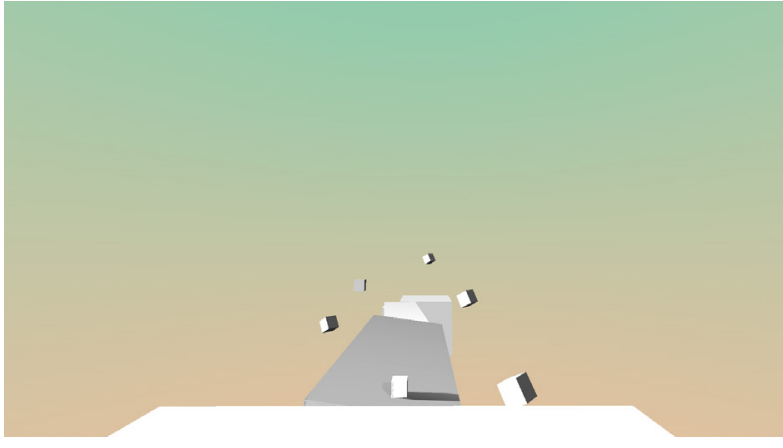

Figure 7.10 The initial color of the path.

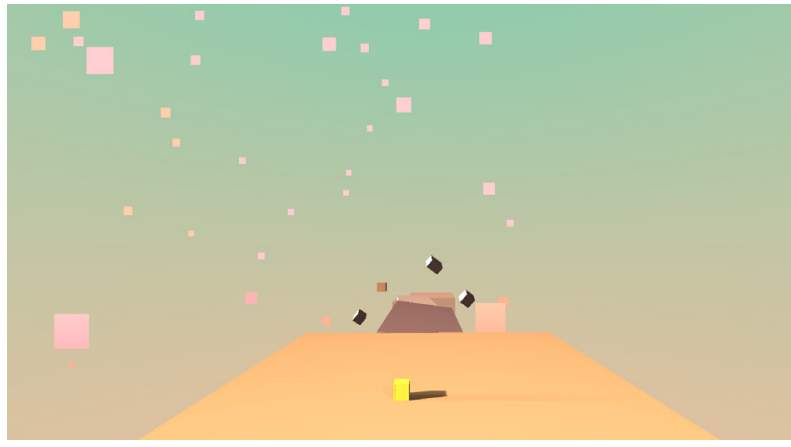

Figure 7.11 The color of the path changed to yellow when the BPM increased slightly.

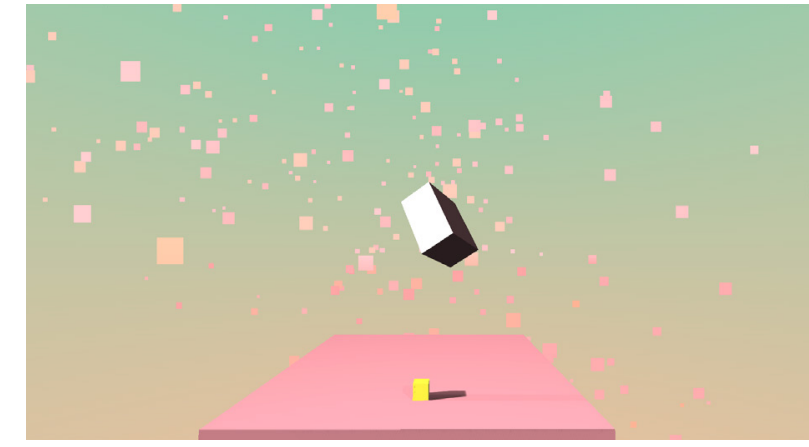

Figure 7.12 The color of the path changed to pink when the BPM increased dramatically.

This experiment built a 3D environment with a controllable cube. The cube

could be moved on a fixed path. The system adapt the color of the path to

the BPM. The result shows adapting the color of the $3 \mathrm{D}$ environment to BPM

is apparent to notice. 
Experiment 3. Basic change using smile

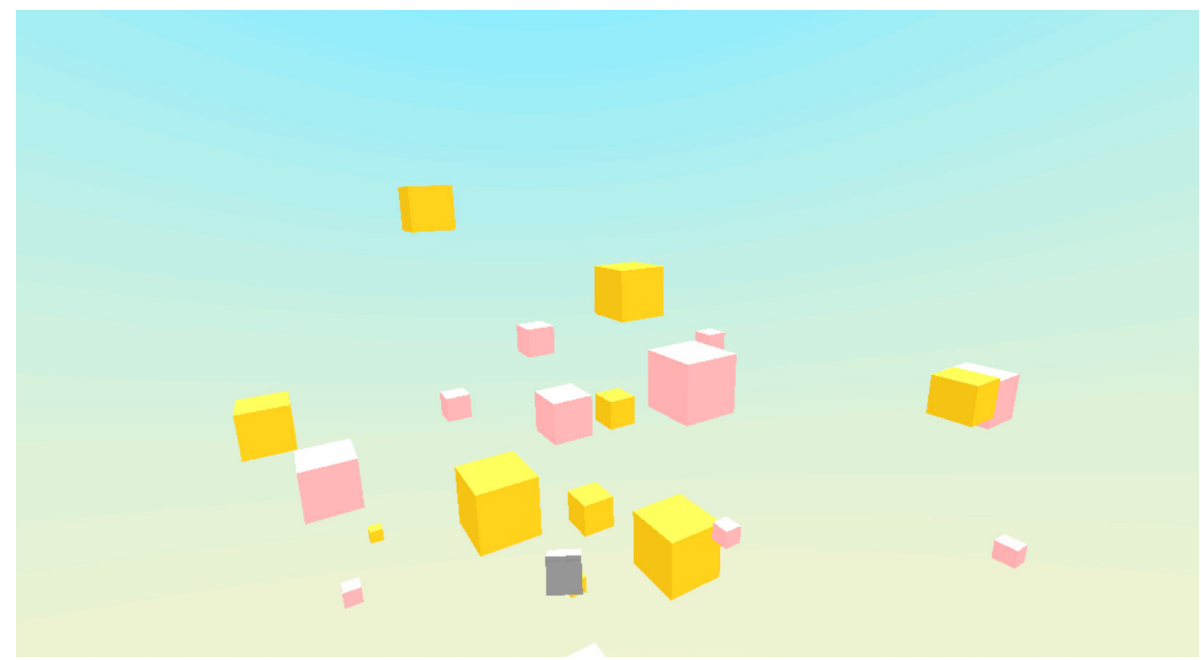

Figure 7.13 When the designer did not have any facial expressions.

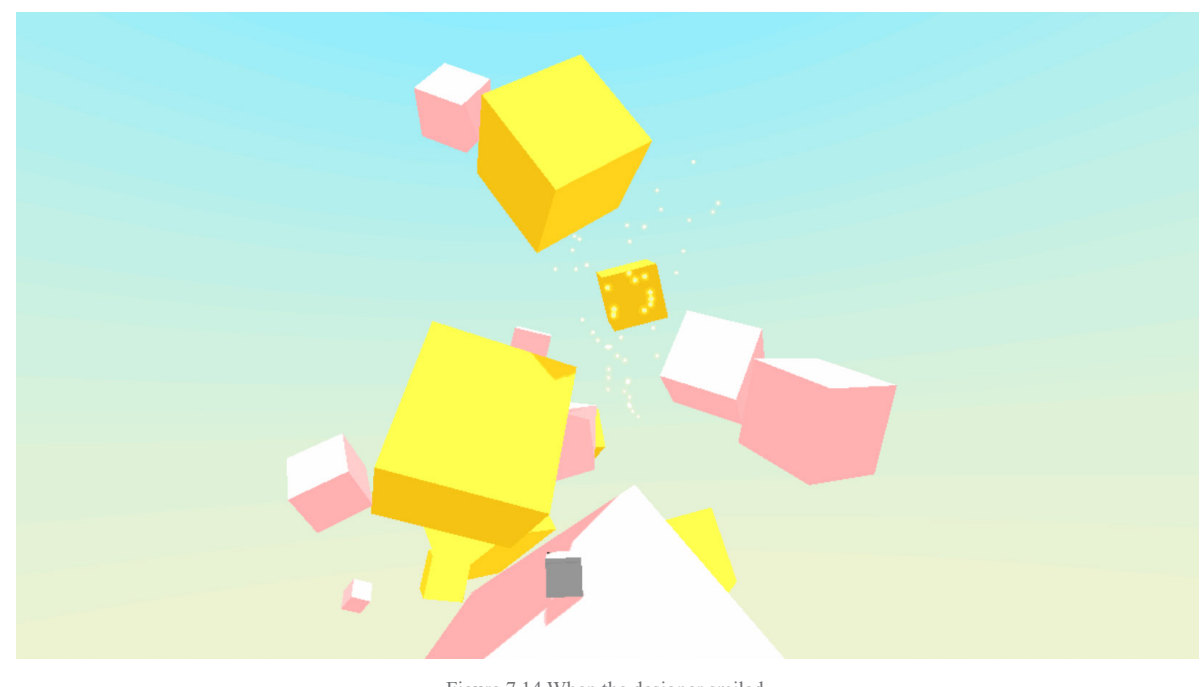

Figure 7.14 When the designer smiled.

This experiment adapted the movement of certain objects according to the player's smile. When smiling, these yellow and pink objects would come closer to the white cube that represented the player. People showed interest in controlling the objects using their facial expressions. The SDK could have a delay on detecting a slight smile. 


\section{Experiment 4. Game environment adjustments}
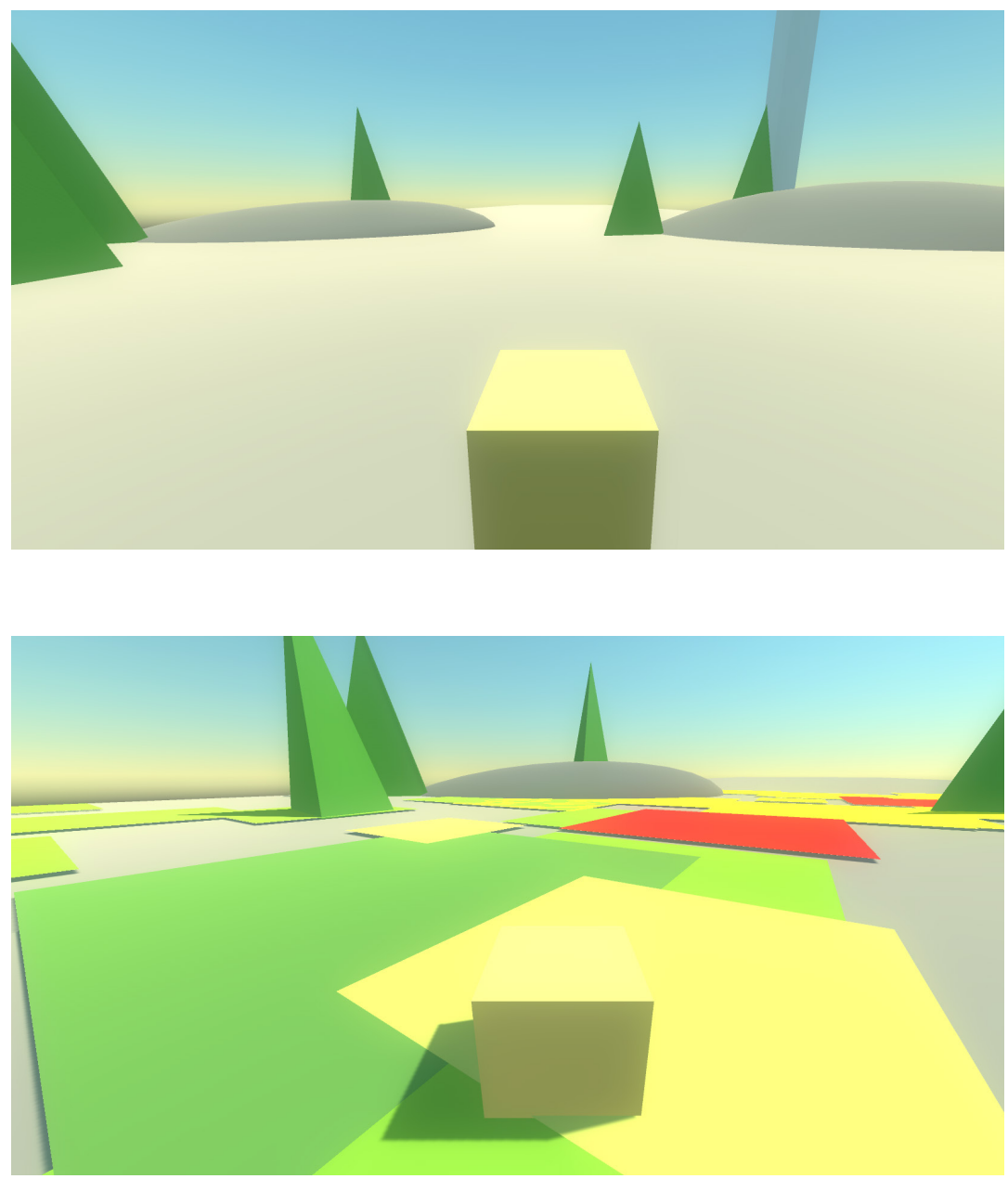

Figure 7.16 The two images showed how would the environment adapt to player's BPM
The experiment adapted more game elements to match the player's BPM. It was intended to create two different game worlds based on if the BPM increased. If the BPM increased, 1) the in-game directional light would increase its intensity, 2) the ground color would change to a brighter color, 3) there would be some petals blowing in the air. If the BPM decreased, 1) the in-game directional light would decrease its intensity, 2) the ground color would change to a darker color, 3 ) there would be rain in the game world.

This experiment used an algorithm to estimate whether the BPM increased or not. Based on the results of the sensor testing, players' BPM should be compared with themselves rather than other players. The algorithm included two states: A and B. A had the BPM values updating slowly while B was updated more frequently. The game system could simply determine if the BPM increased by comparing the difference between these two states. If $\mathrm{A}$ was larger than B, that means the BPM decreased.

The results of this experiment suggests that the game should consider the rate of the changes in game objects. If they update too often, players will not notice the difference between each change. 


\section{Prototype 1}

\section{Focus}

This prototype developed as a walking simulator and emphasize the

environmental visual design including its adjustments to a player's BPM

values. Any audio and background music were not considered.

Game control \& camera viewpoint:

Do players feel easy to master the control?

Is the camera view helpful for generating comfortable gameplay experience?

Nature-related stimuli \& graphics:

Do these abstract nature-related objects make players induce the feeling of serenity?

Are the color schemes compatible with the serene experience?

Environmental adjustment:

Can players notice how their BPM changes (i.e. increase or decrease)

through the color adjustment?

Dose the color change gradually based on the BPM values?

Do these adjustments make a personalized experience?

\section{Sensor included}

The Pulse sensor

The GSR sensor

\section{Game and Biofeedback mechanics}

The avatar was an yellow cube and players could move through two game worlds. There was a day-night shift in the game. The color adjustment of the environment would be different between two worlds.

The objective was to eat the triggers placed on a certain path to generated new objects. The color and shape of the generated objects varied from a

player's BPM state at that time. When players get close to an object, its color would change accordingly based on the players' BPM state.

\section{Visual design}

color schemes
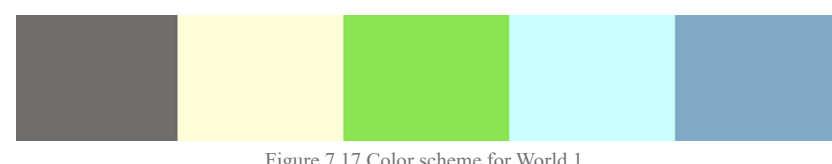

Figure 7.17 Color scheme for World 1

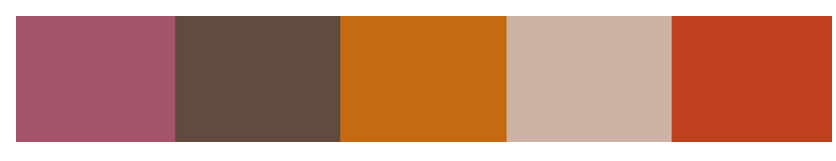

Figure 7.18 Color scheme for World 2

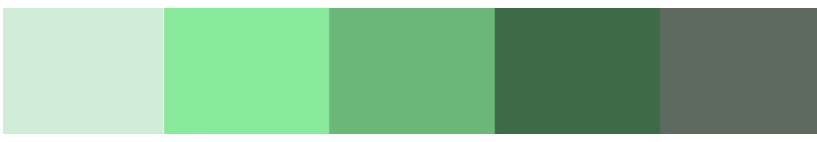

Figure 7.19 Color scheme for color adjustment in World

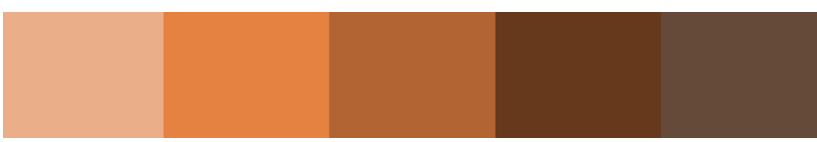

Fioure 7.20 Color scheme for color adjustment in World 2 


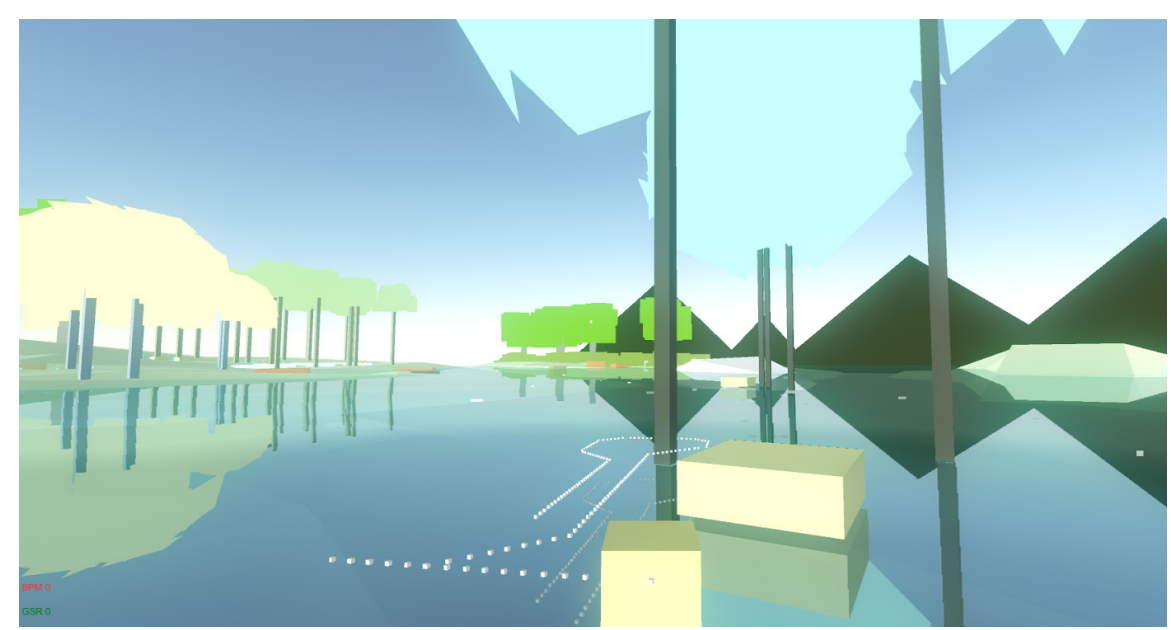

Figure 7.21 Screenshot in the daytime of World

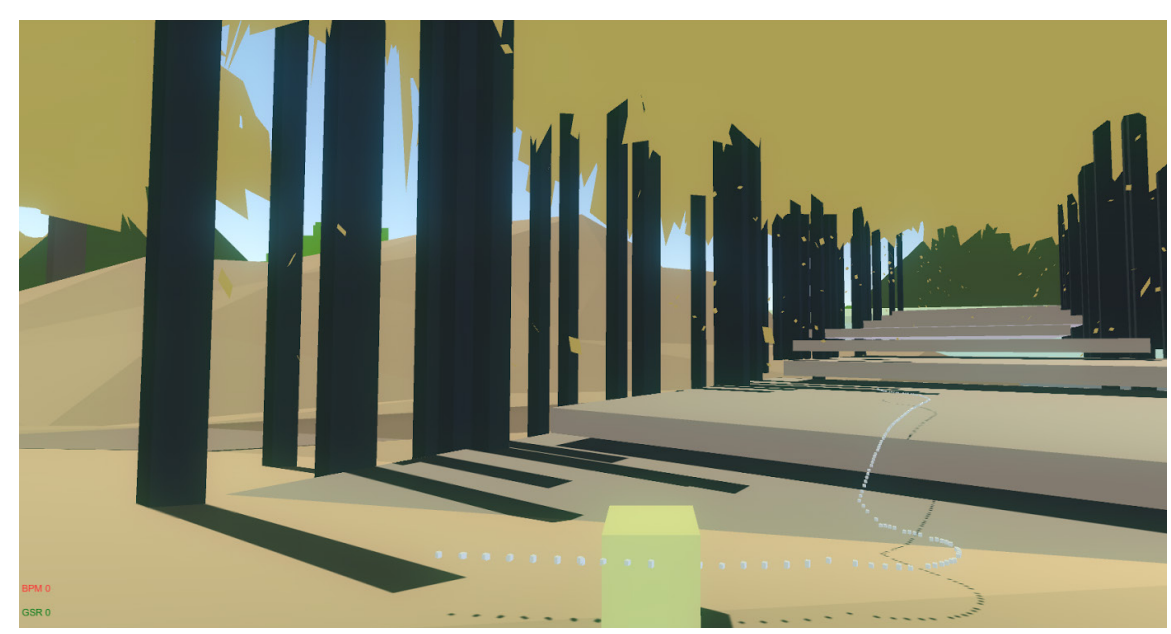

Figure 7.23 Screenshot in the daytime of World 2.

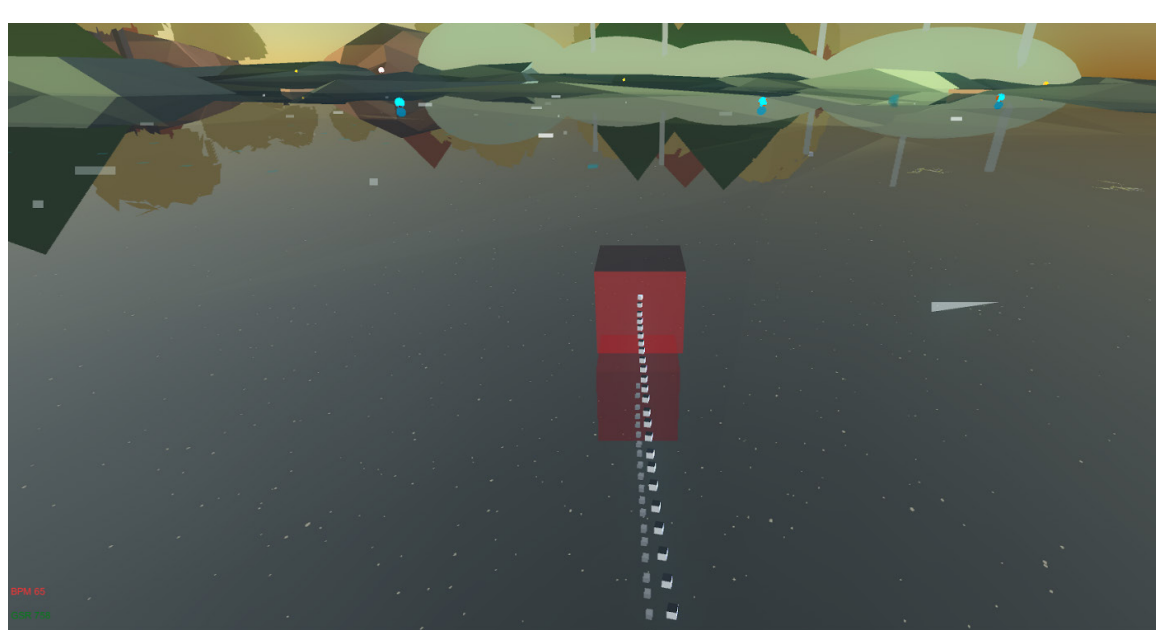

Figure 7.22 Screenshot in the night of World 1.

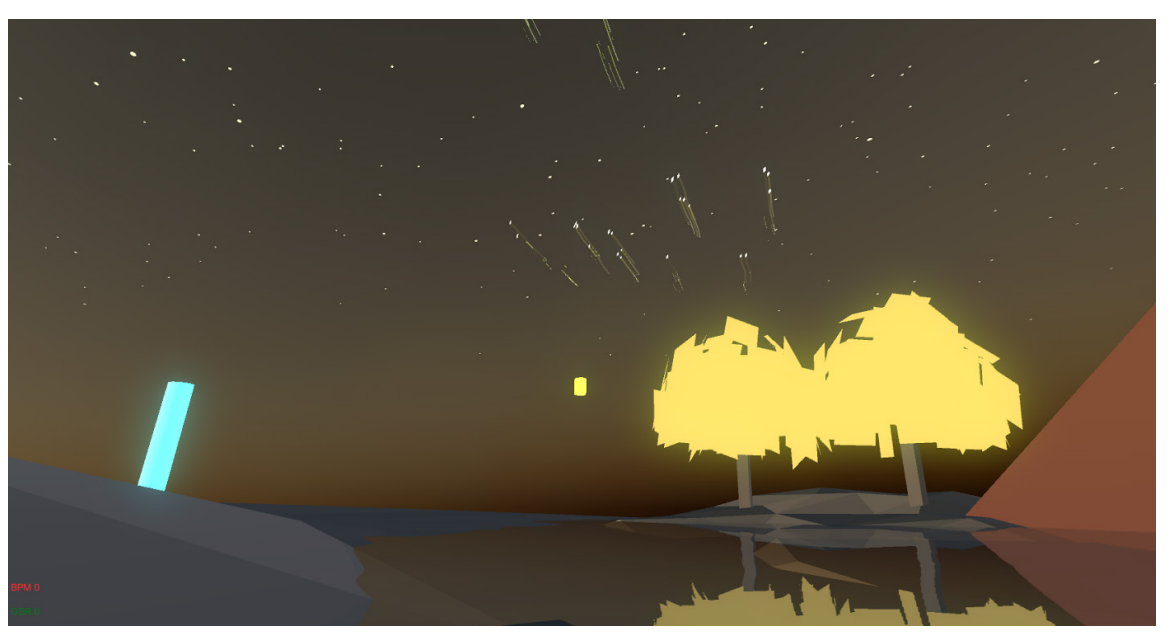

Figure 7.24 Screenshot in the night of World 2 


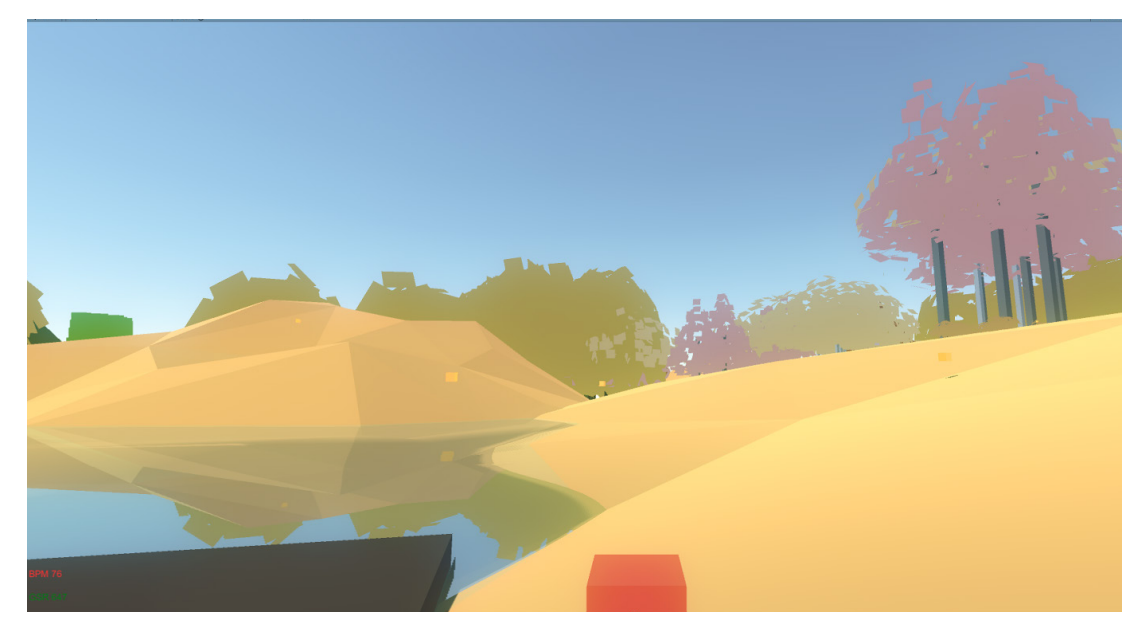

Figure 7.25 Initial color of the ground in World2 .

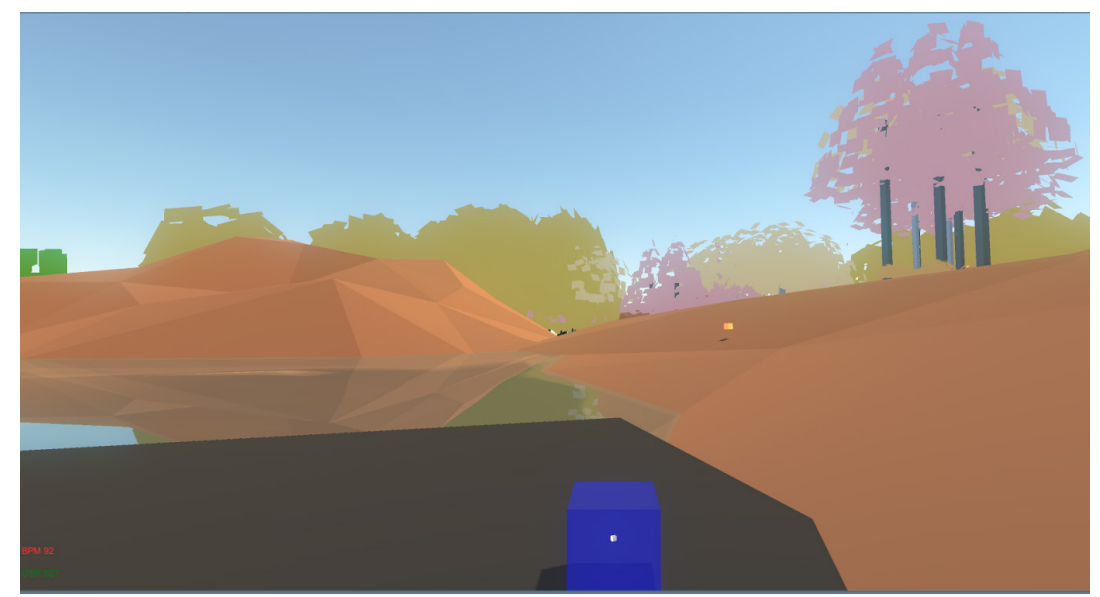

Figure 7.26 The ground color changed when BPM increased in World2 .

\section{Results}

Interviews and observations:

The testing was conducted with three participants. The results of the

interview showed 1) all the players were satisfied with the game control, 2) the camera viewpoint was not suitable to observe the entire environment so that the players might ignore some adjustments, 3 ) the players agreed that these abstract and nature-related elements can trigger serene emotions at the beginning but the color changed too frequently, 4) no participant noticed the BPM state through the color adjustment and participants consider these adjustment were randomly generated 5) some participants felt bored as they were confused about what to do during the game.

\section{Data anlysis:}

The results of the physiological data showed 1) the BPM values correlate to the GSR for some participants (e.g. participant B), 2) both the BPM and the GSR experienced dramatic changes during playing, and 3) the GSR sensor had a lower-rate of error than the Pulse sensor. 
BPM

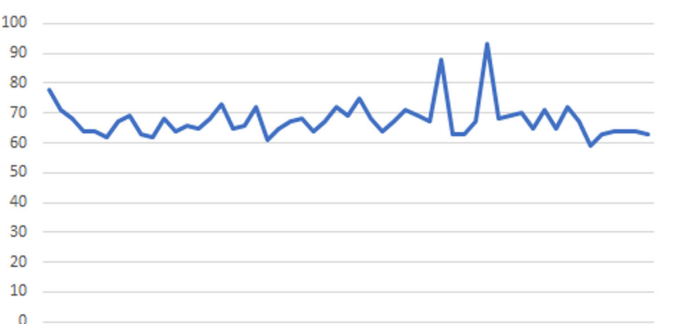

Figure 7.27 The BPM values and GSR values of participant A

BPM

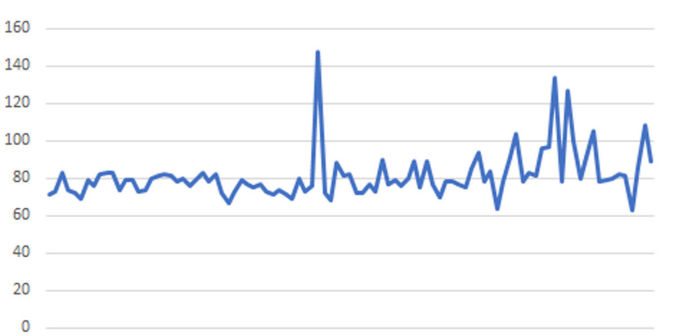

GSR

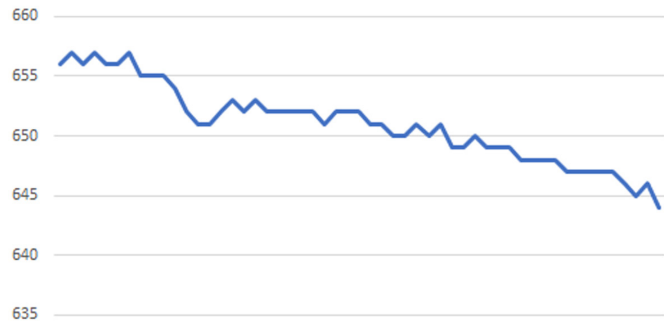

Figure 7.28 The BPM values and GSR values of participant B

BPM

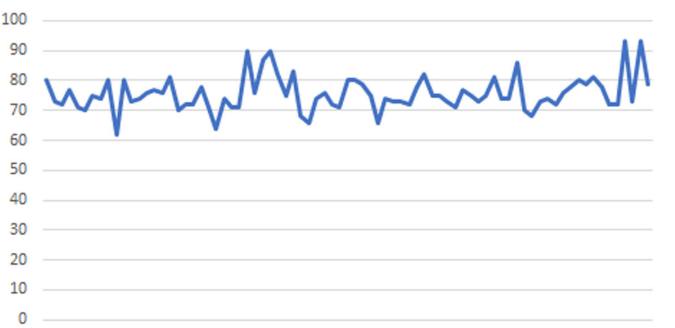

GSR

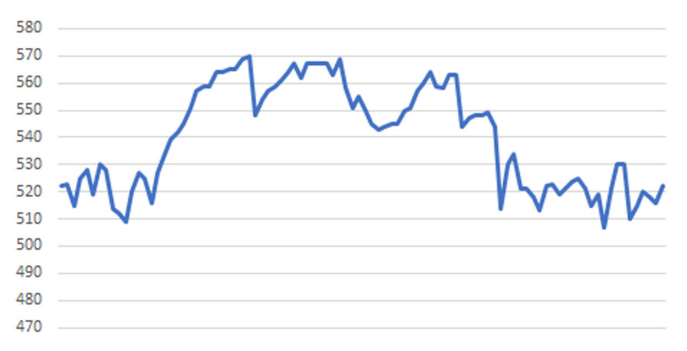

GSR

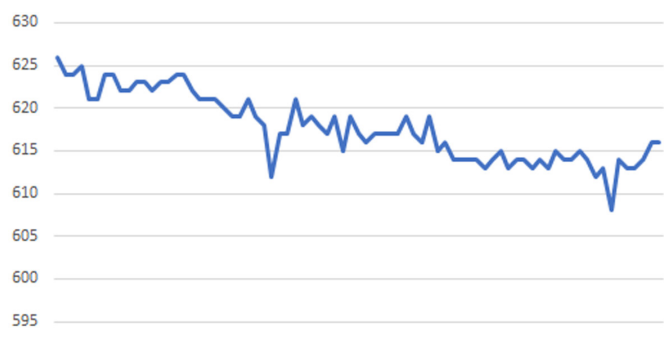

Summary

This prototype is confronted with the following problems:

\section{1) implicit adjustments}

2) too frequent changes generated in color of the environment

3) inapproprite color schemes for biofeedback-based adjustments

4) unordered environmental settings

5) weak connection between the player's physiological data and the game

\section{Potential solutions}

1) integrate in-game tutorials and instructions to introduce how the game adapts to players' physiological data

2) detect a long-term BPM state to reduce the adjustment frequency of the color

3) develop a better designed color scheme and game environment 


\section{Protatype 2}

\subsection{Emotiion arch}

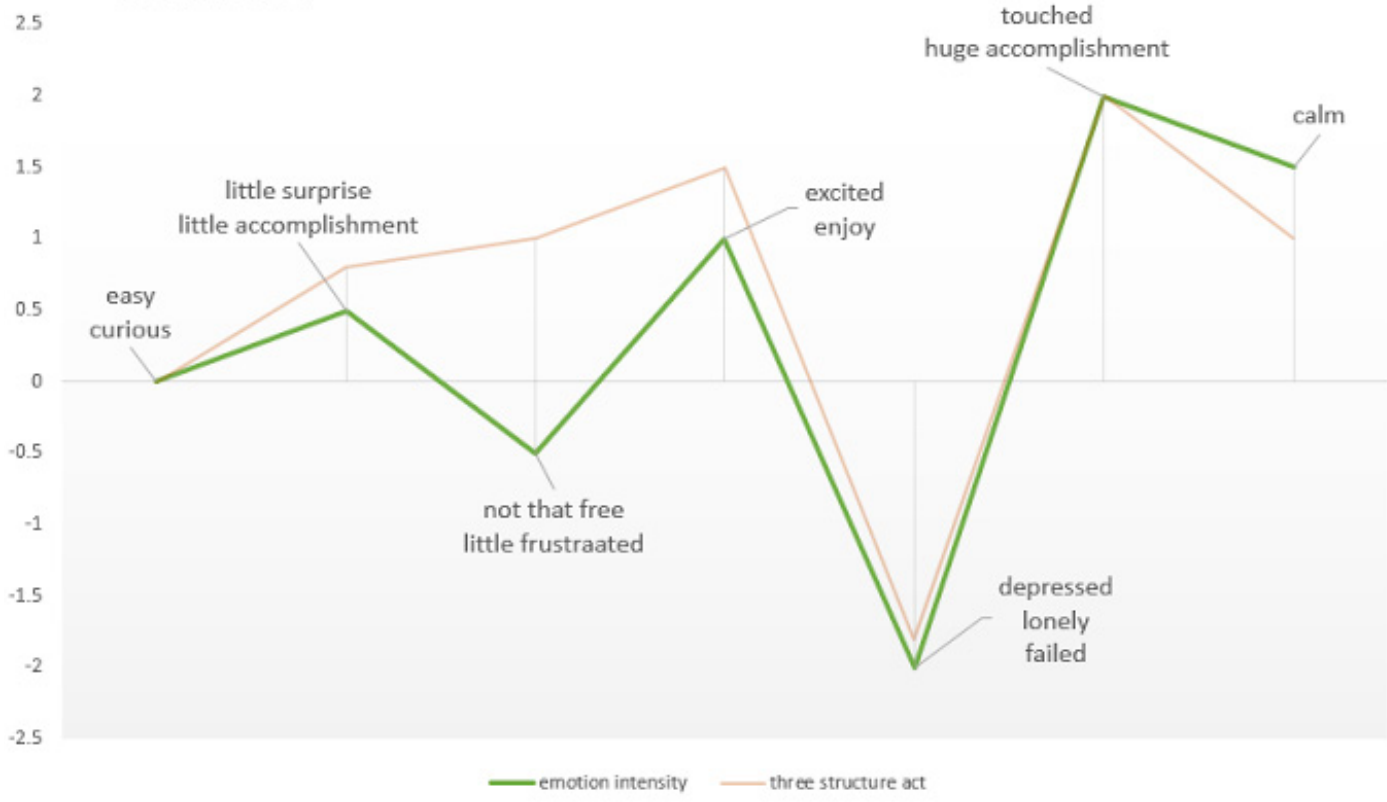

Figure 7.30 This prototype established an emotion arch combined with the Three Structure Act.
2.2 Feedback system

\begin{tabular}{|c|c|c|c|c|c|}
\hline & & World 1 & World 2 & World 3 & World 4 \\
\hline \multirow[t]{2}{*}{ Mechanics } & Game & \multicolumn{4}{|c|}{$\begin{array}{l}\text { Eat red trigger to generate new objects } \\
\text { Move a tree using the mouse }\end{array}$} \\
\hline & Biofeedback & \multicolumn{4}{|c|}{$\begin{array}{l}\text { Get close to an object to change its color (BPM); } \\
\text { Eat yellow trigger to transit to another world (GSR); } \\
\text { The avatar responds to the player's smile (facial } \\
\text { expressions); }\end{array}$} \\
\hline
\end{tabular}

Figure 7.31 This feedback system showed what players could do and how the game would react to the physiological 

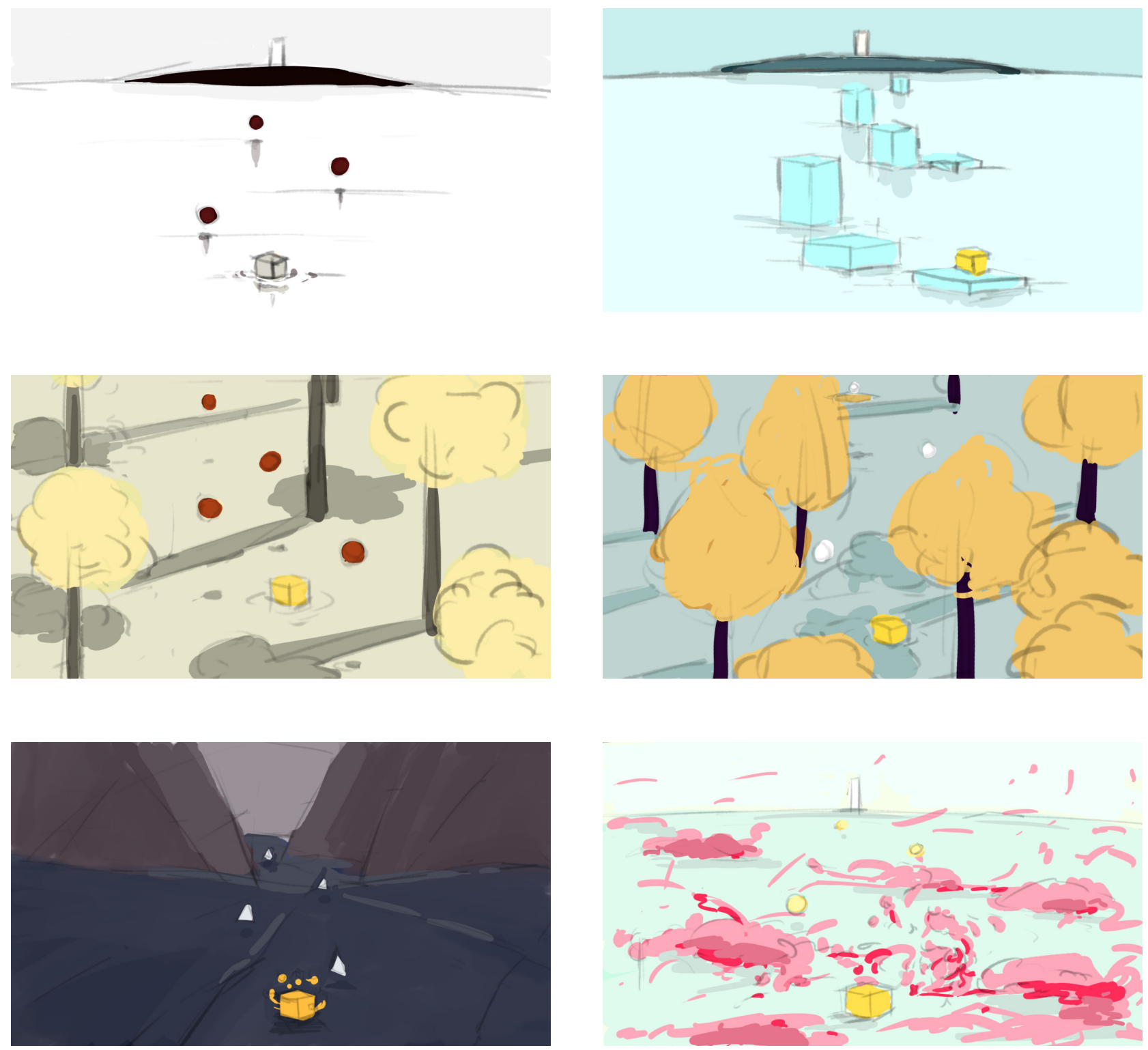


\subsection{Prototype}

Focus

Based on the findings from the prototype 1 , this prototype should address the three questions below:

In-game tutorial and instruction

Are they apparent to players during gameplay?

Do they explain clearly and guide players step by step?

Camera viewpoint \& camera control

Is the camera viewpoint helpful for player's movement?

Is the camera zooming effect useful?

\section{Color adjustment and environment building}

Is the color change in a more obvious to players?

Do the color schemes cause any discomfort for players?

Are players aesthetically satisfied with the color schemes?

\section{Connection between players and their physiological data}

Do players feel more connected when they using facial expressions?

Is the mechanic of changing object's color based on a player's BPM state effective?

Additionally, this prototype applied the emotional arc mentioned above to lead a player to experience from one to another emotional state. Audio effects and background music were included in this prototype.

\section{Sensor included}

The Pulse sensor

The GSR sensor

The webcam
Visual design

color schemes
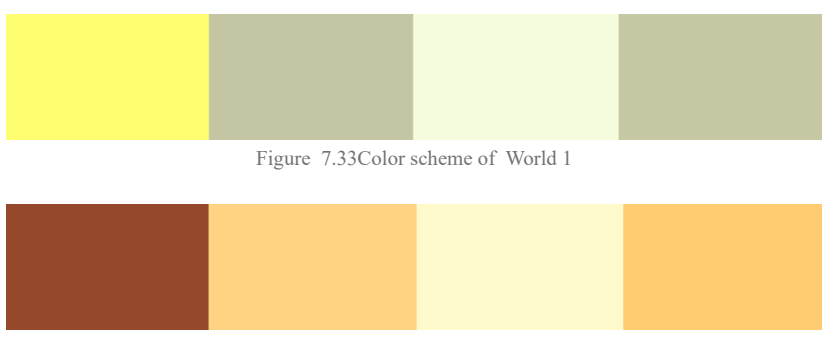

Figure 7.34 Color some of World 2 if the GSR increased

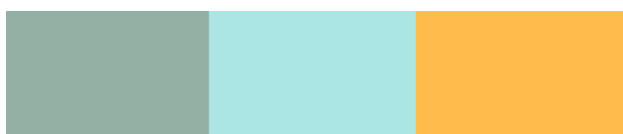

Figure 7.35 Color scheme of World 2 if the GSR dectosed

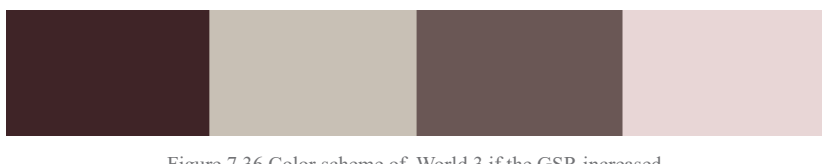

Figure 7.36 Color scheme of World 3 if the GSR increased

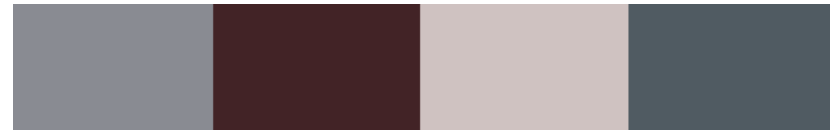

Figure 7.37 Color scheme of World 3 if the GSR decreased

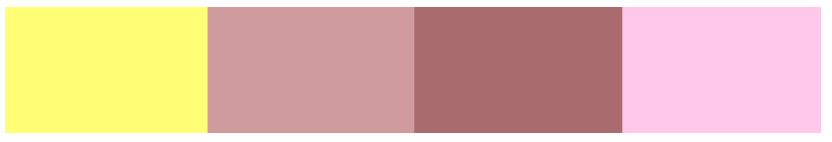

Figure 738 Color scheme of World 4 if the GSR increased

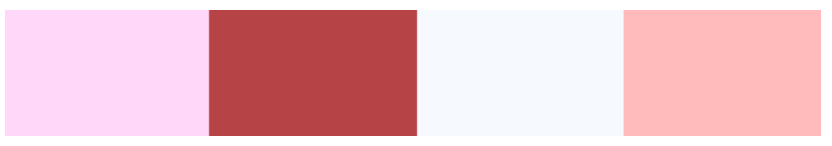

Figure 739 Color scheme of World 4 if the GSR decreased 


\section{Environment settings}

The four game worlds conveyed different visual experiences to players by certain objects. World 1 used trees while World 2 focused more on a water environment. World 3 used mountainous elements to create a depression and intensity while World 4 was filled with flowers. This prototype narrowed the number of the objects that the player can interact with. Players felt

frustration when they faced with too many objects in a small area.

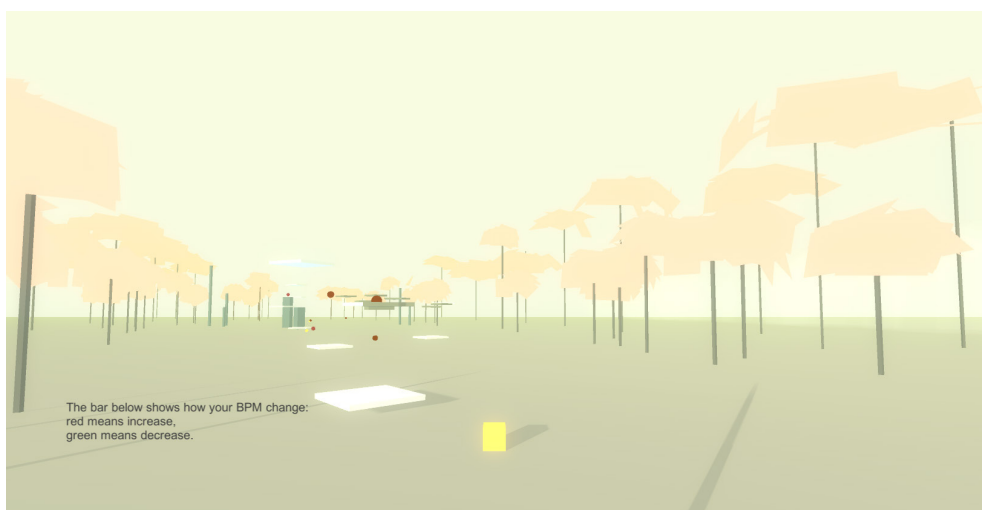

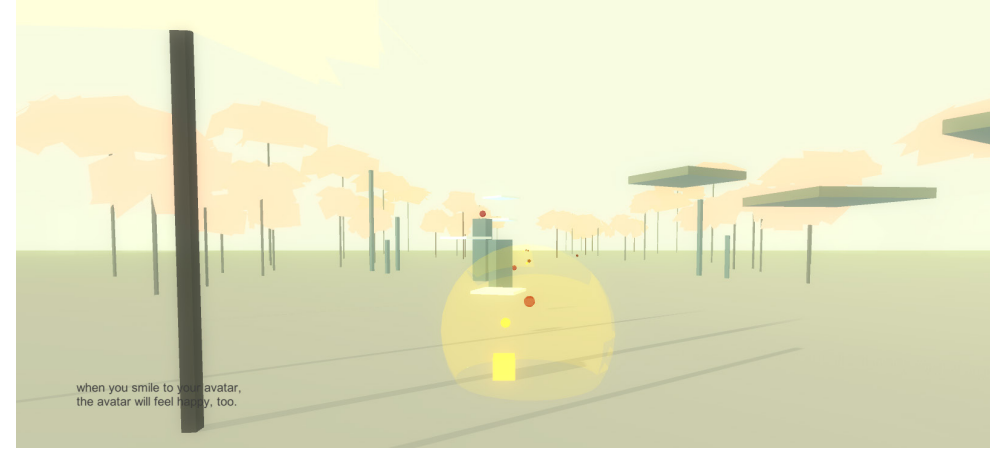

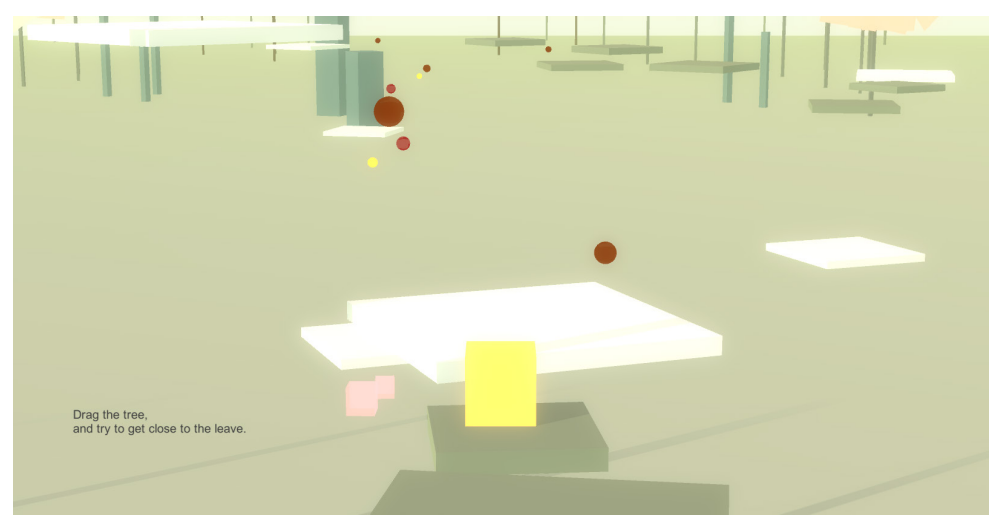

Figure 7.40 The three images presented the situation 1) when avatar was at the begining of the game, 2) when players smiled, 3) 
GSR increase
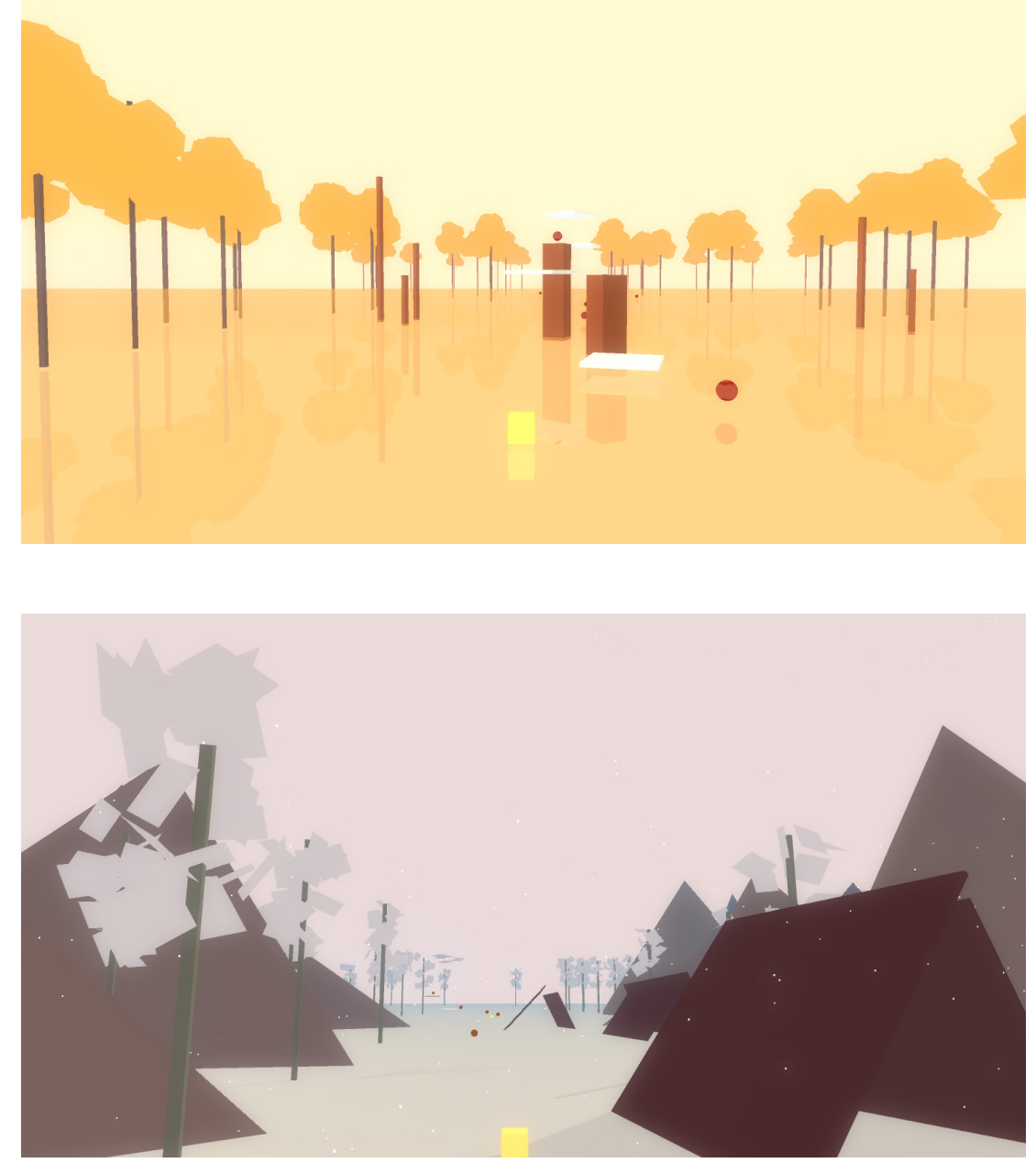

GSR decrease
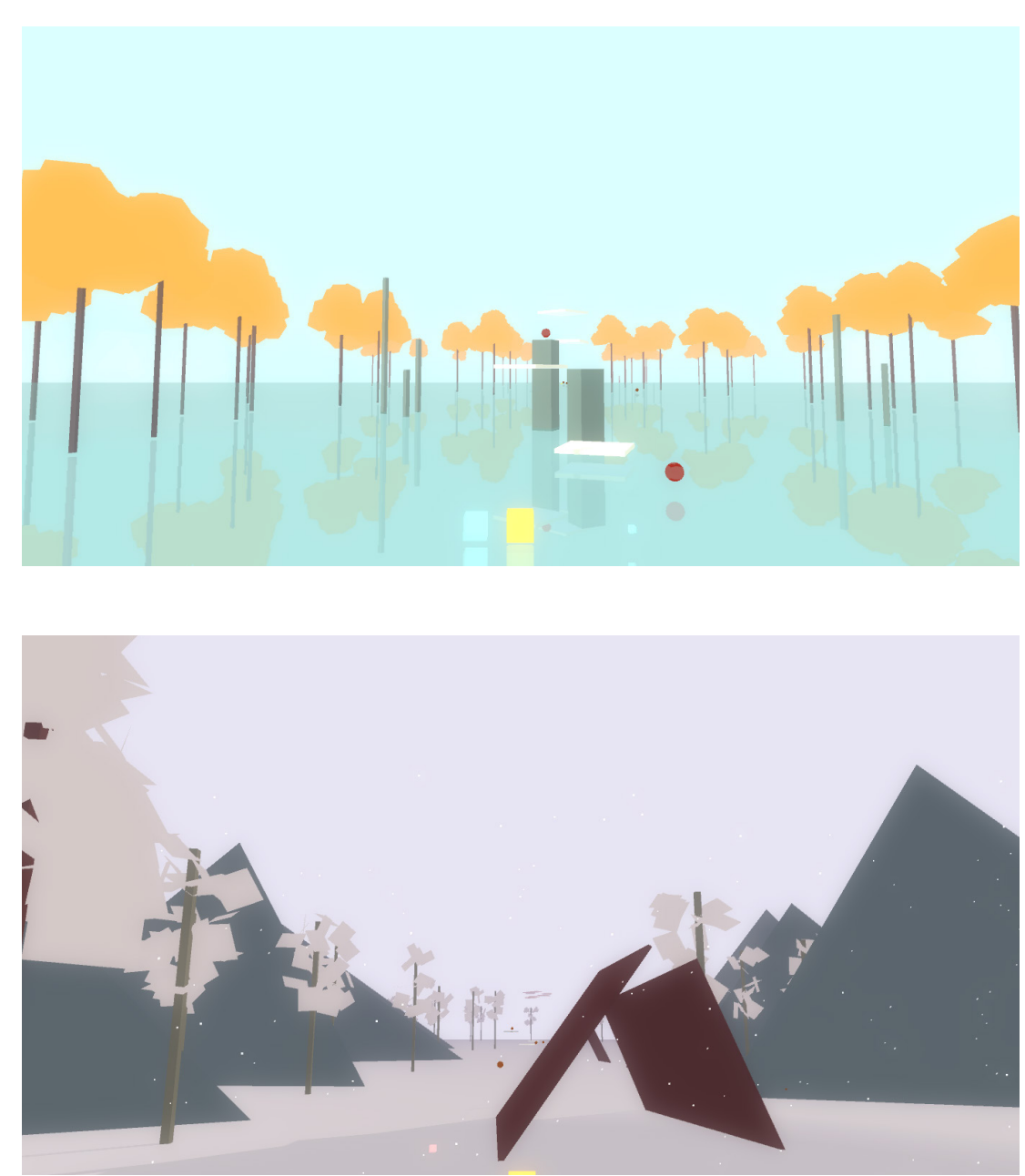

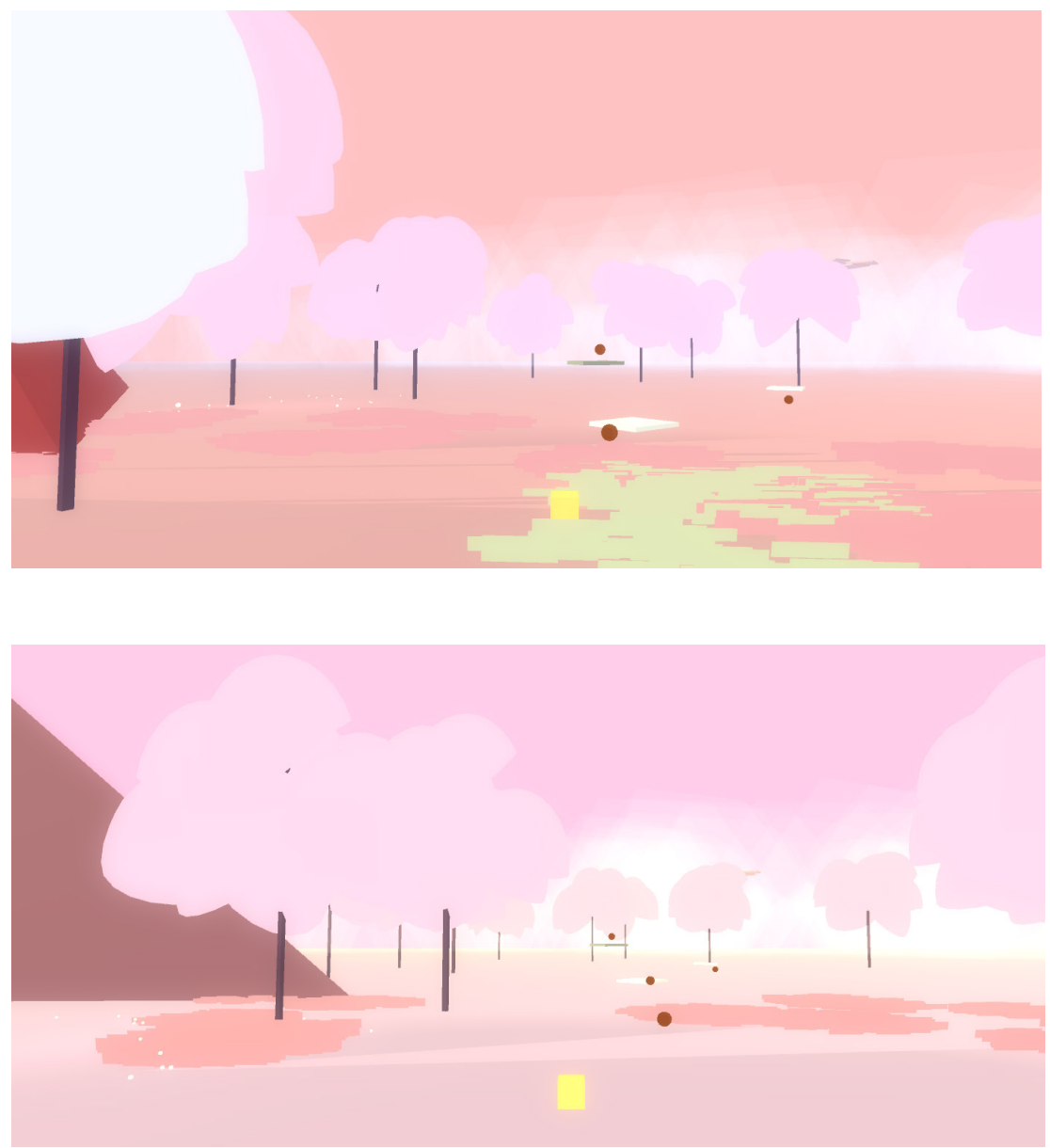

\section{Results}

Interviews and observations:

There were four participants playing the game. Only two sets of physiological data were collected due to an error within the game itself. Participants reported that 1) the color scheme and environmental visual design for each world were helpful to induce a calm and serene experience 2) they had a strong feelings when the environmental color changed dramatically by eating the yellow trigger, 3) they were interested in interacting with the avatar using their facial expressions, and 4) the tutorial and instruction were clear but might be ignored sometimes.

This prototype assumed that players could be more related to the game world by moving and placing trees, however, the feedback from the participants showed this mechanic was not effective. Participants still did not notice they could change an object's color via BPM values when they were close to it. Participants did not experience the intended negative emotion in World 3 . 


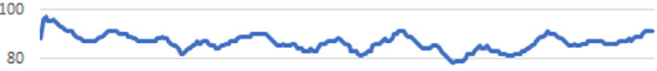

20

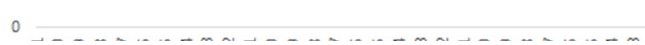

Figure 7.41 The BPM values and GSR values of participant A

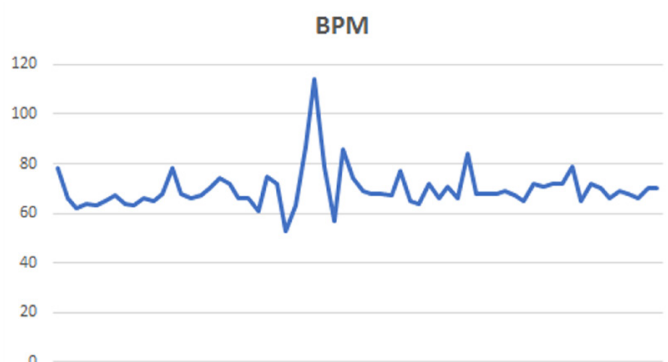

GSR
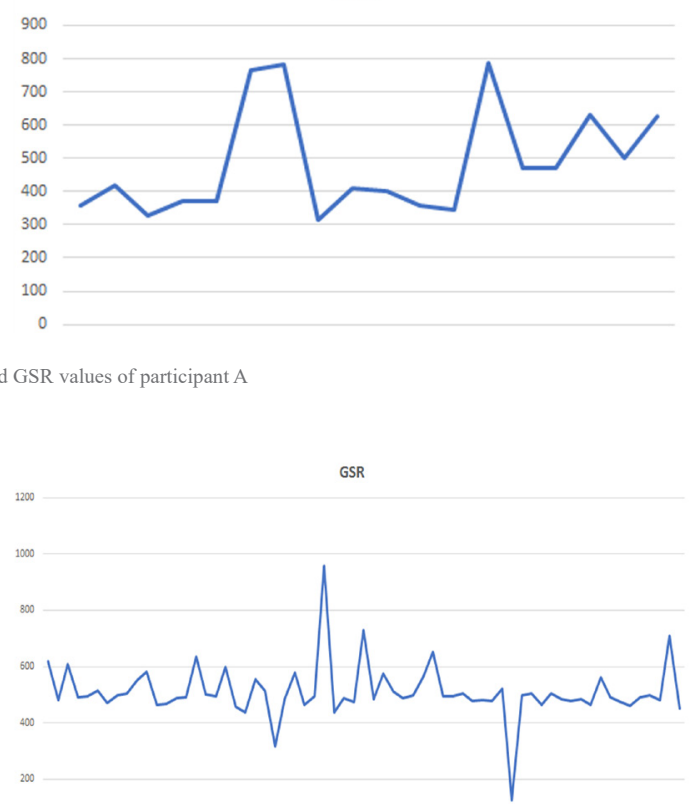

Figure 7.42 The BPM values and GSR values of participant B

\section{Data anlysis:}

The BPM values were in accord with the GSR values most of the time during gameplay. The number seen to increase briefly at the time near the middle of the gameplay. This was the time when players were moving to the World 2 and they needed to jump to a higher space to eat the trigger. I assumed the reason for this increase was the control scheme did not work properly as it was difficult to jump on the certain position. There were no obvious value change in the players near the end of game, which fit the interview feedback that players did not experience a negative emotion in World 3.

\section{Summary}

The well-organized game environment engaged players more than a unordered one. The color adjustment should only generated on certain object or generated dramatically at once. The next prototype could consider more on using facial expressions to interact with the game world as players showed interest. Tutorial and instruction should be more intuitive to players and need to inform players how to make valid facial expressions for the game system.

\section{Potential solutions}

1) use facial expression to interact with the environment directly

2) an interative tutorial

3) a clear instruction to inform players that the object's color would change based on their BPM state 


\section{Final Prototype}

The final prototype implemented 1) the affective design criteria that were discussed in chapter six 2) emotional arc 3) feedback provision for effective biofeedback interaction. The prototype was also refined based on primary feedback and advice summarized from the last two user testings. This prototype included a tutorial and four game worlds, using the player's HR value, facial expression data, and GSR value.

\section{Biofeedback sensors}

The final prototype used the Pulse sensor for BPM, and Grove's GSR sensor for GSR. The sensor from Grove was only used to record the player's GSR data for analysis and was not involved in in-game interaction. The facial expressions were captured by the webcam using the SDK from Affectiva. The facial expressions only included joy and sadness by detecting players' brow furrow, lip corner depressor, and smile.

\section{Visual design}

The game environment in the final prototype consisted of abstract naturerelated elements. All the models were not detailed and realistic, made of basic geometric shapes. The color schemes related to real seasons. The first scene was a green hue and the second scene was mostly yellow and red hues. The third scene was based on dark blue, white, and grey colors while the last one was a pink hue. This scheme was intended to create a harmony of colors to induce a player's aesthetic emotion. When players were interacting with the game, the color would change in a more positive or more negative way. If players were happy, the color would adjust to one that was brighter and more saturated. If players were presenting in a negative way, the color would have a more grayscale.

.

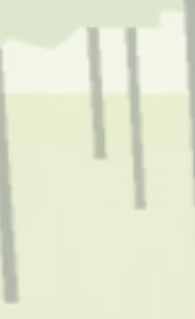




$$
1
$$


Color schemes

Initial
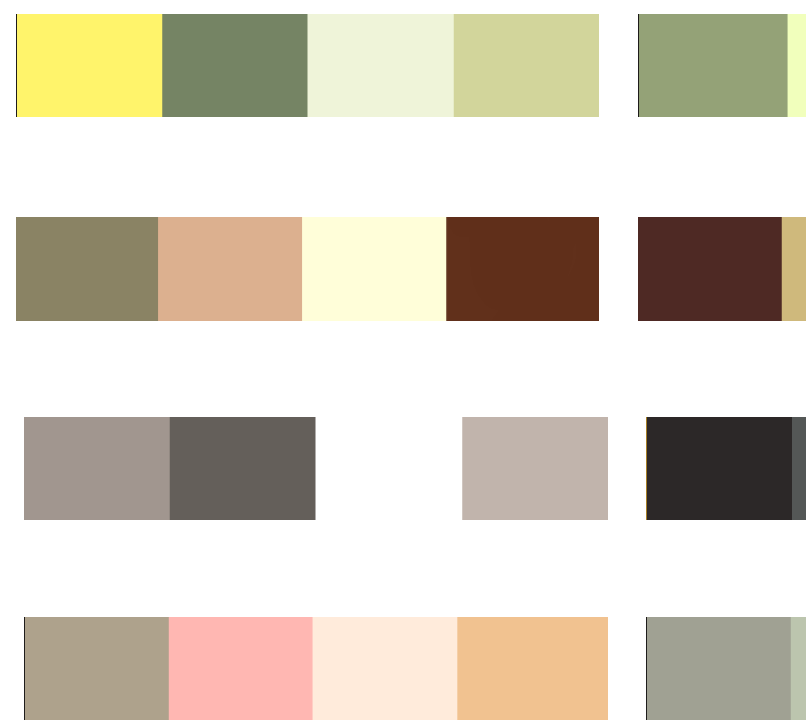

Joy
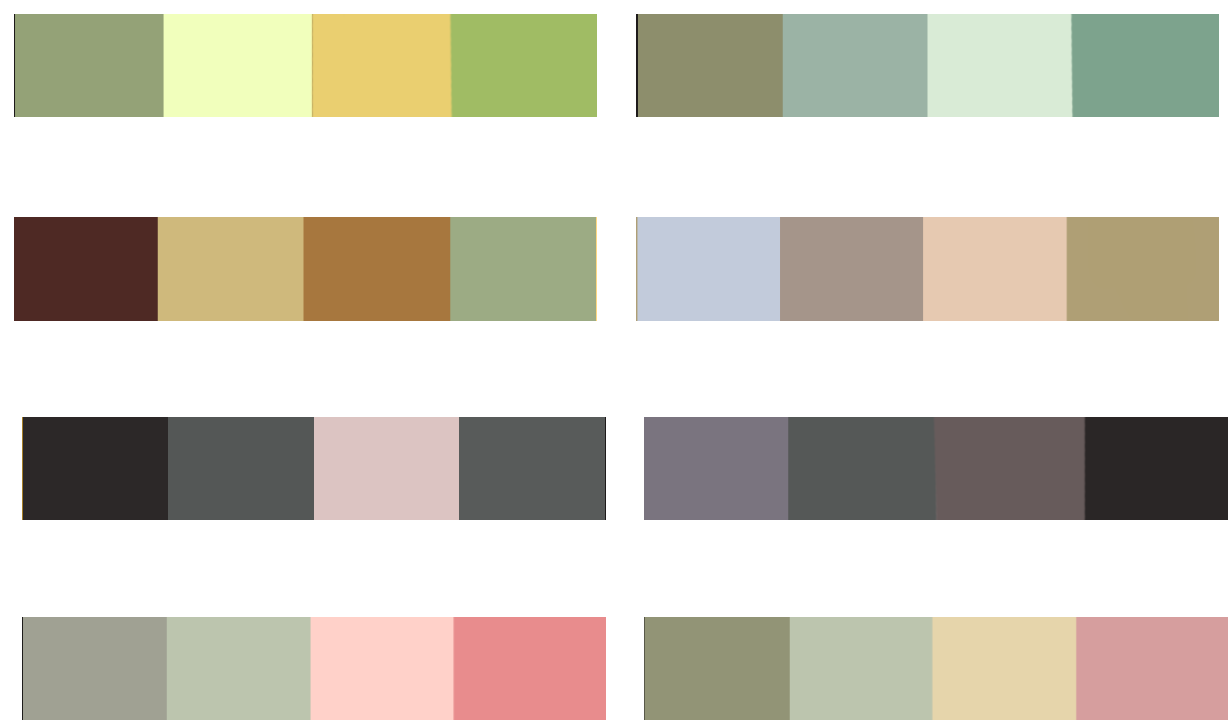

Figure 7.43 These Four set of eolor was created for each seene. There were an initial color scheme, the eolor scheme when players smiled, amd the color scheme when players made a sad face in each set. 
Initial
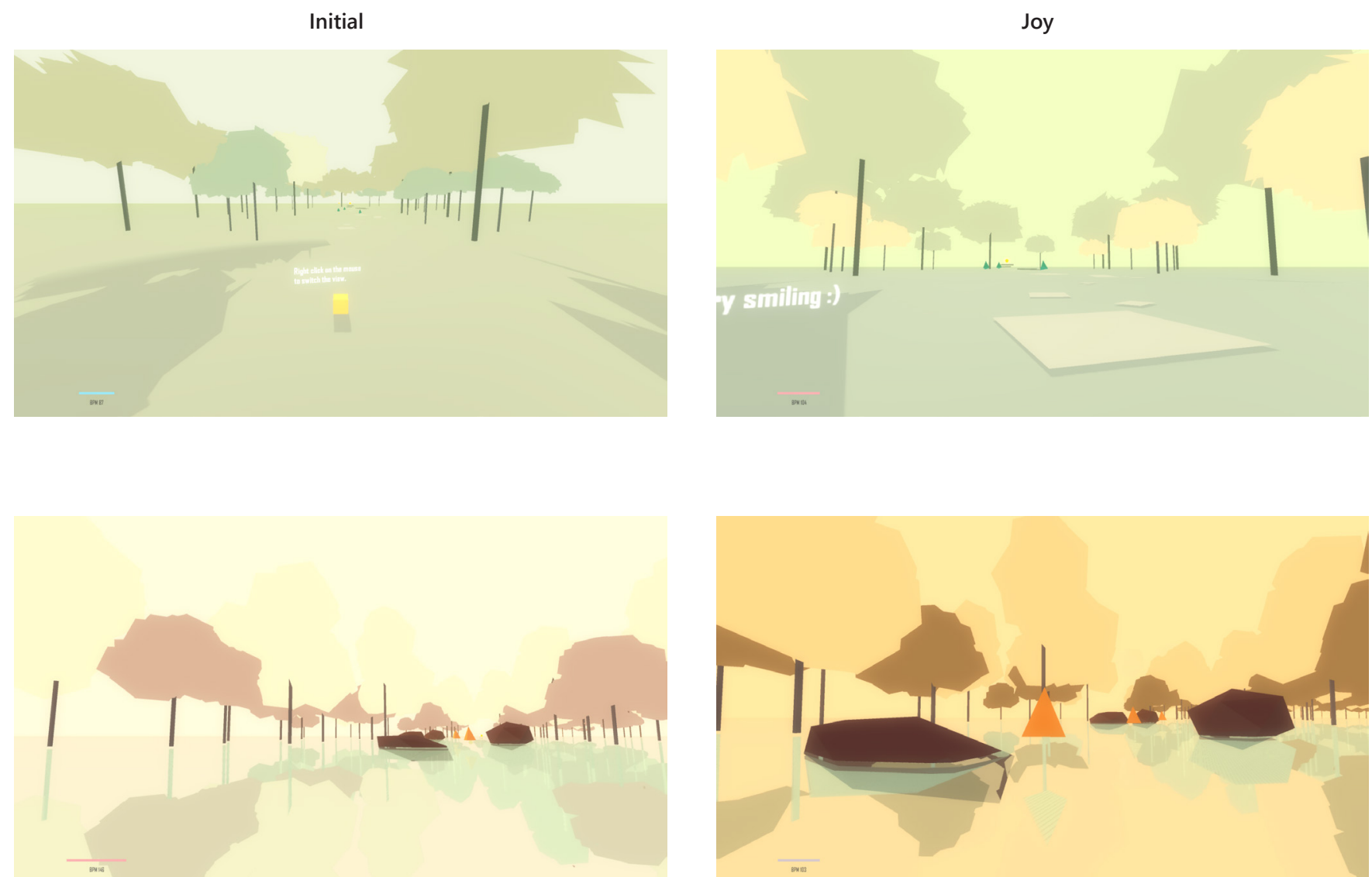

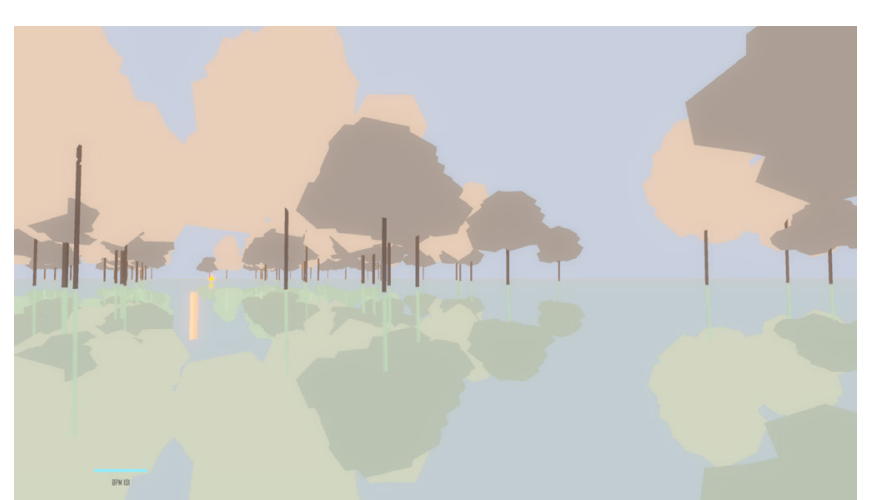

Sad

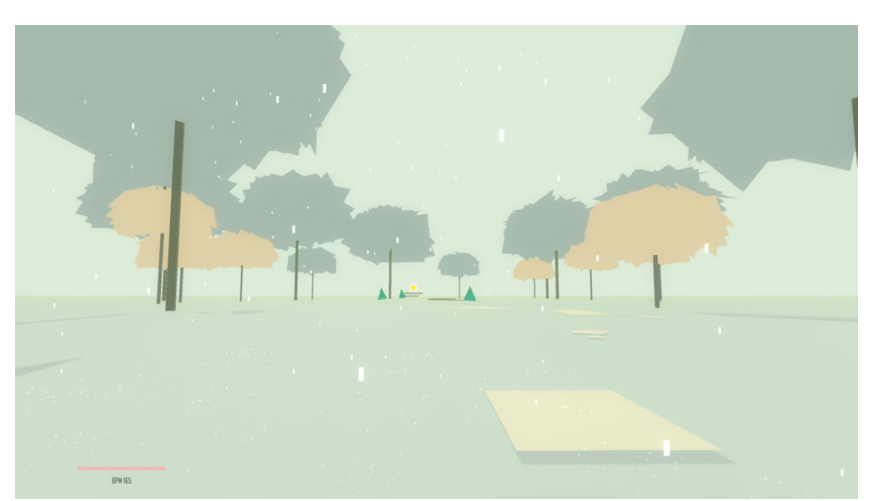

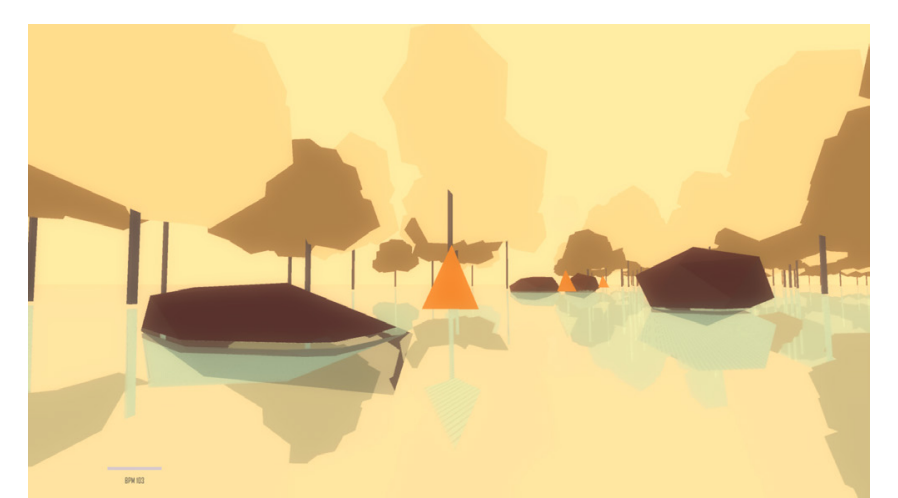

Figure 7.44 How did the game world adapt to players' facial expressions. 
Initial
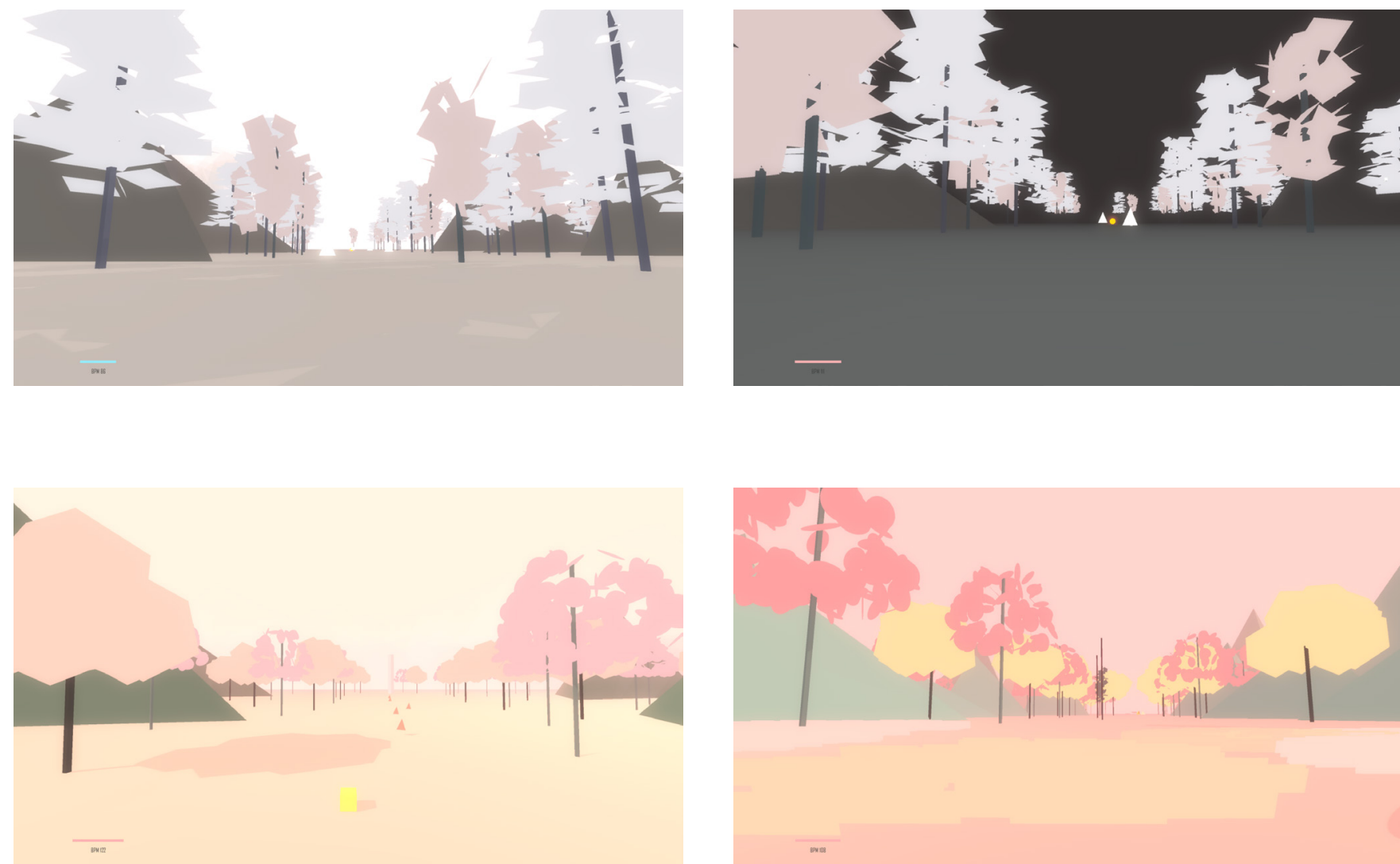

Sad
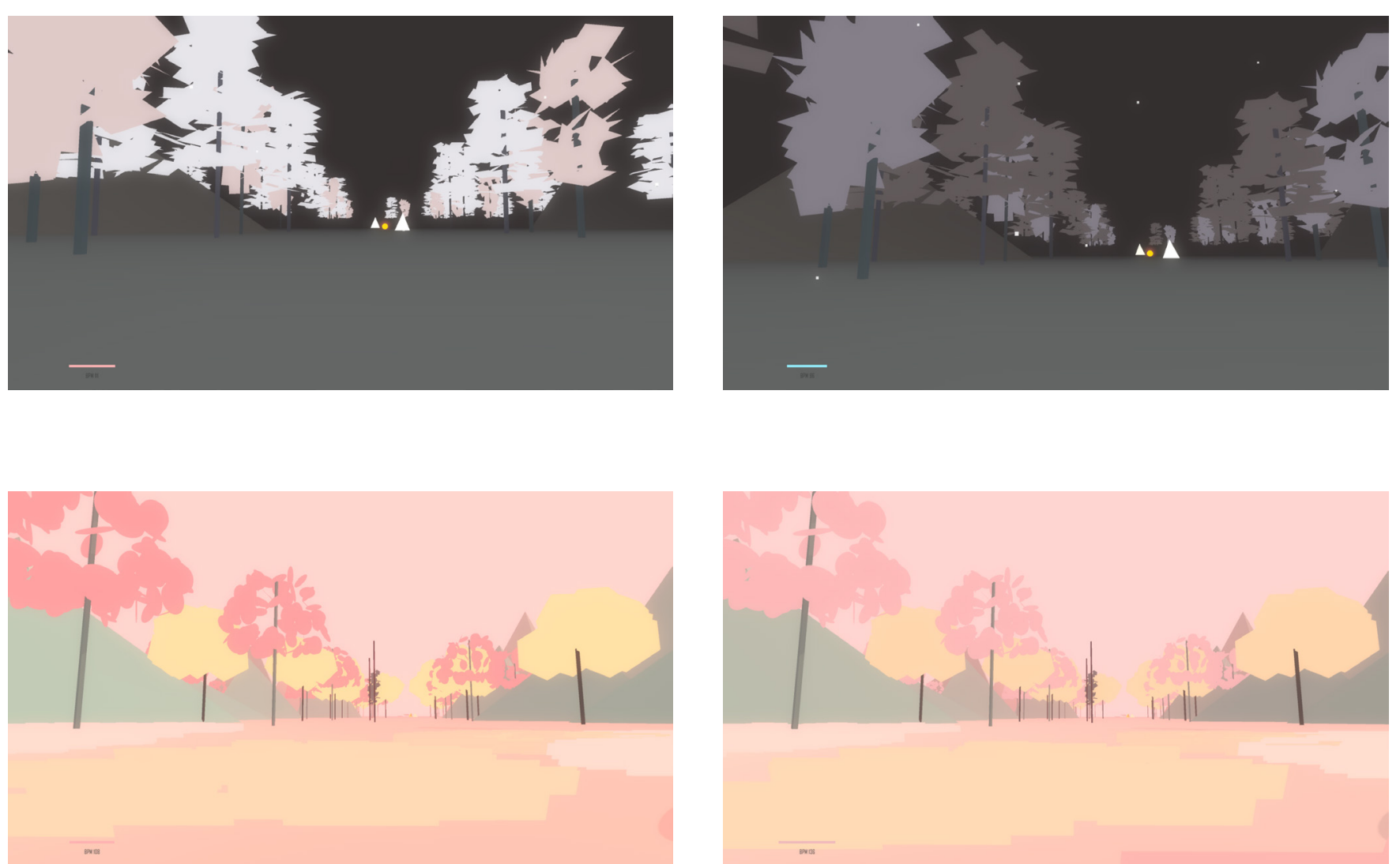

Figure 7.44 How did the game world adapt to players' facial expressions 

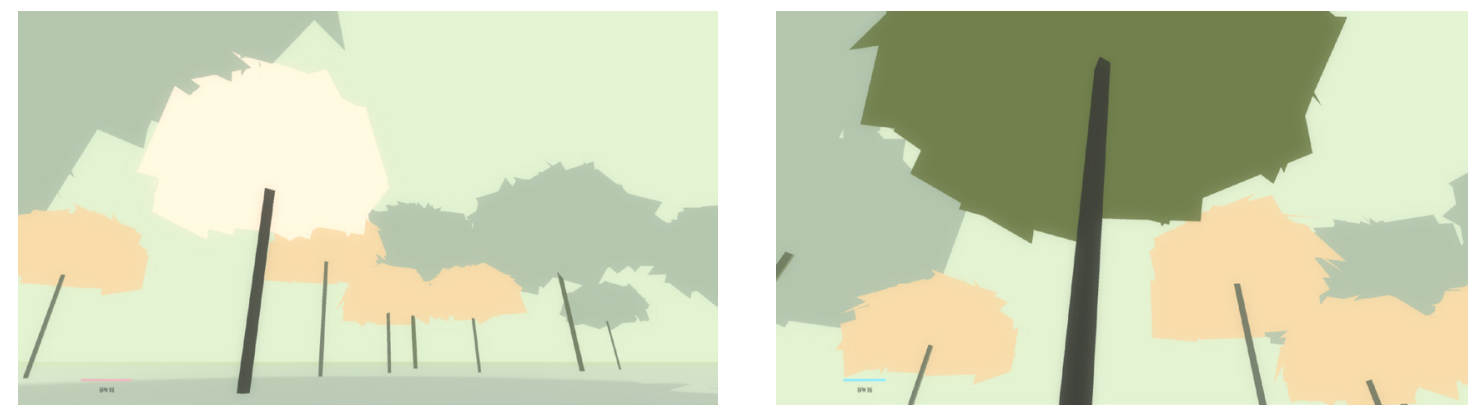

Figure 7.45 The generated tree adapted its color to the player's BPM.
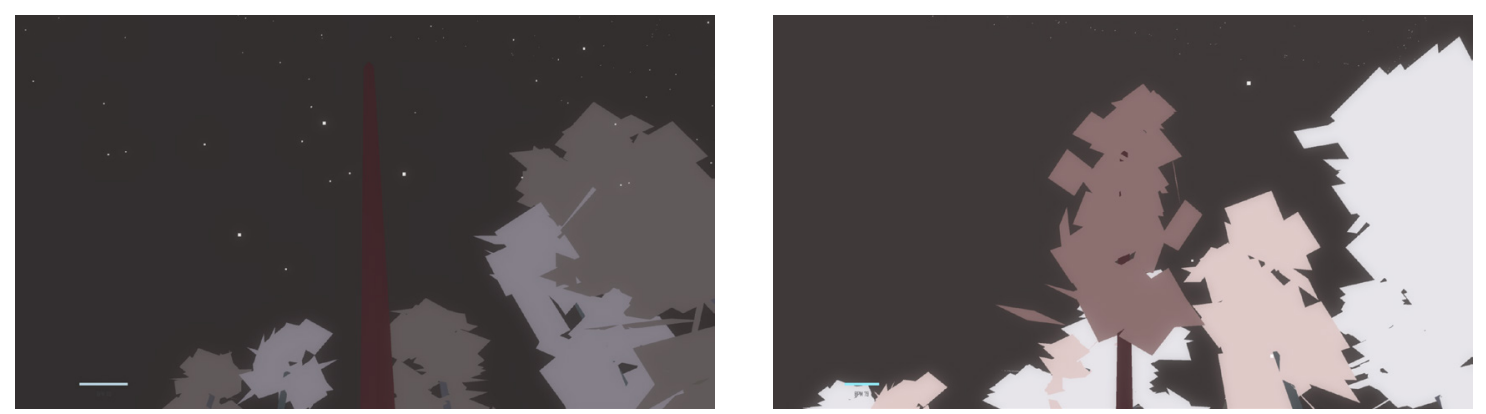

Figure 7.46 The tree might grow if the player smile to it.
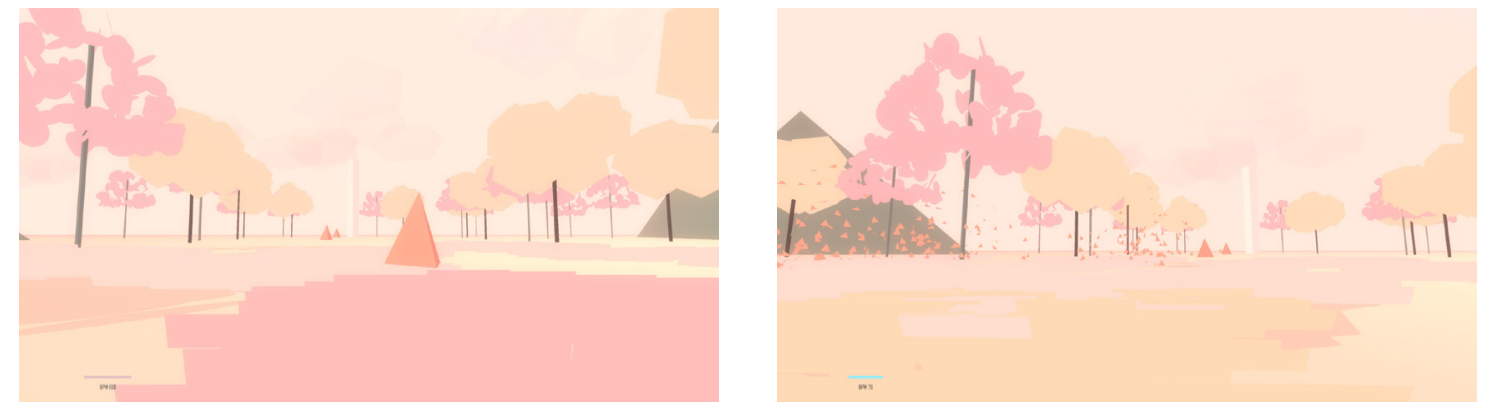

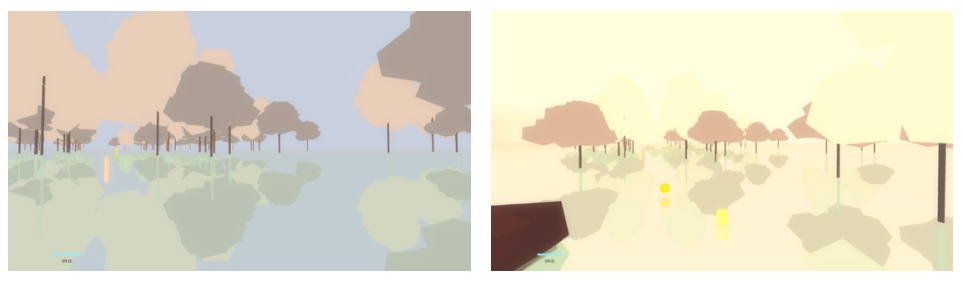

Figure 7.48 When the player switched to third-person view, the environment remains unchanged.

\section{Mechanics}

Following the criteria, this prototype would not contain a competitive mechanics or lose conditions. There were two camera viewpoints in this prototype: third-person view and first-person view. Players could explore the game world through the third-person view and first-person view. Players' physiological data would only be detected when playing in first-person. There was no biofeedback interaction when players used a third-person view. In addition, the game world would remain same in the third-person view even if the game world in the first-person view had changed due to a player's body signals.

In the first-person view, players' facial expressions could impact the color scheme of the game world. This has been discussed in the section on graphics design above. The color of certain objects would change based on players' BPM trends (i.e. increasing or decreasing) when players got close to them. Some interactions with in-game objects varied in each world. Those interactions involved features of seasons to avoid a repetitive gameplay experience. 


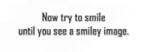

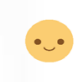

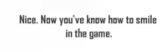

Pres ware

Figure 7.48 In-game tutorial of how to make a valid expression
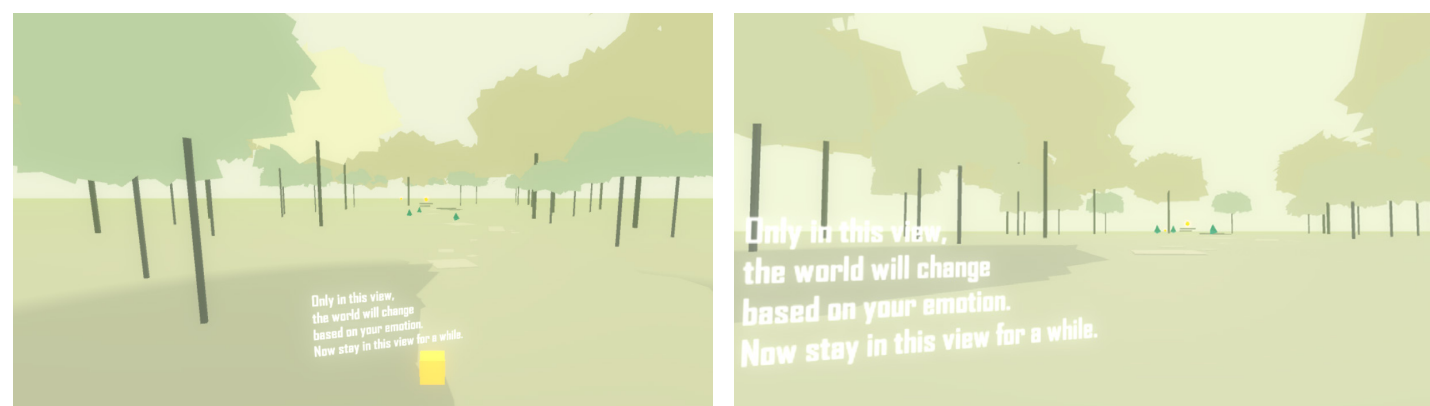

Figure 7.49 In-game intrsuctions.
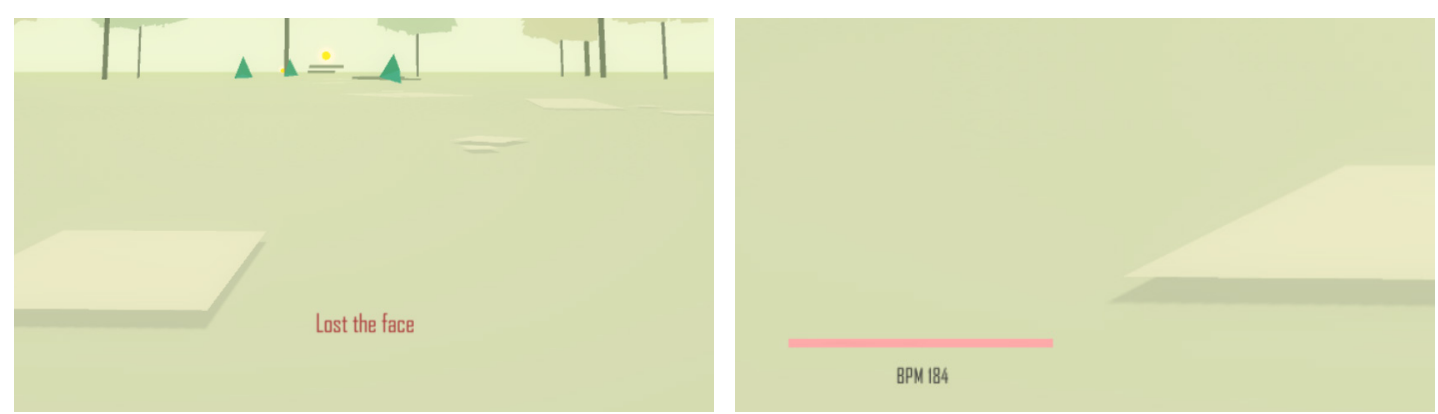

Figure 7.50 "Lost the face" feedback \& real-time BPM graph.

\section{Feedback provision}

Face lost feedback:

When players did not keep their faces right to the camera, there would be text stating "Lost the face" on the screen.

HR bar:

The number of HR bars showed the real-time BPM values of players and its scale showed how much they changed. Red indicated that they were

increasing while blue indicated they were decreasing.

\section{Facial expression feedback:}

When players smiled, depressed lip corners, or furrowed their brows, they would discover a note about the game world's feeling. A note should not be if players did not make facial expressions to a certain degree which was the premise to trigger variation in the game world.

\section{Summary feedback:}

In the end of prototype, it would show the biggest and smallest number, of the BPM and GSR data.

\section{Tutorial:}

At the beginning of the prototype, players would experience a brief tutorial.

This tutorial showed players what types of physiological data would be used and how they presented in the prototype. It also taught players how to make a valid smile and sad face enabling the camera recognize them.

When players were in the first game world, they could follow instructions to switch camera views and interact with objects. These instructions gave players some basic knowledge about how this prototype worked. 


\section{Testing}

Four participants took part in the final testing. Players needed to wear two sensors on their left hand. The Pulse sensor was on the thumb and GSR sensor was both on the middle and third fingers. Players were required to sit right next to the webcam on the computer while playing the game. This ensured their facial expressions were captured. Players used a mouse to control the game view and a keyboard for movement.

The tutorial before the actual gameplay could show players basic knowledge about sensors. The game normally took two to five minutes to play and players were informed to play until they reached the end. A one-on-one interview was conducted with players after playing. The questions' aimed to players' gameplay experiences, aesthetic experiences, and biofeedback interaction experiences.

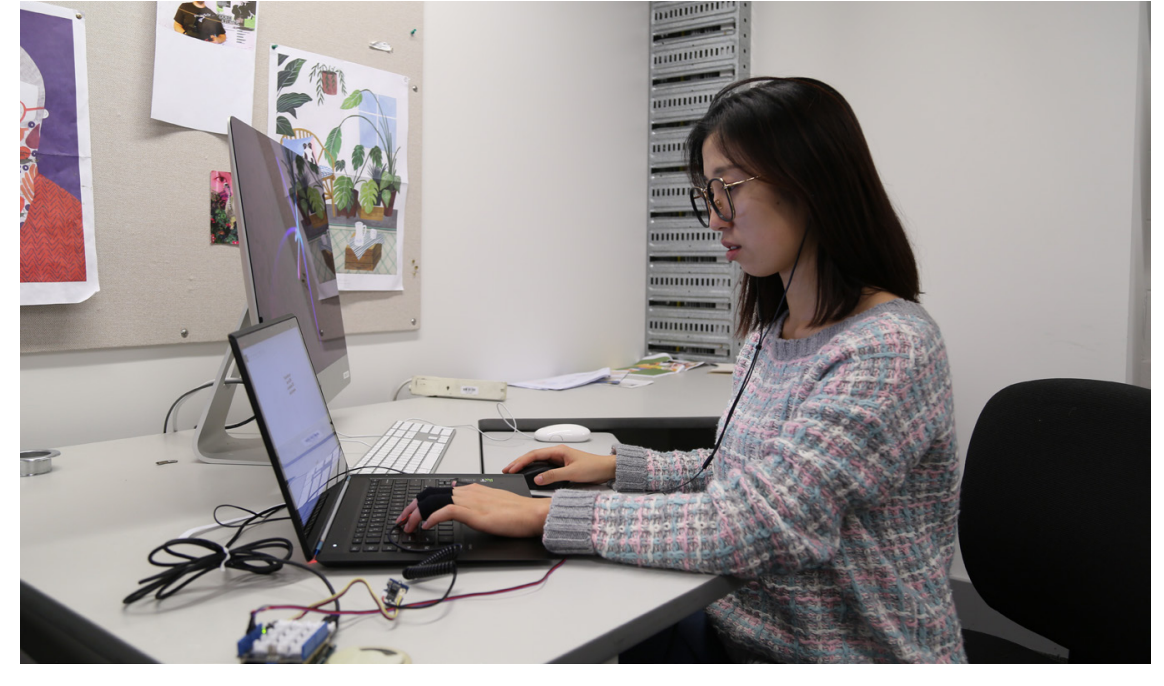

Figure 7.51 During gameplay.

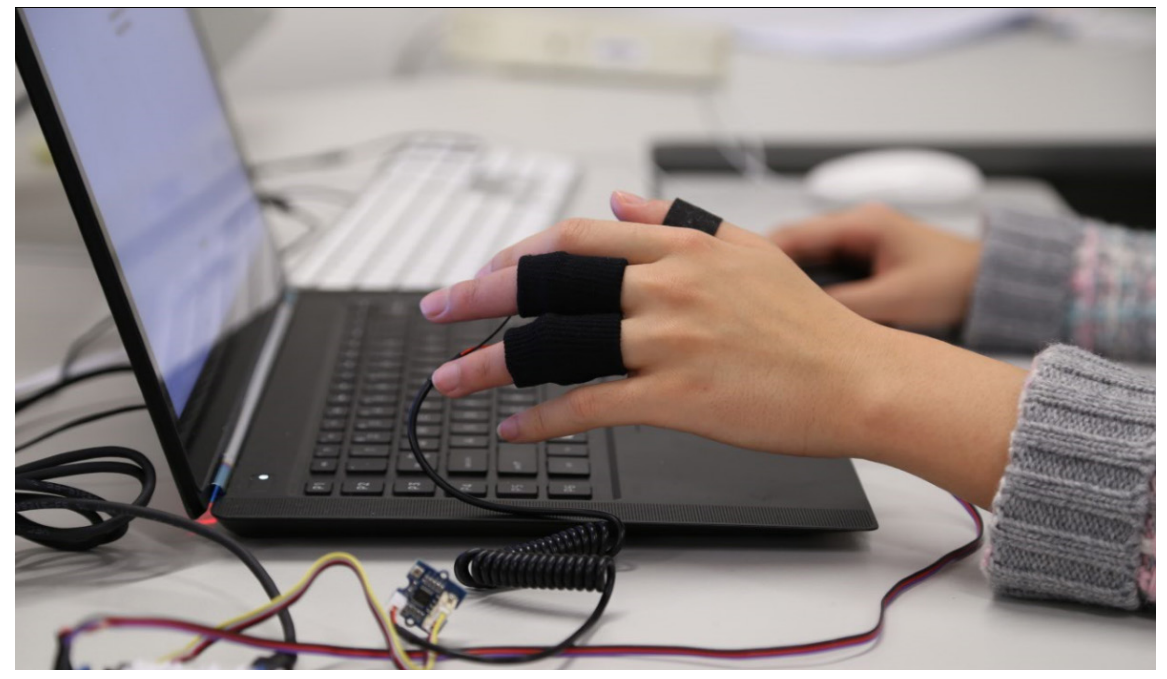

Figure 7.52 The Pulse sensor \& GSR sensor were attached to the player: 


$$
8
$$




\section{Interview}

Tutorial

Participants reported that them had a preliminary understanding about sensors after the tutorial at the beginning of the game. The tutorial was clear and straightforward. As to the instruction in the first scene, participant reported that the position of instructions should be more obvious. In most cases, the instructions were concise and explicit.

\section{Controlling}

The game control was very easy for all the participants. There was no issue occurring in the avatar's movement during testing. Participants were satisfied with the distance from the camera to the avatar in the game. One participant reported that she could not see much path below in the firstperson view and this made her feel a little frustrated when she wanted to jump to the stairs.

\section{Visual design}

Participants agreed that the graphic design was helpful to enhance the feeling of serenity. They described the game environment as simplistic and subtle. The color of each scene provided participants a sense of peacefulness. Participants also reported that those abstract in-game objects avoid overwhelming information in the game which might cause them discomfort. The game environment was well-organized compared with the first prototype.

When participants smiled or made a sad face to the camera, some of them felt confused if the color had changed. They thought the mechanic of changing color according to their facial expressions was interesting however, the outcome was not apparent enough to make them have emotional responses. 


\section{Biofeedback interaction}

Participants actively interacted with the game environment using their facial expressions. They said that it was easy to notice that game environment had changed when they smiled.

This enabled participants to have a connection between the game and themselves, however, the connection was not strong. Participants were confused about what could be regarded as a valid sad face. They were trying to change the environment in a negative way but most of them failed. The changes that were brought by BPM and GSR values were not clear to participants. Some of them did not notice that the tree's color would change when they were getting close to it. Participants felt the game was less linked to their BPM and GSR values than facial expressions.
Questionnaire

\begin{tabular}{|l|l|l|l|l|l|}
\hline & Participant A & Participant B & $\begin{array}{l}\text { Participant } \\
\text { C }\end{array}$ & Participant D & Average \\
\hline Game control & Very easy & Very easy & Very easy & Very easy & Very easy \\
\hline Graphics affect & 7 & 8 & 8 & 7 & 7.5 \\
\hline Serenity & 7 & 6 & 8 & 7 & 7 \\
\hline
\end{tabular}

Figure 8.1 The table showed what degree players felt about for certain aspects after playing. 

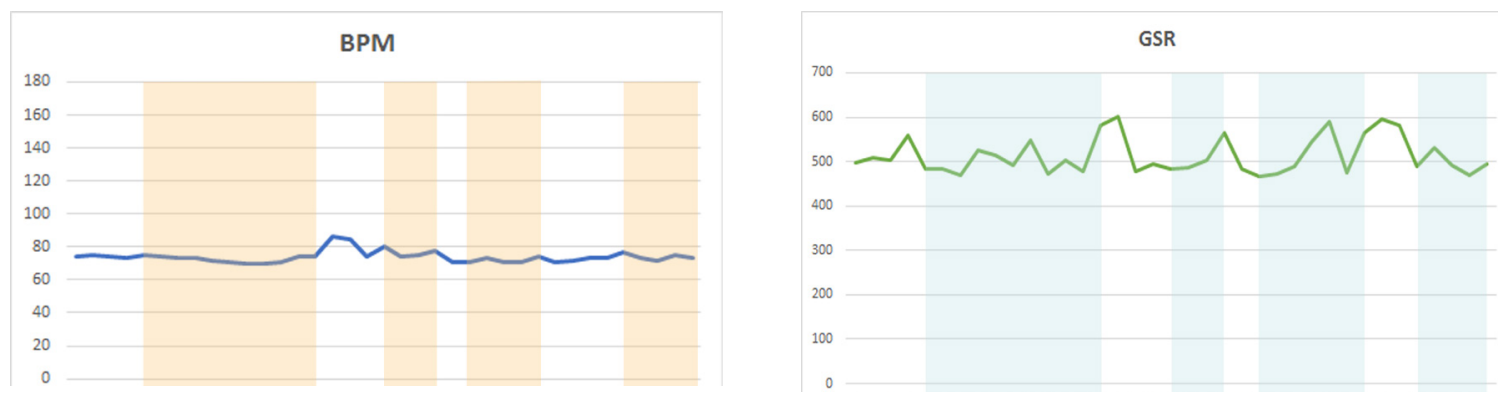

\section{Data analysis}

The following graphs showed the BPM, GSR values of each participant.

The orange parts in the BPM graphs and the blue parts in the GSR values

represented the time period when participants were in the first-person view.
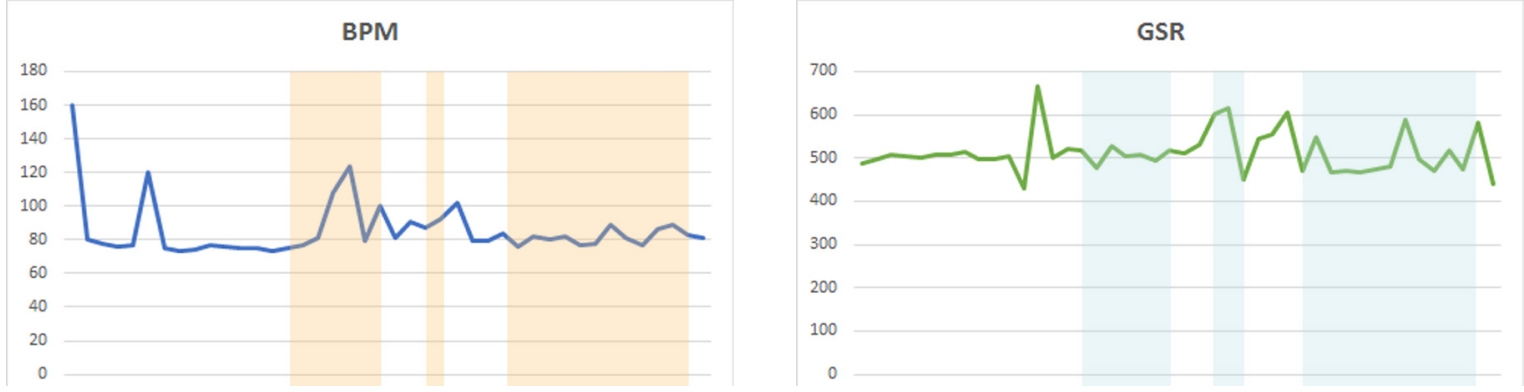

Figure 8.3 The BPM values and GSR values of participant $B$

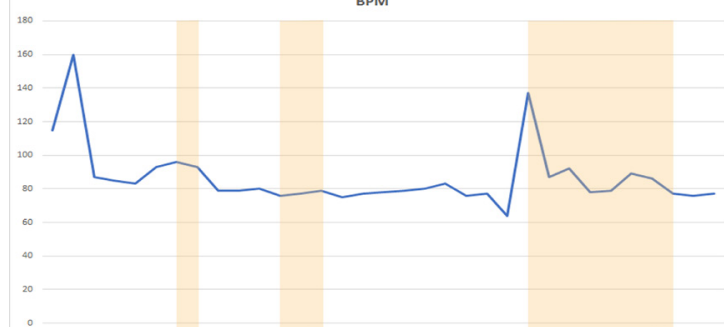

GSR

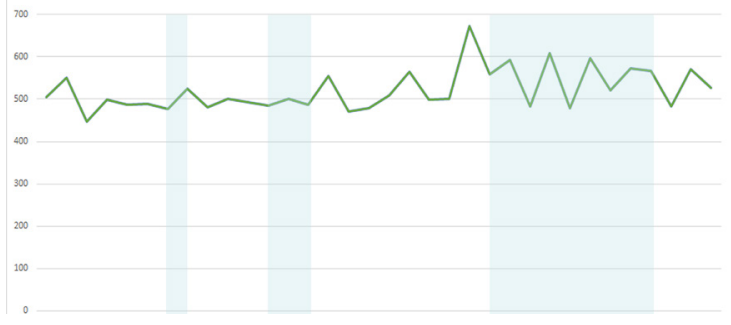

Figure 8.4 The BPM values and GSR values of participant $\mathrm{C}$ 


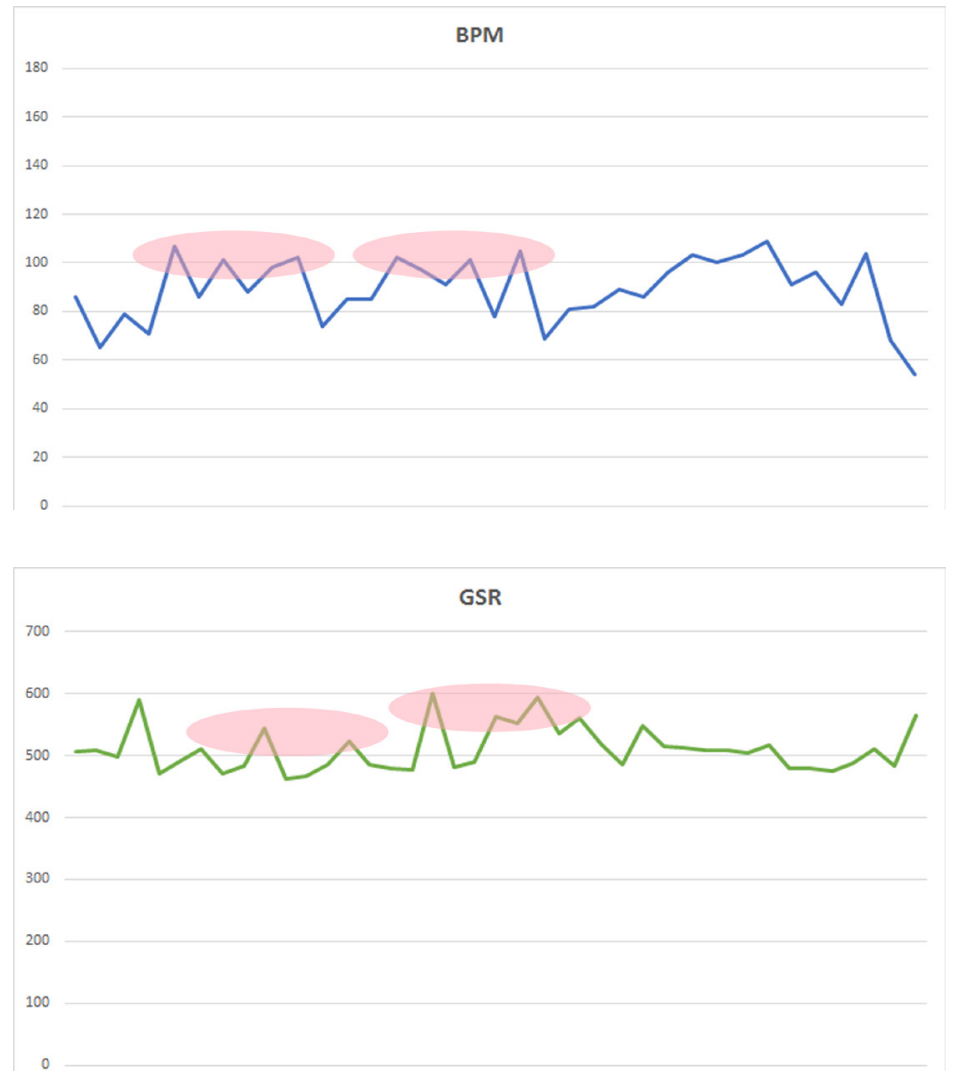

Figure 8.5 The BPM values and GSR values of participant D who used the first-person view during the whole gameplay. Red areas indicates he was trying to increase his data deliberately.
In the final testing, the BPM values generally were in accord with the GSR values. Despite the errors of the sensors, serenity was increased during gameplay for some (e.g. participant B, C, and D) but not all of the participants. The increase of serenity was reflected in 1) the decrease of the BPM values and GSR value, or 2) remaining in a stable level of the intensity.

Participant $D$ experienced the entire game within the detection of the sensors. The pulse sensor seen to detect the change of the player's BPM accurate and rapidly. Although the participant $D$ intended to increase his $B P M$, the BPM values seen to remain stable during the rest of the gameplay. Near the end of the game, the BPM values of the participant $D$ experienced a dramatically change from increasing to decreasing. This change might be correlated to the emotional arc design in the game. Players were meant to experience a transition of emotional state from negative to positive when they move from Winter scene to Spring scene.

The results from the questionnaire and the sensor measurements correlated. This indicates that the sensor measurements were a valid means of measuring real time serenity during gameplay. Thus, the sensor platform and methodology could be used for further design experiments to accomplish increased serenity across more of the population. One thing that should be noted is that although the BPM values of the participant B remained stable, the participant reported a lower degree of generated serenity in the questionnaire than other participants. The only difference between participant $B$ and others was participant B was not a gamer. There was not enough evidence from the results showing this was the cause. 



$$
9
$$


This research aimed to implement biofeedback techniques in a video game environment to build emotional relations with players and trigger their feelings of serenity.

This research followed two aims with specific objectives. The first aim was to investigate design principles and strategies of cultivating a positive emotional gameplay experience in video games, especially a serene experience. The second aim was to develop a game mechanic combined with biofeedback sensors to impact the player's feeling of serenity.

The research proposed an affective game design criteria based on the literature review, design review, and theoretical concept. The criteria were established as a guideline to interact with the player's physiological data using certain design strategies such as nature-related stimuli, color schemes, avoid aesthetic or mechanical distractions, and the genre of walking simulation to create a positive emotional experience. Additionally, the criteria adopted implicit-based physiological control method for biofeedback interactions.
Then the research used an iterative design process to develop a game prototype aiming to facilitate the design criteria. The process included prototyping, testing, and iterations were done according to 1) the qualitative feedback from interviews 2) the quantitative data detected by the sensors. Final testing also conducted questionnaires. The process started with an experiment usingsensors. This research used three devices to detect different types of physiological data: the Pulse sensor for heart rates, the GSR sensor for galvanic skin conductance, and the webcam for facial expressions. The experiment was to obtain preliminary knowledge of player's physiological data and how different emotions affect them. After these experiments, I conducted several prototypes including the final prototype. The first stage of prototyping focused on the kinesthetics design including the control schemes and camera viewpoint. The second stage was to explore potential approach for an effective biofeedback-based interaction. The third stage was to test the feasibility and the effectiveness of the adaptations mentioned in second stage in an actual video game environment. The fourth stage implemented certain game mechanics, aesthetics design, and an emotional arc. The prototypes in this stage had a complete game process. The final prototype was tested with four participants and it emphasized on the biofeedback interaction with the game environment rather than avatar and non-player characters (NPCs). 
The final result from the interviews, questionnaires, and observations during testing suggested that controlling the camera viewpoint influenced players emotional experiences. Simple controls and appropriate distance from ingame camera to the avatar in third-person view enabled players to feel relaxed and comfortable. Challenging controls (e.g. jumping on the right position) and overclose distance increased players' discomfort.

There was no obvious evidence from testing indicating that non-competitive mechanics could enhance players' feelings of serenity. Some of players reported that they felt bored sometimes in the game due to its easy mechanics.

Compared with the feedback from the stage three and stage four, the final results confirmed that it was necessary to have in-game tutorials and instructions. This informed players how to interact with the game and players would have more responses when the game is adapting to their physiological data.

One of the assumptions in this research was that the adjustment of game environment's color scheme could impact players' emotions. The final results of the qualitative data supported the criteria that induced and strengthened the serenity using abstract nature-related elements. Wellorganized environmental settings with simplistic shapes and gentle color schemes could help players provoke or increase their feelings of serenity. The quantitative data collected from the sensors showed that this mechanics may work with some players.
The game environment was designed to adapt its color to the player's facial expressions. Players showed interest in using their facial expressions to change the color of the game environment. Players preferred to smile to the webcam because it was an easier action than making a sad face. There was no obvious difference of players' emotional states between before changing and after changing when using facial expressions.

The BPM values were used to adjust the trees' color when players were close to them. This mechanic only worked with certain players. Some players did not notice a tree's color would change based on their heart rate. Even when players noticed this change, they did not see its relationship to their body signals.

A social aspect (e.g. online gameplay or collaborate gameplay) was not integrated into the game, but players were interested in inquiring about other player's physiological states. Each player's experience was personalized, and this personalization is unique to the time the sensor readings were taken. As more design techniques are employed to increase serenity for more users, I would expect an increased emotional bond with players and increased replayability of the game over time. 
There were several limitations in this research. The first one was the number of participants. A larger group of samples could provide a more objective result from interviews and questionnaires. The second one was that the play-game duration time was too short (2-5 minutes) to make the players experience strong emotional changes. The last one was the condition of hardware. The game strongly relied on the accuracy of sensors. If sensors could not detect signals precisely and constantly, the performance of the game would not be ideal.

\section{Discussion}

The future study could investigate approaches to acquire more reliable physiological data to identify players' in-game emotional states, as well as expanding the playing duration time. A longer duration time can embed the emotional arc more fully. The further study could enhance the positive emotional bond between players and the game through NPCs, avatar and other players. Designing an affective-based camera viewpoint can engage players more in the game narrative and game world. 


\section{Reference}

Aguiar, R. P. (2014). Affective Game Design: Creating Better Game Experiences based on Playersapos; Affective Reaction Model.

Ambinder, M. (2011, March). Biofeedback in gameplay: How valve measures physiology to enhance gaming experience. In game developers conference (Vol. 2011).

Atari.(n.d.). Bionic Breakthrough. Retrieved from https://atariage.com/ software_page.php?SoftwareID $=2274$

Bell, C. (2003). The Journey to wild divine. The Wild Divine Project: Las Vegas, NV, USA.

Bereiter, C., \& Bird, M. (1985). Use of thinking aloud in identification and teaching of reading comprehension strategies. Cognition and instruction, 2(2), 131-156.

Bernhaupt, R., Boldt, A., Mirlacher, T., Wilfinger, D., \& Tscheligi, M. (2007, June). Using emotion in games: emotional flowers. In Proceedings of the international conference on Advances in computer entertainment technology (pp. 41-48). ACM.

Bersak, D., McDarby, G., Augenblick, N., McDarby, P., McDonnell, D., McDonald, B., \& Karkun, R. (2001, September). Intelligent biofeedback using an immersive competitive environment. Paper at the Designing Ubiquitous Computing Games Workshop at UbiComp.

Bischke, C., \& Debnath, N. (2014, April). Biofeedback Implementation in a Video Game Environment. In Information Technology: New Generations (ITNG), 2014 11th International Conference on (pp. 7883). IEEE.

Bizzochi, J. (2007). Games and narrative: An analytical framework. Loading..., $7(1)$.
Bogost, I. (2007). Persuasive Games: Video Game Zen. Retrieved from http://www.gamasutra.com/view/feature/130994/persuasive games_video_game_zen.php

Bone, S. (2015). Minimalism in Game Design: Examples, Tips, and Ideas. Retrieved from https://gamedevelopment.tutsplus.com/ articles/minimalism-in-game-design-examples-tips-and-ideas-cms-23446

Bopp, J. A., Mekler, E. D., \& Opwis, K. (2015, April). It was sad but still good: Gratifications of emotionally moving game experiences. In Proceedings of the 33rd Annual ACM Conference Extended Abstracts on Human Factors in Computing Systems (pp. 1193-1198). ACM.

Bouchard, S., Bernier, F., Boivin, E., Morin, B., \& Robillard, G. (2012) Using biofeedback while immersed in a stressful videogame increases the effectiveness of stress management skills in soldiers. PloS one, 7(4), e36169.

Boyd-Wilson, B. M., McClure, J., \& Walkey, F. H. (2004). Serenity: Much more than just feeling calm.

Cacioppo, J. T., Tassinary, L. G., \& Berntson, G. (Eds.). (2007). Handbook of psychophysiology. Cambridge University Press.

Calleja, G. (2011). In-game: From immersion to incorporation. MIT Press.

Calleja, G., Herrewijn, L., \& Poels, K. (2016). Affective Involvement in Digital Games. In Emotion in Games (pp. 39-56). Springer International Publishing.

Carroll, N. (1999). Film, emotion and genre. na.

Cavazza, M., Pizzi, D., Charles, F., Vogt, T., \& André, E. (2009, May). Emotional input for character-based interactive storytelling. In Proceedings of The 8th International Conference on Autonomous Agents and Multiagent Systems-Volume 1 (pp. 313-320). 
Coulson, M., Barnett, J., Ferguson, C. J., \& Gould, R. L. (2012). Real feelings for virtual people: Emotional attachments and interpersonal attraction in video games. Psychology of Popular Media Culture, 1(3), 176.

Cutting, J. E., Brunick, K. L., \& DeLong, J. E. (2011). How act structure sculpts shot lengths and shot transitions in Hollywood film. Projections, 5(1), 1-16.

Ekman, P., \& Friesen, W. V. (1975). Pictures of facial affect. consulting psychologists press.

Fabricatore, C. (2007). Gameplay and game mechanics design: a key to quality in videogames. In Proceedings of OECD-CERI Expert Meeting on Videogames and Education.

Falstein, N. (2005). Understanding fun-the theory of natural funativity. Introduction to game development, 71-98.

Felder, D. (2015). Design 101: Emotional Alignment. Retrieved from http://www.gamasutra.com/blogs/DanFelder/20150707/247905/ Design_101_Emotional_Alignment.phpFe

Flying Mollusk. (2015). Nevermind [Biofeedback-enhanced horror game]. Flying Mollusk.

Freeman, D. (2004). Creating emotion in games: The craft and art of emotioneering? Computers in Entertainment (CIE), 2(3), 15-15.

Frome, J. (2007, September). Eight Ways Videogames Generate Emotion. In DiGRA Conference.

Fullerton, T. (2014). Game design workshop: a playcentric approach to creating innovative games. CRC press.

Geslin, E. (2015). What is an "Emotional Game"? Retrieved from Retrieved from www.emotionalgamesawards.comBiofeedback and video_games
Geslin, E., Jégou, L., \& Beaudoin, D. (2016). How color properties can be used to elicit emotions in video games. International Journal of Computer Games Technology, 2016, 1.

Gilleade, K., Dix, A., \& Allanson, J. (2005). Affective videogames and modes of affective gaming: assist me, challenge me, emote me. DiGRA 2005: Changing Views-Worlds in Play.

Hemphill, M. (1996). A note on adults' color-emotion associations. The Journal of genetic psychology, 157(3), 275-280.

Hunicke, R., LeBlanc, M., \& Zubek, R. (2004, July). MDA: A formal approach to game design and game research. In Proceedings of the AAAI Workshop on Challenges in Game Al (Vol. 4, No. 1, p. 1722).

Isbister, K. (2016). How games move us: Emotion by design. Mit Press.

Johan, H. (1950). Homo Ludens: A Study of the Play Element in Culture.

Joosten, E., Van Lankveld, G., \& Spronck, P. (2010). Colors and emotions in video games. In 11th International Conference on Intelligent Games and Simulation GAME-ON (pp. 61-65).

Joosten, E., Van Lankveld, G., \& Spronck, P. (2010). Colors and emotions in video games. In 11th International Conference on Intelligent Games and Simulation GAME-ON (pp. 61-65).

Journey and Catharsis. (n.d.). Retrieved from http://schneeblog.com/ journey-and-catharsis-or-depth-part-iv/

Kirkpatrick, G. (2011). Aesthetic theory and the video game (pp. 31-34). Manchester: Manchester University Press.

Larsen, R. J., \& Diener, E. (1992). Promises and problems with the circumplex model of emotion

Lazzaro, N. (2004). Why we play games: Four keys to more emotion without story. 
Liu, C., Agrawal, P., Sarkar, N., \& Chen, S. (2009). Dynamic difficulty adjustment in computer games through real-time anxiety-based affective feedback. International Journal of Human-Computer Interaction, 25(6), 506-529.

Lockhart, R. (2016). Emotion in Single-Player Games. Retrieved from http://www.gamasutra.com/blogs/RobLockhart/20161004/282611/ Emotion in SinglePlayer_Games.php

Mackey, B (2015). The Gateway Guide to Walking Simulators. Retrieved from http://www.usgamer.net/articles/the-gateway-guide-towalking-simulators

Mateas, M. (2005). Build it to understand it: Ludology meets narratology in game design space.

Nacke, L. E., Kalyn, M., Lough, C., \& Mandryk, R. L. (2011, May). Biofeedback game design: using direct and indirect physiological control to enhance game interaction. In Proceedings of the SIGCHI conference on human factors in computing systems (pp. 103-112). ACM.

NAz, K. A. Y. A., \& Epps, H. (2004). Relationship between color and emotion: A study of college students. College Student J, 38(3), 396.

Niedenthal, S. (2009). What we talk about when we talk about game aesthetics.

Nogueira, P. A., Torres, V., Rodrigues, R., Oliveira, E., \& Nacke, L. E. (2016). Vanishing scares: biofeedback modulation of affective player experiences in a procedural horror game. Journal on Multimodal User Interfaces, 10(1), 31-62.

Norman, D. (2002). Emotion \& design: attractive things work better interactions, 9(4), 36-42

Oliver, M. B., Bowman, N. D., Woolley, J. K., Rogers, R., Sherrick, B. I., \& Chung, M. Y. (2015). Video games as meaningful entertainment experiences. Psychology of Popular Media Culture, 5.
Ortiz-Vigon Uriarte, I. D. L., Garcia-Zapirain, B., \& Garcia-Chimeno, Y. (2015). Game design to measure reflexes and attention based on biofeedback multi-sensor interaction. Sensors, 15(3), 6520-6548.

Pope, A. T., \& Palsson, O. S. (2001). Helping Video Games Rewire" Our Minds"

Posner, J., Russell, J. A., \& Peterson, B. S. (2005). The circumplex model of affect: An integrative approach to affective neuroscience, cognitive development, and psychopathology. Development and psychopathology, 17(3), 715-734.

Ravaja, N., Salminen, M., Holopainen, J., Saari, T., Laarni, J., \& Järvinen A. (2004, October). Emotional response patterns and sense of presence during video games: Potential criterion variables for game design. In Proceedings of the third Nordic conference on Human-computer interaction (pp. 339-347). ACM.

Reynolds, E. (2013, July). Nevermind: creating an entertaining biofeedback-enhanced game experience to train users in stress management. In ACM SIGGRAPH 2013 Posters (p. 77). ACM

Roberts, K., \& Cunningham, G. (1990). Serenity: Concept analysis and measurement. Educational Gerontology: An International Quarterly, 16(6), 577-589.

Rogers, R., Woolley, J., Sherrick, B., Bowman, N. D., \& Oliver, M. B. (2017). Fun versus meaningful video game experiences: A qualitative analysis of user responses. The Computer Games Journal, 6(7-2) $63-79$.

Rose, M. (2013). Biofeedback and video games: What does the future have in store? Retrieved from http://www.gamasutra.com/view/ news/203252/

Salen, K., \& Zimmerman, E. (2004). Rules of play: Game design fundamentals. MIT press.

Shinkle, E. (2008). Video games, emotion and the six senses. Media, culture \& society, 30(6), 907-915 
Stuart, K. (2016). How walking sims became as important as the firstperson shooter. Retrieved from https://www.theguardian.com/ technology/2016/sep/20/how-walking-sim-first-person-shooterdear-esther

Suits, B. (2014). The Grasshopper-: Games, Life and Utopia. Broadview Press

Swink, S. (2009). Game feel. A Game Designer's Guide to Virtual Sensation. Burlington, MA, 1

Tavinor, G. (2005, November). Video games, fiction, and emotion. In Proceedings of the second Australasian conference on Interactive entertainment (pp. 201-207). Creativity \& Cognition Studios Press.

Unity Technologies. (2017). Unity 2017: The world-leading creation engine for gaming. Retrieved from https://unity3d.com/unity

University of Maryland Baltimore Washington Medical Center (2015). What is biofeedback? Retrieved from https://www.mybwmc.org/ library/33/000349

Welsh, T, J. (2012). Notes toward the concept of contemplative gaming Retrieved from http://www.timothyjwelsh.com/2012/03/notestoward-the-concept-of-contemplative-gaming/

Yannakakis, G. N., \& Paiva, A. (2014). Emotion in games. Handbook on affective computing, 459-471

Yannakakis, G. N., \& Togelius, J. (2011). Experience-driven procedura content generation. IEEE Transactions on Affective Computing, 2(3), 147-161.

Zagal, J. P. \& Tomuro, N. (2010, October). The aesthetics of gameplay: lexical approach. In Proceedings of the 14th International Academic MindTrek Conference: Envisioning Future Media Environments (pp. 9-16). ACM 


\section{Cited application or technology}

Grove. (n.d.) GSR sensor.

\section{Affectiva. (2013) Affdex}

Murphy, J., \& Gitman, Y. (2011). Pulse Sensor.

\section{Cited film (used for testing)}

Movieclips. (2011, May. 26). Come Play With Us - The Shining (2/7) Movie CLIP (1980) HD [Video file]. Retrieved from https://www.youtube.com/watch? $v=C M b|7 D m L C N|$ watch? $v=$ AEijdTeBMRM\&index $=5$

\&feature $=$ plcp

Movie Trailers. (2016, Jul. 3). VOYAGE OF TIME Official Trailer (2016) HD Sci-Fi Movie [Video file]. Retrieved from https://www.youtube.com/watch?v=zHPH wg1Xut0\&feature $=$ plcp

Universal Pictures Home Entertainment Benelux. (2012, Mar. 15). La Grande vadrouille (1966) Trailer [Video file]. Retrieved from https://www.youtube. $\mathrm{com} /$ watch?v=nB_jhCp4XCk\&t=2s

StarlingsFilm. (2014, Dec. 15). [TH-Official] Little Forest : Summer \& Autumn [Video file]. Retrieved from https://www.youtube.com/watch?v=_dMjsSelgeA

StarlingsFilm. (2014, Dec. 15). [TH-Official] Little Forest : Summer \& Autumn [Video file]. Retrieved from https://www.youtube.com/watch?v=_dMjsSelgeA

\section{Cited game}

Barlow, S. (2016). Her story [Interactive movie].

Capcom \& Nintendo NST. (1987). Bionic Commando [Platformer game].

Irrational Games. (2013). Bioshock: Infinite [First-person shooter]. Ken Levine. Key, E., \& Kanaga, D. (2013). Proteus [Exploration game].

King. (2012). Candy Crush Saga [Puzzle game]

Nintendo R\&D4. (1985). Super Mario Bros [Platformer game].

Numinous Games. (2016). That Dragon, Cancer [Adventure game].

Playdead. (2010) Limbo [Puzzle game]. Playdead \& Microsoft Game Studios.

Supermassive Games. (2015). Until Dawn [Horror game]. SCEA.

Thatgamecompany. (2009). Flower [PlayStation game]. SCEA.

Thatgamecompany. (2013). Journey [PlayStation game]. SCEA.

TheChineseroom. (2012). Dear Esther [Exploration game]. TheChineseroom.

USC Interactive Media Division. (2005). Cloud [Puzzle game].

Valve Corporation. (2007). Portal [Puzzle game]. Valve Corporation.

Veltman, F. (2016). Lieve Oma [Exploration game]. 


\section{Figure List}

All unlisted figures belong to author

Figure 4.1

Thatgamecompany. (2013). A screenshot of Journey [Online image]. Retrieved from http://thatgamecompany.com/games/journey/

Figure 4.2

Twisted Tree. (2013). A screenshot of Proteus [Online image]. Retrieved from http:// twistedtreegames.com/proteus/\#gallery

Figure 4.3

Flying Mollusk. (2012). A screenshot of Nevermind [Online image]. Retrieved from

http://www.flyingmollusk.com/press/sheet.php?p=nevermind\#images 


\section{Appendix}

\section{0}

\section{MEMORANDUM}

\begin{tabular}{l|l}
\hline TO & Kunyang Ji \\
\hline COPY TO & Tom White \\
\hline FROM & Dr Averil Coxhead, Acting Convener, Human Ethics Committee \\
\hline DATE & 1 June 2017 \\
\hline PAGES & 1 \\
\hline SUBJECT & $\begin{array}{l}\text { Ethics Approval: 23393 } \\
\text { To cultivate positive emotion bond between players and } \\
\text { biofeedback video games }\end{array}$ \\
\hline
\end{tabular}

Thank you for your request to amend your ethics approval. This has now been considered and the request granted.

Your application has approval until 31 July 2017. If your data collection is not completed by this date ycu should apply to the Human Ethics Committee for an extension to this approval.

Best wishes with the research

Averil Coxhead,

Acting Convener, Victoria University Human Ethics Committee 


\section{Interview questions}

\section{For sensor testing:}

1. Please describe your feelings in 1-2 adjective when you listen to the piece of given music (like happy, sad)

2. How do you feel when you wear a sensor or are captured by a cam?

\section{For game testing:}

1. This prototype uses nature-related elements. Do their shapes and colors help you feel relaxed or serene?

2. Is the game easy to control?

How do you feel about the camera view?

Are there any places that are confusing you?

Is the tutorial and instruction clear in the game?

Is the tutorial and instruction clear in the gam
Did the avatar move the way you expected?

3. Did you notice the game changing your emotional states?

4. Which part in the game do you think is related to your body signals? Is it obvious?

How do you think they are related?

5. Do you expect more changes in the game? What kind of change did you expect?

6. How do you feel about seeing your emotional data changing in real-time?

7. Do you think the audio and background music help you feel relaxed or serene?

8. Did you feel any parts of the game were depressing or stressful?

9. Did you feel relaxed or serene after playing?

\section{Questionnaires}

1. How do you feel about the game control?

very easy

vasy

easy

difficult

very hard

2. Do you think the graphic design is helpful for inducing or enhancing the feeling of serenity?

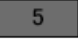

(1)

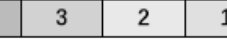

Neutra
Neutral

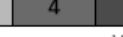

3. Do you feel strong connection with your avatar?

4. What degree you score for the serenity you feel after playing?

\begin{tabular}{|l|l|l|l|l|l|l|l|l|l|l|}
0 & 1 & 2 & 3 & 4 & 5 & 6 & 7 & 8 & 9 & 10 \\
\hline
\end{tabular}

